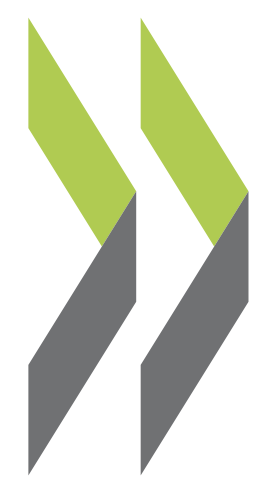

OECD Economics Department Working Papers No. 576

\section{Joaquim Oliveira Martins,}

The Policy Determinants of Investment in Tertiary

\section{Education}

Romina Boarini, Hubert Strauss, Christine de la Maisonneuve, Clarice Saadi 
ECONOMICS DEPARTMENT

THE POLICY DETERMINANTS OF INVESTMENT IN TERTIARY EDUCATION ECONOMICS DEPARTMENT WORKING PAPERS No. 576

by Joaquim Oliveira Martins, Romina Boarini, Hubert Strauss, Christine de la Maisonneuve and Clarice Saadi

All Economics Department Working Papers are available through OECD's Internet website at http:/www.oecd.org/eco 


\section{ABSTRACT/RÉSUMÉ}

\section{The Policy Determinants of Investment in Tertiary Education}

This paper assesses how policies and institutions affect private returns to invest in tertiary human capital, the ability of individuals to finance this investment and the institutional characteristics of tertiary education systems. Focusing on core tertiary education services, the paper presents new measures of private returns to tertiary education, the institutional setting for supplying tertiary education and the availability of individual financing in OECD countries. Using a panel of 19 countries, the number of new tertiary graduates (a proxy for investment in tertiary education) is regressed on these new proposed measures, as well as other standard determinants of investment in tertiary education. The resulting estimates are used to assess empirically the relative importance of several education, taxation and social policies affecting investment in tertiary education. Several avenues for reform and the trade-offs they present for public policy are discussed.

JEL Classification: I21, I22, I28, J24

Key words: Investment in tertiary education, Returns to education, Supply of tertiary education, Student individual financing systems and Taxation

$$
\text { ********** }
$$

\section{L'impact des politiques économiques sur l'investissement en éducation supérieure}

Cette étude examine comment les politiques économiques et les institutions affectent le rendement privé de l'éducation supérieure, la possibilité pour les individus de financer cet investissement et les caractéristiques institutionnelles de l'offre d'enseignement supérieur. Se concentrant sur les services de l'éducation supérieure proprement dite, l'étude présente des nouvelles mesures des rendements privés de l'éducation supérieure, le contexte institutionnel de l'offre d'enseignement supérieur et la disponibilité de financement individuel pour les pays de l'OCDE. Utilisant un panel sur 19 pays, le nombre harmonisé de nouveaux diplômés (une approximation de l'investissement dans l'enseignement supérieur) est régressé sur ces nouvelles mesures ainsi que sur d'autres déterminants standards de l'investissement en éducation supérieure. Les estimations qui en résultent sont utilisées pour évaluer empiriquement l'importance relative des différentes politiques ayant trait à l'éducation, à la fiscalité ou dans le domaine social et ayant un impact sur l'investissement en enseignement supérieur. Plusieurs options de réforme et les arbitrages qu'elles représentent pour la politique économique sont discutées.

Classification : I21, I22, I28, J24

Mots Clés : Investissement en éducation supérieure, Rendements de l'éducation, Offre d'éducation supérieure, Financement individuel pour les étudiants et fiscalité

\section{Copyright OECD, 2007.}

Applications for permission to reproduce or translate all, or part of, this material should be made to: Head of Publications Service, OECD, 2 rue André-Pascal, 75775 Paris CEDEX 16, France. 


\section{TABLE OF CONTENTS}

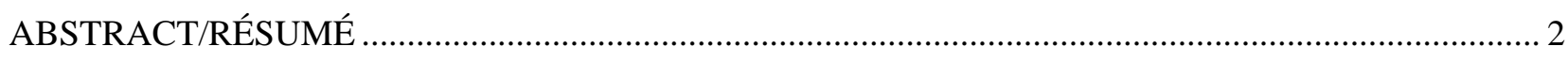

THE POLICY DETERMINANTS OF INVESTMENT IN TERTIARY EDUCATION.............................. 5

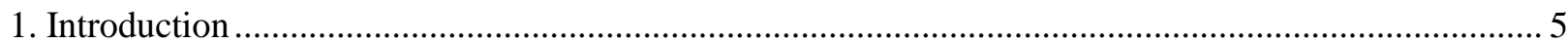

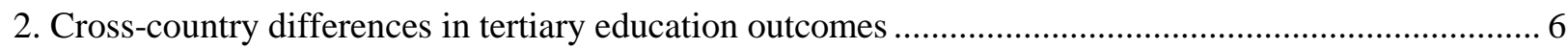

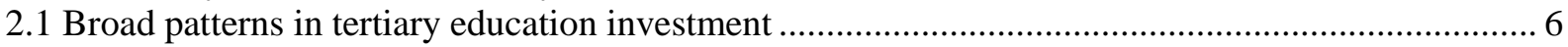

2.2 The structure of investment by fields of education....................................................................... 8

2.3 Wage premia from higher education and the quality of tertiary human capital .............................. 8

3. The structural and policy determinants of tertiary graduation ratios ................................................ 9

3.1 Supply-side factors: the institutional set-up of tertiary education ................................................. 9

3.2 Demand-side factors: the Internal Rate of Return to education and its drivers .............................. 12

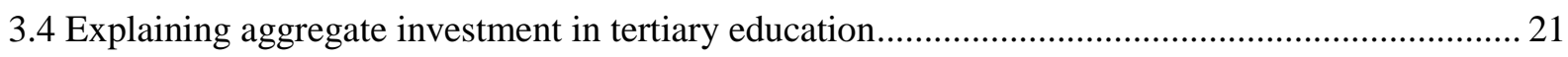

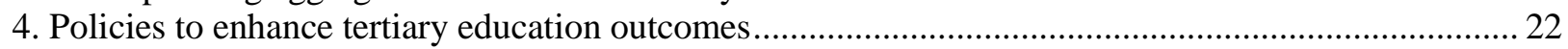

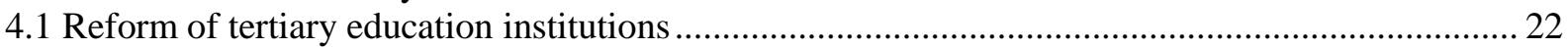

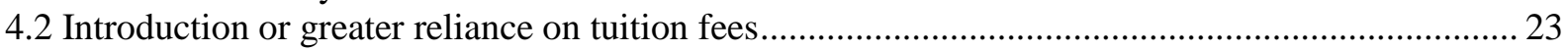

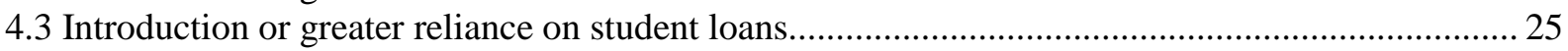

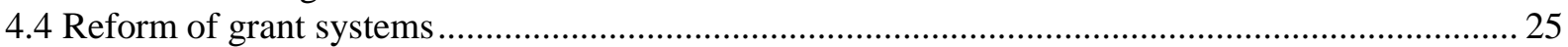

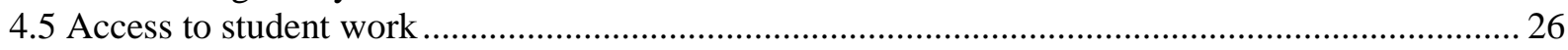

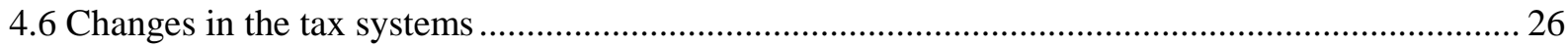

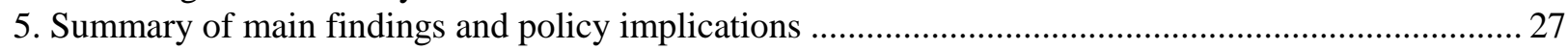

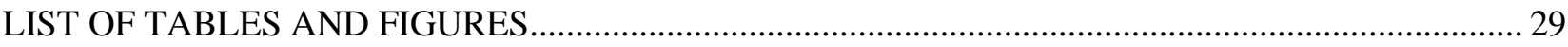

ANNEX: SUPPORTING MATERIAL ON DATA SOURCES AND STRUCTURAL INDICATORS .... 59

A. DATA SOURCES AND DERIVATION OF INDIVIDUAL VARIABLES ….................................. 59

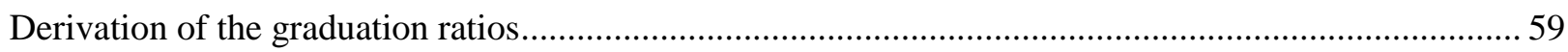

Harmonised graduate statistics: the unduplicated count method ........................................................... 59

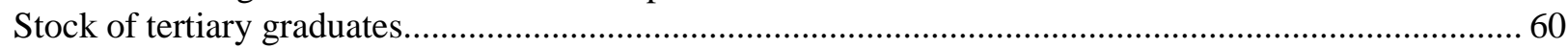

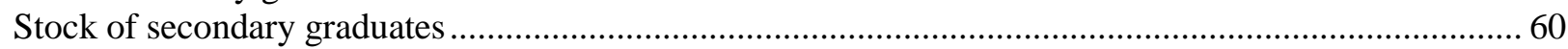

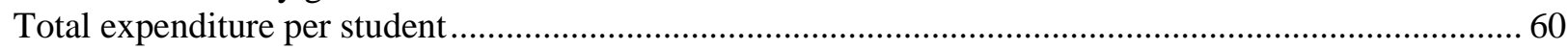

B. AN INDICATOR OF THE INSTITUTIONAL SET-UP OF TERTIARY EDUCATION .................. 61

C. SYSTEMS OF INDIVIDUAL FINANCING OF TERTIARY EDUCATION: AN INDICATOR OF

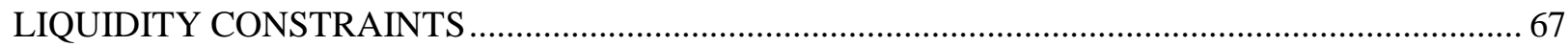

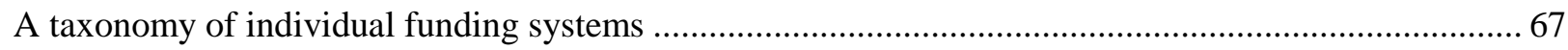

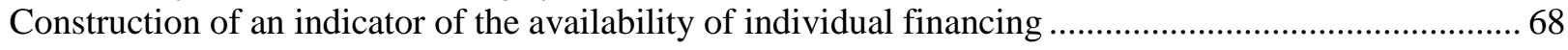

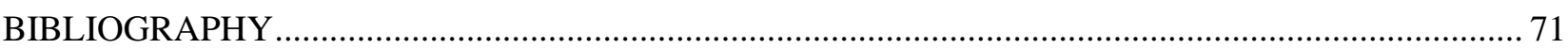

\section{Boxes}

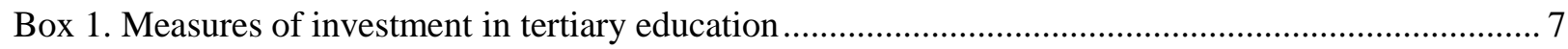




\section{ECO/WKP(2007)36}

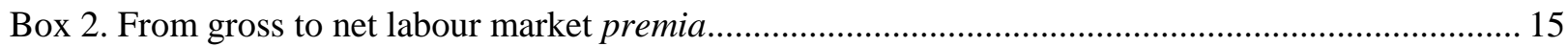

Box 3. Returns to education by fields: evidence from national studies ................................................. 19 
ECO/WKP(2007)36

\title{
THE POLICY DETERMINANTS OF INVESTMENT IN TERTIARY EDUCATION
}

\author{
by \\ Joaquim Oliveira Martins, Romina Boarini, Hubert Strauss, \\ Christine de la Maisonneuve and Clarice Saadi ${ }^{1}$
}

\section{Introduction}

1. In a number of OECD countries, the need for reforming higher education systems has been intensively debated. ${ }^{2}$ There are several sources of concern with the way core tertiary education services are currently provided. ${ }^{3}$ Among these, the following are widely shared:

- Tertiary education institutions do not always have the right incentives for achieving excellence and may not be sufficiently flexible and responsive to match changing labour market needs;

- Current settings often provide large private returns to graduates, while the extent of social externalities is unclear; ${ }^{4}$

- Public subsidies for tertiary education are typically regressive and pre-empt the use of public resources to target groups that are liquidity-constrained or to fund improvements elsewhere in education systems. ${ }^{5}$ Moreover, subsidisation through low-price education or grants may lower students' incentives for successful and timely study completion;

1. OECD Economics Department. Corresponding authors are Joaquim Oliveira Martins (Email: joaquim.oliveira@oecd.org) and Romina Boarini (romina.boarini@oecd.org). Hubert Strauss is currently economist at the European Investment Bank. Clarice Saadi participated in this project as an intern from Sciences Po, Paris. The authors would like to thank Jean-Philippe Cotis, Jorgen Elmeskov, Mike Feiner and Giuseppe Nicoletti for their comments and inputs during the preparation of this study. The collaboration and the expertise of Paulo Santiago and Thomas Wecko were also particularly useful, as well as comments we received from other colleagues of the OECD Directorate for Education. Irene Sinha provided secretarial assistance. The views expressed here are those of the authors and do not necessarily represent those of the OECD or its member countries.

2. Notably in Continental Europe, see for example Aghion and Cohen (2004) and Jacobs and Van der Ploeg (2006).

3. A different, though related, set of issues have been raised concerning Research activities performed in higher education institutions. These are beyond the scope of this paper.

4. Rather, empirical evidence suggests that private returns are typically higher than social returns, weakening the case for the current level of public subsidies (cf. Psacharopoulos, 1995; Sianesi and Van Reenen, 2003).

5. Indeed, the decision to invest in tertiary education is voluntary and individuals can appropriate most of the returns attached to it. By contrast, the policy questions surrounding primary and secondary education are rather different in nature, as these levels of education are largely compulsory. 
- At the same time, many countries lack effective individual financing systems that would help students to cope with university fees (if any) and living costs during tertiary education, thereby jeopardizing equality of access;

- Finally, the high international mobility of high-skilled workers increases private returns but could reduce the fiscal returns to public spending on tertiary education.

2. The purpose of this paper is to discuss how policies can affect investment in tertiary education in ways that would eliminate some of the perceived shortcomings of existing systems, while preserving or (preferably) enhancing equality of access to higher education. To this end, the analysis focuses on the institutional set-up of tertiary education that provides incentives for supplying quality educational services; the private returns from higher education which act to attract prospective students, ${ }^{6}$ and individual funding mechanisms to help overcome the liquidity constraints that may restrict participation in higher education. These mechanisms should also be designed so as to prevent uncertainty about future incomes from unduly deterring investment in tertiary studies by risk-averse individuals.

3. The paper draws on the extensive economic literature on the determinants of investment in tertiary education. Traditionally, this literature has focused on demand-side determinants of investment (e.g. Becker, 1967; Freeman, 1986; Heckman et al. 2005) and, more recently, on the role of the supply structure (e.g. Rotschild and White, 1995; Epple et al. 2006). The supply of tertiary education systems is still highly regulated in most OECD countries, with the exception of some English-speaking OECD countries where the provision of educational services has been increasingly organised on a market basis. In this context, the analytical framework used in this paper accounts for the main demand-side determinants of the investment in tertiary education, but takes into account the supply-side determinants only through the effect of the institutional set-up of tertiary education systems.

4. The paper is structured as follows. First, tertiary education outcomes, including the labour market rewards accruing to graduates, are documented (Section 2$){ }^{7}$ Second, the paper explores the role of policies and institutions in affecting private incentives to invest in tertiary human capital, the ability of individuals to finance this investment and the characteristics of university systems (Section 3). Third, the relative importance of several policies affecting tertiary education outcomes is empirically assessed (Section 4), with the analysis covering not only education policies but also taxation and social policies. The trade-offs involved for public policy are also examined in this context. A final section summarises the main insights and policy implications of the paper.

\section{Cross-country differences in tertiary education outcomes}

\subsection{Broad patterns in tertiary education investment}

5. As a proxy for investment in tertiary education (see Box 1), average graduation ratios in the OECD area have increased steadily during the 1990s and accelerated at the turn of the century (Figure 2.1, Panel A). ${ }^{8}$ The increase was particularly strong for women. By 2004, the average graduation ratio of

6. Estimates of private returns to tertiary education are drawn from Boarini and Strauss (2007), who also provide more detail on the impact of policies and other factors on these returns.

7. Estimates of such rewards, commonly known as wage premia, are drawn from Strauss and de la Maisonneuve (2007).

8. This study uses the harmonised number of graduates, i.e. new graduates recorded by highest diploma achieved divided by the population in the age group 20-29, (see Box 1 for a discussion). 
women was 1.5 percentage points higher than the average ratio for men. Historically, the stocks of female tertiary graduates (as a share of the female population 25-64) were significantly smaller than the stocks of males, but reflecting the recent pattern of flows, by 2004 the two levels had nearly converged (Figure 2.1, Panel B).

\section{[Figure 2.1 Trends in tertiary human capital]}

\section{Box 1. Measures of investment in tertiary education}

Investment in tertiary education is usually measured through education outputs (see Le, Gibson and Oxley, 2005). Output measures can cover different (stock and flow) dimensions such as enrolment, literacy, graduation ratios and the average number of years of schooling (which may be adjusted or not for the returns on education as a proxy for quality, see below). The best measure depends on the issue at hand.

Attainment rates are a popular measure of stocks of human capital (Barro and Lee, 1993). However, these data contain a considerable amount of noise due to changes in classification criteria and other inconsistencies in the primary data (de la Fuente and Doménech, 2000). Enrolment rates cover all investment flows (leading or not to the obtainment of a degree), but may be affected by significant differences in drop-out rates (i.e. the proportion of students engaging in tertiary education without obtaining a degree) across countries. Graduation ratios only cover 'successful' investments, but are less affected by the large cross-country differences in drop-out rates. Given that this paper focuses on education outcomes that may have an impact on economic performance it seemed appropriate to focus on graduation statistics.

To make cross-country comparisons of graduation numbers more meaningful, the OECD has produced harmonised statistics. National graduation statistics typically cover the number of diplomas rather than the number of graduates. These statistics are less comparable across countries since systems with more fragmented study programmes tend to deliver a higher number of degrees than systems where only one degree is obtained at the end of a longer track (e.g. before the implementation of the European Bologna process, the length of tertiary education in Germany was around five years and typically no intermediate diplomas were delivered, while in countries like France a similar study programme would give rise to three diplomas). For this reason, this paper relies on the OECD harmonised number of graduates so as to avoid multiple-counting.

It should be kept in mind, nevertheless, that countries with several intermediate diplomas and where the average duration of studies is lower will still display higher graduation ratios since students are likely to engage more often in shorter and more flexible study tracks, as well as to drop out less systematically. The cross-country comparability of graduation ratios may also be affected by the share of foreign students in total graduates. Countries that attract a lot of foreign students would, ceteris paribus, display graduation ratios that will not be totally reflected into the accumulation of human capital in the country.

In order to derive consistent time series for a sufficiently long period (1991-2004, whenever possible), the OECD harmonised graduation ratios for the year 2004 were combined with information on graduation ratios derived from other sources (notably UNESCO). More details on sources and methods are provided in the Annex.

To avoid confusion, it should be stressed that the harmonised graduation ratios used in this paper are not directly comparable with the usual attainment rates (i.e. the percentage of individuals in a given age group having a tertiary diploma). Apart from reflecting a different measure (notably stocks vs. flows), attainment rates are derived from Labour Force Surveys, whereas graduation statistics are based on specific education surveys conducted by the OECD.

6. In all countries, except Finland and Norway, graduation ratios have increased between 1995 and 2004. Female graduation ratios in 2004 reached above $7 \%$ in New Zealand, Korea and Iceland. In New Zealand in particular, they reached nearly $10 \%$. For males, graduation ratios were above $5 \%$ in Korea, New Zealand, Japan and Ireland, whereas they were below 2\% in Turkey, Mexico and Greece (Figure 2.2). Using harmonised graduation ratios modifies commonly accepted wisdom. For example, the United States and Canada appear to rank somewhat lower than in usual graduation statistics, which are affected by crosscountry differences in the number of intermediate diplomas delivered during study years.

[Figure 2.2 New tertiary graduates as a share of the 20-29 population by gender for selected years] 


\subsection{The structure of investment by fields of education}

7. The structure of investment in tertiary education displays a considerable variation across countries, but certain common features emerge by field and gender (Figure 2.3). For the OECD average, the largest shares of tertiary graduates are in Social Sciences, Business and Law, with shares evenly distributed across female and male graduates. But striking gender differences characterise the next most populated fields. The share of women is higher in Education, Health \& Welfare and Humanities \& Arts, whereas that of males tends to be higher in Science and Engineering.

[Figure 2.3: Flows of new tertiary graduates by field of education, 2004]

\subsection{Wage premia from higher education and the quality of tertiary human capital}

8. Tertiary education has an impact on wage earnings of the graduates, the so-called education wage premia. Measuring these premia is important on at least two counts. Education premia reflect to some extent the increase in labour productivity from investing in higher education, which could be a proxy for the quality of tertiary human capital. ${ }^{9}$ As well, they affect the individual incentives to invest in tertiary education.

9. Controlling for a number of individual and context-specific characteristics (other than the level of education) that may affect individual wage earnings, it is possible to estimate the percentage increase in the gross hourly wage earned by an individual completing higher education relative to the wage earned by an otherwise similar individual holding an upper-secondary degree (so-called Mincerian approach).

10. The gross education premia estimated in this way reflect inter alia both the average quality of skills acquired by tertiary graduates and their scarcity relative to other types of skills. The results presented here are based on individual household panel data (see Strauss and de la Maisonneuve, 2007, for details). The education wage premia range from above $25 \%$ for men in Spain and around $33 \%$ for women in Austria to above $90 \%$ for both men and women in Hungary (Figure 2.4), suggesting that tertiary education can provide indeed a substantial wage premium over secondary education. ${ }^{10}$ Estimates of the Mincerian coefficients for earlier periods (1994-2001) also show that, despite some cyclical fluctuations, these premia are fairly stable over time.

\section{[Figure 2.4: Gross wage premia from tertiary education]}

11. To the extent that average productivity differentials associated with tertiary education are reflected in these estimates, the wage premia could be seen as a measure of the quality of human capital embodied in tertiary graduates (evaluated in units of secondary graduates). However, when the stocks of tertiary human capital (expressed as a ratio to the population 25-64) are adjusted for the differences in the estimated wage premia significant level differences emerge but the relative country-ranking remains

9. Accurately measuring differences in the quality of tertiary human capital across countries is clearly beyond the scope of this study. It would require an explicit indicator, equivalent to the OECD-PISA literacy tests available for 15-year olds. Some adult literacy tests are available, but they do not cover specifically the segments of the population having a tertiary degree.

10. The premia displayed in the Figure correspond to the coefficient of tertiary education in the usual Mincerian equation (see Psacharopoulos, 1981), where the log of hourly wages is regressed on a string of dummy variables corresponding to the different levels of education, experience and a number of other control variables. In order to have a better estimate for larger values, the wage premium was approximated by $e^{\beta}-1$, where $\beta$ is the estimated coefficient from the Mincerian equation. 
roughly the same (Figure 2.5). Thus, captured in this way, quality differences do not appear to induce a large bias in the analysis of graduation ratios (at least as far as relative country rankings are concerned). ${ }^{11}$

\section{[Figure 2.5: Stocks of tertiary human capital: the effect of adjusting for wage premia]}

\section{The structural and policy determinants of tertiary graduation ratios}

12. There is a longstanding theoretical and empirical literature addressing investment in tertiary education. Traditionally, it has been focusing on the demand-side determinants of such investment (e.g. Becker, 1967; Freeman, 1986; Heckman et al. 2005) and, more recently, on the role of the supply structure of tertiary education services (e.g. Rotschild and White, 1995; Epple et al. 2006). Both the demand and the supply-based approaches have been the object of uneven developments, as they are challenged by the large cross-country heterogeneity in the provision of educational services in OECD countries. In many countries, the supply is not directly responsive to market forces (e.g. Continental Europe), whereas in others (particularly English-speaking countries) there has been an evolution towards organising supply on a more market-structure basis.

13. Drawing from this literature, this paper focuses on the following three main economic determinants of investment in tertiary education are the following three main elements: $i$ ) the supply characteristics of education systems; $i i)$ the expected private returns from engaging in tertiary education studies; and, iii) individual financing opportunities that are made available to students. This section describes cross-country patterns in these three elements and provides econometric estimates of their quantitative impact on investment in tertiary education, as measured by the annual graduation ratios described above. In the empirical analysis it is assumed that private returns to education are pre-determined (i.e. they are not affected in turn by investment decisions). However, relaxing this assumption does not invalidate the main conclusions (for a more comprehensive model introducing labour-market interactions, see Boarini, Nicoletti and Oliveira Martins, 2007).

\subsection{Supply-side factors: the institutional set-up of tertiary education}

14. Research on higher education has identified a range of institutional features that may influence the supply of education by tertiary institutions. These include prominently freedom in managing resources and setting objectives, incentives to improve performance and rules for accessing funds.

15. Based on information concerning these characteristics, a summary indicator of supply of tertiary education (hereafter, STE) was constructed reflecting the situation in 2006 (see Annex). ${ }^{12}$ More precisely, the indicator covers the following three main sub-categories (Figure 3.1):

11. An important caveat to using education premia for adjusting stocks of human capital is that the estimated premia are at best an imperfect proxy of differences in quality of graduates for at least two reasons. First, as already mentioned, the education premia reflect the average quality of skills acquired by tertiary graduates (which partly depends on the structure of education by field) and their scarcity relative to other types of skills. Second, differences in these estimated premia across countries may deviate from marginal productivity gains from tertiary education due to a number of labour market imperfections.

12. Information was provided by OECD Member countries through a questionnaire (see Annex). For Belgium and Canada the answers were provided by region/province. For Canada, these answers were aggregated into a single country estimate by using weighted averages, the weights corresponding to the population in each province/region. For Belgium, the country level indicator is a simple average of the Flemish and Francophone regions. For the United States, the questionnaire was answered by the Federal authorities and was also used to collect state-level information for Texas and Ohio. Given that a representative sample of 
- Input flexibility comprises the criteria for the selection of students, institutional autonomy to decide on the sources and structure of funding (e.g. level of tuition fees), and staff policy (e.g. hiring/firing rules, wage setting, etc.).

- Output flexibility includes the possibility to decide on course content, product diversity (shortterm, part-time, distant learning studies), existing regional restrictions to access universities (captured by the degree of regional mobility of students) and the existence of numerus clausus for the number of diplomas attributed each year.

- Accountability of tertiary education institutions covers features of evaluation and funding. Relevant aspects of evaluation include the type of evaluation (independent agency, stakeholders) and the public availability of evaluation reports. Funding rules can be output-based (e.g. graduation, quality rankings) or based on grand-fathering or inputs (e.g. number of students). Information on the types of private entities that provide funding (e.g. households, businesses) is also covered.

\section{[Figure 3.1: The structure of the supply of tertiary education indicator]}

16. Figure 3.2 shows point estimates and confidence intervals for the three sub-categories. Input flexibility displays a wide variance across countries (Figure 3.2, Panel A). Particularly rigid systems from this point of view appear to characterise tertiary education in Greece, France, Turkey and Belgium, while some Canadian provinces, Mexico, the Slovak Republic and the United States (Ohio) appear to have the most flexible systems. Confidence intervals obtained by random choice of the weights used to aggregate low-level indicators into the sub-category confirm the relative positions of countries at the extreme bounds of the scale, whereas the relative position of countries closer to the middle of the range is open to some uncertainty. ${ }^{13}$

\section{[Figure 3.2: Tertiary education supply indicator by category, 2005-2006]}

17. On the output flexibility side (Figure 3.2, Panel B), Germany and Greece appear to have particularly rigid systems. Conversely, institutions seem to have the largest scope for deciding on their education outputs in the United States (Texas), Japan, two Canadian provinces, New Zealand and Turkey. The confidence intervals for this sub-category are relatively wide, reflecting a large dispersion in the values of the low-level indicators characterising output flexibility.

18. The accountability indicator (Figure 3.2, Panel C) displays a slightly more uniform pattern across countries, but education systems in Australia and Canada (New Brunswick) appear as the most accountable, whereas in Turkey, Greece and Belgium (French-speaking region) the levels of accountability seem to be significantly below average.

19. In the case of the United States, the fact that state-level authorities have a substantial autonomy to assess and fund tertiary education may imply that the USA-Federal indicator may not adequately reflect the

state-level data was not available, the economy-wide indicator for the United States corresponds to the framework at the federal level, but some caveats apply (see below).

13. This procedure is quite demanding as it abstracts from the nesting structure of the indicator. Since such a nesting is involved in the aggregation of the input and accountability indicators described in Figure 3.1, the 95\% confidence intervals are not necessarily centred on the point estimates of these indicators. Nonetheless, the statistical average obtained trough the random weighting and the point estimates are very close. 
actual level of accountability existing in the US university system. ${ }^{14}$ This is reflected in the higher accountability scores obtained for the states of Texas and Ohio. ${ }^{15}$

20. It should also be stressed that in countries with a stronger reliance on market mechanisms, some of the aspects of accountability in the education sector may not be adequately captured by the institutional features covered in the indicator. For example, higher education institutions in the United States are subject to evaluation by bond rating firms that review and assess the credit-worthiness of institutions, a feature that is not reflected in the STE indicator. Capturing these market-based mechanisms of accountability was beyond the scope of the present paper.

21. Aggregating the scores of input and output flexibility, and accountability, the value of the composite STE indicator is estimated to be significantly below average for Greece, Germany, Belgium (French-speaking regions), Turkey and France, while being significantly above average for New Zealand, Australia, the United States (Texas and Ohio), three Canadian provinces, the United Kingdom and Mexico (Figure 3.3).

\section{[Figure 3.3: Composite supply indicator of tertiary education (STE), 2005/2006]}

22. It is also important to consider the overall coherence of the education system. For example, a system having full flexibility but no accountability could be inferior to a more centralised system, even if the composite indicator would display a higher value for the former. To measure institutional coherence, a concentration indicator was calculated ${ }^{16}$ and compared with the supply indicator (STE). As a broad pattern, the STE rankings are positively related to the coherence in the tertiary education systems (Figure 3.4). In other words, countries having a low STE also tend to have a less coherent system. In Turkey, for example, the high output flexibility is neither matched by high input flexibility nor by high accountability, resulting on both a low STE and a low level of coherence. This suggests that a reform path increasing the composite STE indicator could also lead to a more coherent institutional set-up. In turn, exploiting synergies (or complementarities) across different areas is likely to have a positive impact of performance.

[Figure 3.4: Supply indicator and coherence of tertiary education systems]

14. Nonetheless, the indicator may still capture shortcomings in the way accountability mechanisms are set-up at the federal level. For example, federal funds are allocated on the basis of inputs (number of students and teachers) rather than outcomes, which tends to decrease the value of the accountability sub-indicator.

15. Ideally, given diversity at the state level, the economy-wide indicator should have been calculated on the basis of a representative, number of state-level survey data and then aggregated according to some weighting scheme. Unfortunately, this was not possible.

16. This indicator is based on the scores obtained by each country on the five intermediate indicators (selection of students, budget autonomy, staff policy, evaluation rules and funding rules) supplemented with the indicator for the output flexibility category (for which no intermediate indicators are available). More precisely, institutional coherence (IC) across these six indicators ( $\mathrm{Ii}, \mathrm{i}=1, \ldots, 6)$ is defined as follows:

$$
\frac{1}{I C}=\sum_{i=1}^{6}\left(\frac{I_{i}}{\sum_{j=1}^{6} I_{j}}\right)^{2}
$$

Note that the more concentrated the indicator structure is, the lower the coherence. By construction, IC varies from 1 to 6 . The maximum is attained when all the Ii have the same value. See Braga de Macedo and Oliveira Martins (2006) for a discussion of the use of this indicator to measure policy coherence and to test the existence of policy complementarities. 


\subsection{Demand-side factors: the Internal Rate of Return to education and its drivers}

23. The private internal rate of return $(I R R)$ to tertiary education is a comprehensive measure of economic incentives for individuals to take up tertiary education. It can be defined as the discount rate that just equates the future benefits with the costs of education. From an economic point of view, the benefits of tertiary education essentially consist in a higher future stream of earnings after graduation. To illustrate the costs and benefits of tertiary education, Figure 3.5 compares the profile of net lifetime earnings for a person who decides to take a tertiary education with the earnings profile of a person with upper-secondary education. ${ }^{17}$

\section{[Figure 3.5: Individual returns to tertiary education illustrated]}

24. The higher net lifetime earnings of a tertiary-educated individual reflect different cost and benefit components: ${ }^{18}$

- $\quad$ The direct costs of education;

- The opportunity costs associated with the several years of income of an upper-secondary educated individual foregone during the duration of studies;

- Higher net wages driven by the gross education premium, discussed above;

- A higher probability of being employed throughout working life (or employability premium);

- Eventually higher statutory pension benefits (or pension premium).

25. The computation of the IRR combines information concerning labour market outcomes and government policies affecting the costs and benefits of tertiary education in two main steps. First, the gross hourly wage premia from tertiary education described in Section 2 are translated into net labour market premia - taking into account the duration of studies, the higher probability of employment after study completion and the influence of tax and benefit systems on net earnings. Second, the costs of tertiary education are considered - taking into account both the direct costs and the opportunity costs of studying. These two steps are summarised below (more details can be found in Boarini and Strauss, 2007).

17. In both cases, real earnings slope upward due to individual accumulation of labour market experience and overall labour productivity growth. Note that, even with the same annual experience premia, the income of a tertiary educated worker has a steeper slope than the one with a secondary degree. As pensions are usually not fully indexed to productivity growth, pension benefits grow more slowly than labour earnings.

18. More specifically, the following policy variables or parameters enter the calculation of the private IRR: average and marginal tax rates on labour earnings (including employees' contributions to social security); average and marginal unemployment benefit replacement rates; average and marginal tax rates on replacement income (unemployment and pensions); tuition fees, student grants and loans; the average duration of (completed) tertiary studies; benefit replacement rates of pension systems and their indexation to productivity growth (only public pension systems are considered here, but this simplification is not overly restrictive if private pension systems are actuarially fair). As all these flows have to be properly discounted, the pension premia that occur in the distant future typically have a lower weight in the calculations than, say, immediate direct or opportunity costs. 
ECO/WKP(2007)36

\section{From gross wage premia to net labour market premia}

26. A number of adjustments must be made to the gross wage premia from tertiary education to derive the corresponding net labour market premia, which summarise the expected increase in net lifetime earnings from engaging in tertiary education. First, in order to reflect as closely as possible the returns per additional year of education, the Mincerian coefficients have been adjusted for the length of tertiary studies. ${ }^{19}$ This adjustment improves the wage premia of countries with short study duration. ${ }^{20}$ For example, gross wage premia are roughly comparable in Spain and Australia but Spanish students take almost twice as long to graduate as their Australian counterparts, so the adjusted wage premia is higher for Australia.

27. Second, wage premia are conditional on being employed. To estimate employment probability, individual-level data were used, controlling for both factors affecting employability unrelated to tertiary education and the decision to participate in the labour force (Boarini and Strauss, 2007). In 2001, the estimated probability of employment (conditional on participating in the labour market) for an uppersecondary degree holder was around $92 \%$ for women and $95 \%$ for men in most countries. With a tertiary education degree, the conditional employment probability increases on average by around two percentage points (Figure 3.6). The largest gains in employability (between 4 and 6 percentage points) are found, for men, in Italy, ${ }^{21}$ Poland, Canada and Finland; and, for women, in Hungary, Finland, Sweden and Canada. The gender differences are large in Italy and Belgium. The marginal effect of higher education on employment probabilities estimated on micro-data are generally in line with the gaps between aggregate unemployment rates of upper-secondary and tertiary degree holders and display some cyclical sensitivity. ${ }^{22,23}$

\section{[Figure 3.6: Marginal effect of higher education on the employment probability]}

28. Third, the effect of tax systems must be taken into account. Both average and marginal tax rates are relevant. The reason is that the higher absolute amount of money earned by a tertiary degree holder can be decomposed into two components: an increase in net wages (i.e. adjusted for marginal tax rates) holding employment probability constant and the monetary equivalent of an increase in the employment

19. To make this calculation, it was assumed that every year of tertiary studies yields the same percentage wage gain. While this linear interpolation is crude, data limitations prevent more precise estimates of these incremental gains. The direction of the potential bias introduced by this simplifying assumption is not clear, because it depends on the distribution of the incremental gains over the study cycle, which could be different across countries.

20. For six countries (Belgium, Canada, Poland, the United States, Portugal, Luxembourg) the average duration of studies was not available, so the OECD average for available countries was applied. In all countries, the average duration is assumed to be the same for men and women.

21. The employment probabilities refer to the average woman/man for all countries except Italy, where these probabilities are calculated for a woman/man coming from middle-income regions (mostly central regions). This isolates the impact of education on the employment probabilities from the impact of idiosyncratic labour market conditions. Italy is the country where the regional characteristics of the reference individual matter the most for the marginal effect of schooling on the employment probability.

22. The microeconomic estimates are generally lower than aggregate figures (on average across countries, $2.2 \%$ versus $3 \%$ for women, and $1.9 \%$ versus $2.1 \%$ for men) and show a lower cross-country dispersion ( $1.8 \%$ versus $2.8 \%$ for women, and $1.7 \%$ versus $2.3 \%$ ).

23. Notably, gains in employability display a stronger cyclical sensitivity than wage premia. For some countries and years, the effect on employability can even be negative. 
probability holding net wages constant (i.e. adjusted for average tax rates). Analogously, marginal and average tax rates are respectively applied to marginal and average unemployment replacement rates. ${ }^{24}$

29. Accounting for the combined effect of unemployment benefits and taxation makes it possible to compute net labour market premia. This calculation, involving the wage premia and the monetary equivalent of gains in employability (employability premia), changes somewhat country rankings obtained in gross terms. These adjustments lower the average wage premium from $10.8 \%$ in gross to $5.6 \%$ in net terms (see Box 2 for details).

30. To complete the calculation of the benefits, pension premia should also be taken into account. Indeed, individual pension savings and entitlements are heavily subsidised in most OECD countries and can attract tertiary graduates. Nonetheless, net pension premia occur in a distant future and therefore, due to discounting effects, play a relatively minor role on the total returns to education. ${ }^{25}$

\section{Direct and indirect costs of tertiary education}

31. The gross direct costs of tertiary education are mostly related to tuition fees. However, in most countries, tertiary education is publicly provided or heavily subsidised with tuition fees set at low levels. The tuition fees (net of grants) in 2001 appeared to be much higher in the United States than in other OECD countries (Figure 3.7). ${ }^{26}$ Net tuition fees were also relatively high in Australia and Poland, where public subsidies for tuition fees are negligible. At the other end of the scale, there are virtually no direct costs in Greece due to large public subsidies. In Nordic and Continental European countries, the net direct costs of tertiary education studies are also estimated to be relatively low.

\section{[Figure 3.7: Net direct costs of tertiary education]}

24. The calculation of these premia was based on the OECD Benefits and Wages Model (OECD, 2004a, 2006c). The marginal replacement rate for unemployed could only be calculated for year 2001 and was assumed to remain constant over the sample period. The tax rates used in the calculations are specific to the labour force status of individuals (employed, unemployed or retired) but not to gender, and are assumed to be constant over the life-cycle. While taxation is not usually indexed on labour productivity growth or experience, it may change over the individual life-cycle. This potential source of error is somewhat mitigated by the fact that all calculations are done for a representative individual at the mid-point of his/her career (see de la Fuente and Jimeno, 2005).

25. The pension benefits incorporated in this calculation reflect the pension entitlements for a worker entering the system in 2002 at the age of 20 and retiring after a full career. These entitlements include changes in pension rules that have been legislated and are being implemented. It is assumed that they will remain unchanged over the life cycle of the representative individual. The gross pension replacement rates were drawn from the new OECD Pensions Model (see OECD, 2005). The pension model includes all mandatory pension schemes for private-sector workers as well as systems with near-universal coverage (at least $90 \%$ of the employees). Both mandatory individual accounts and resource-tested benefits are also included. Replacement rates are calculated separately for men and women whose gross pre-retirement earnings were $100 \%$ of the average earnings. As for other out-of-work benefits, specific average and marginal tax rates were applied to, respectively, average and marginal pension replacement rates.

26. The estimates of direct annual costs are normalised by the annual average earnings of a mid-career secondary-education worker (man or woman). While private direct costs are not gender specific, the denominator of the ratio reflects gender differences. For Canada, Luxembourg and Switzerland no comparable data were available on direct costs. Computation of internal rates of return for these countries was made under the assumption that direct costs were at the average OECD level. 


\section{Box 2. From gross to net labour market premia}

The net wage premia are calculated by multiplying the gross wage premia per additional year of tertiary education by the expected marginal tax factor. The latter is expressed as the average of the marginal tax rate for workers, weighted by the employment probability $P_{e}$, and the marginal tax rate of unemployed multiplied by the marginal replacement rate of out-of-work benefits, weighted by $\left(1-P_{e}\right)$. These probabilities are held constant (i.e. fixed at the level of an uppersecondary degree holder). The net wage premia also takes into account dropping-out rates of tertiary education. ${ }^{1} \mathrm{~A}$ comparison of gross and net wage premia is provided in Figure A. In many countries, the changes are sizeable, reducing the premia by between 2 and 14 percentage points.

Figure A. Comparison of gross and net wage premia ${ }^{1}$

(Per year of tertiary education, 2001)
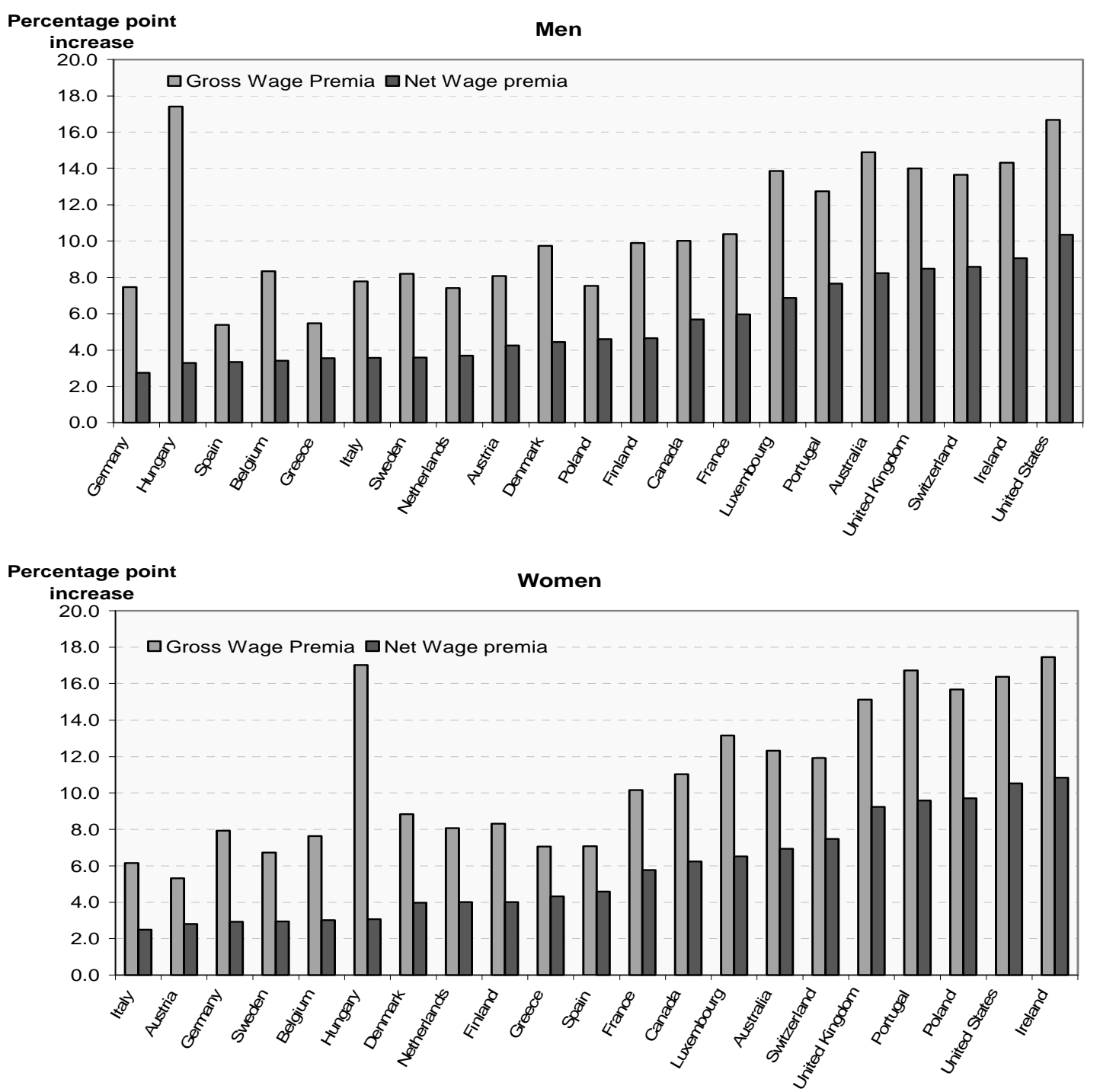

1. Adjusted for survival rates, experience premia, marginal tax rate for employed and unemployed, marginal gross out-of-work replacement rates, probability of unemployment and duration of studies.

Source: Boarini and Strauss (2007).

The net employability premia (Figure B) are the monetary equivalent of the increase in the probability of employment as a result of tertiary graduation. The increase represents the net expected income due to the change in the probability of employment given by an additional year of tertiary education. In this calculation, wages are fixed at the level of an upper-secondary degree holder. The net employability premium depends on the marginal effect of schooling on 
employment, but also on the size of out-of-work replacement income and taxation. There are marked differences between net and gross employability premia across countries, but as these premia are expressed in monetary equivalents their magnitude is small compared with other drivers of the returns. In gross terms, employability premia are on average around $1 / 2 \%$ whereas, in net terms, they decrease to a negligible $0.1 \%$. Negative premia are mostly due to the effect of the cycle in 2001 (for details see Boarini and Strauss, 2007).

Figure B. Comparison of gross and net employability premia ${ }^{1}$ (Per year of tertiary education, 2001)
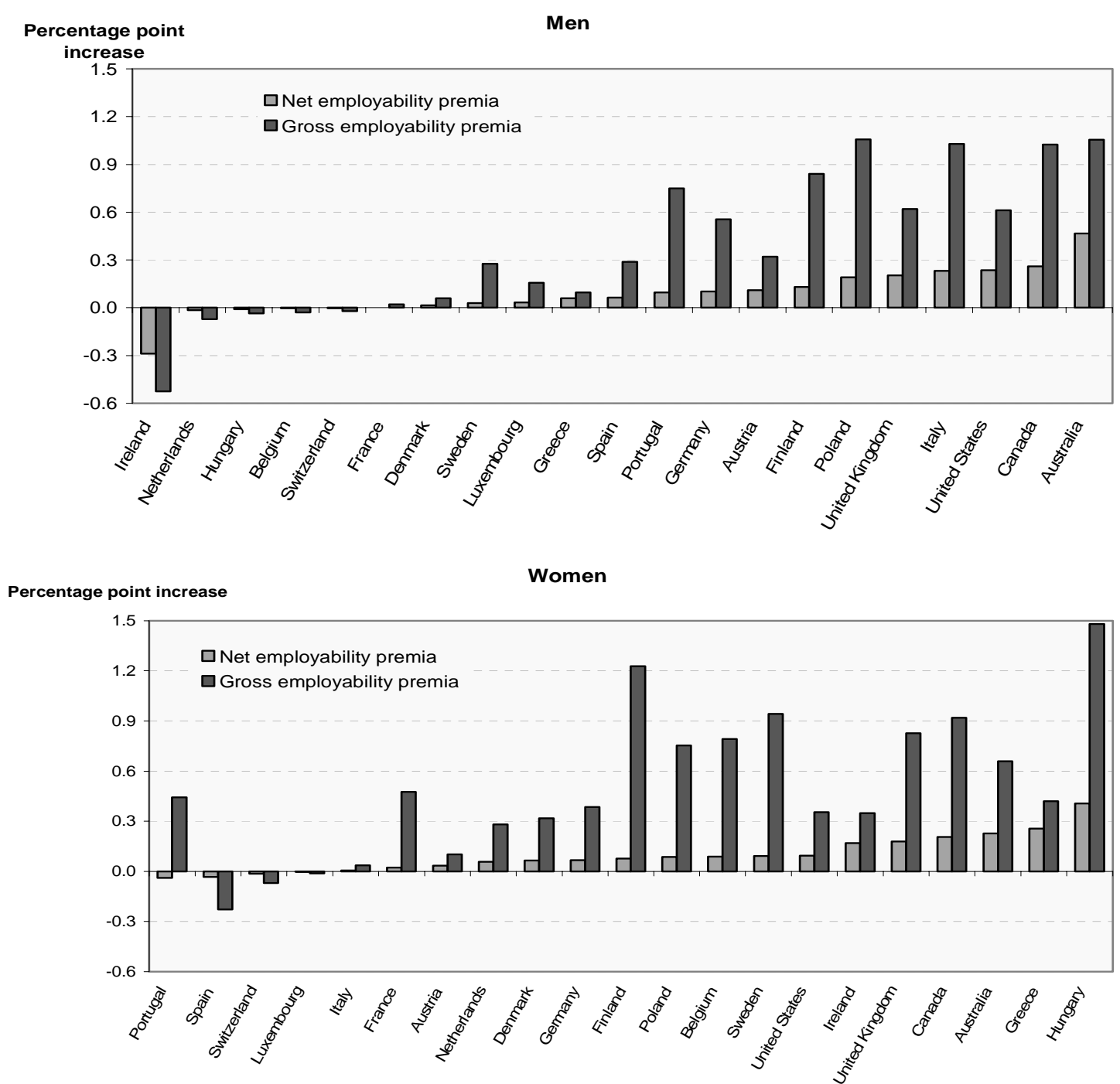

1. Monetary equivalent adjusted for the difference between net labour market earnings and net out-of-work benefits, survival rates and duration of studies.

Source: Boarini and Strauss (2007).

1. In practice, the gross wage premia per additional year of tertiary education is multiplied by the survival rate in tertiary education. The survival rates are based on OECD estimates (see OECD, 2004b).

32. Living expenses are not a direct cost of education (as secondary graduates also have living expenses), but in some countries there are public subsidies targeted for these costs (see below). In principle, these grants for living expenses should be included in the baseline calculation, but cross-country data are not fully available. For the same reason, the calculation implicitly assumes that students' loans are 
fully repaid and abstracts from any implicit subsidisation of such loans. Only for a limited set of countries, it was possible to compute direct costs including grants for living expenses and loans that are not repaid (Figure 3.7, Panel B). With this more comprehensive measure, direct costs turn out to be negative for Greece, Denmark, Austria, Finland, Germany and Sweden. Therefore, it should be borne in mind that the omission of grants for living expenses may introduce a downward bias in the baseline calculation of the returns for these countries.

33. The indirect cost of tertiary education is essentially the opportunity cost of foregone earnings while studying. ${ }^{27}$ Intuitively, high labour income taxation and low unemployment benefits reduce opportunity costs. Opportunity costs appear to be relatively uniform across countries (Figure 3.8), though they tend to be higher in countries with low wage taxation (e.g. Ireland, Portugal, Spain and Switzerland). In Nordic countries, Belgium and Germany opportunity costs are low, primarily reflecting high average tax rates, and notwithstanding relatively high unemployment benefit replacement rates. The possibility for student part-time work is not introduced in the baseline calculation of the opportunity costs, but will be considered in the sensitivity analysis below.

\section{[Figure 3.8: Opportunity costs of tertiary education]}

\section{Cross-country differences in the Internal Rates of Return to education}

34. Incorporating all the elements described above, as well as an estimate for future productivity growth, ${ }^{28}$ yields internal rates of return (henceforth $I R R$ ) that vary from over 4 to over $14 \%$ in 2001 for the 21 OECD countries covered by the analysis (Figure 3.9). The average return (across both countries and gender) is $8.5 \%$, which is lower than previous OECD estimates (see Blöndal, Field and Girouard, 2002) but still substantially higher than current market interest rates adjusted for inflation. The range of returns for women is somewhat wider than for men (from over 4 to over $14 \% v s .5$ to $12 \%$ ). Gender differences in the $I R R$ are particularly large in Poland (almost four percentage points).

\section{[Figure 3.9: Estimates of the Internal Rates of Return to Tertiary Education]}

35. Relatively low returns for both men and women are found in Spain, Italy, Netherlands, Sweden and Belgium. These low education returns are driven by below-average wage and employability premia, which more than offset low (direct or opportunity) costs. Hungary, although with very high wage premia, also displays relatively low returns due to very high marginal taxes. In contrast, Ireland, the United Kingdom and Portugal have among the highest returns for both men and women because these countries have high wage premia, reinforced either by high employability premia and/or low costs of education. Other countries display either moderate returns or significant differences by gender. In most cases, wage and employability premia are just around average or are offset by high direct costs of education.

27. These opportunity costs were calculated as the average of net wages and unemployment benefits for an individual who participates in the labour market instead of studying, weighted by the probabilities of being employed or unemployed.

28. Since the duration of working life is assumed to be the same for all educational levels, tertiary-degree holders enter and quit the labour market later than upper-secondary degree holders. With aggregate productivity growing over time, they therefore enjoy a higher labour productivity level throughout their career. This effect enters in the calculation of the education premium. In the baseline, labour productivity growth is assumed to be uniform across countries and set equal to $1.75 \%$ per year. As an alternative, internal rates of return were also calculated using country-specific average labour productivity growth rates over the past decade. 


\section{Main drivers of the Internal Rates of Return}

36. To compare the sensitivity of the $I R R$ to changes in its different drivers, each component was increased by one percentage point (holding all the others constant), except for study duration, which was increased by $1 \%$ (with working life shortened accordingly) ${ }^{29}$ Figure 3.10 shows the results for the OECD average, but their cross-country variance is sometimes considerable (as shown by the maximum and minimum values). The main conclusions are:

- Taxation: A one percentage point increase in the marginal tax rate reduces the net IRR by about 0.12 percentage points. By contrast, a similar increase in the average income tax rate tends to increase the IRR by three-quarters of this amount (0.09), mainly via a reduction in opportunity costs, which represent the bulk of total private costs. ${ }^{30}$

- Unemployment benefits: An increase in the average unemployment benefit replacement rate by one percentage point reduces returns to education (as long as tertiary degree holders have a higher employment probability than upper-secondary degree holders) and slightly increases the expected opportunity cost of studying. But the total negative effect on the IRR is very small. ${ }^{31,32}$

- Education policy: A rise in tuition costs by one percentage point (as a fraction of gross annual earnings of the average upper-secondary degree holder) reduces the IRR by around 0.1 percentage points. A marginal increase in the study duration of $1 \%$ (corresponding to around two weeks) also reduces the return per year of tertiary education.

- Labour market characteristics: An increase in the gross wage premium on tertiary education by one percentage point increases the private $I R R$ by 0.13 percentage points on average, with the effect ranging from less than 0.05 to 0.2 percentage points. A one percentage point increase in the employability premium results in a somewhat smaller average increase in the $I R R$, albeit with wide country variation. Finally, if students devote one percent of their time to paid work (a share that is assumed to be zero in the baseline) with no repercussions on study duration, opportunity costs are reduced and, therefore, the IRR increases by around 0.1 percentage points. ${ }^{33}$

\section{[Figure 3.10: Sensitivity analysis on the IRRs: effects of changes in the main drivers]}

29. Over and above those reported, a number of other parameter changes have been analysed. In most cases, their IRR effect is very small, such as for the pension benefit replacement rate, the degree of pension indexation, the length of the working life, and the average experience premium. As to changes in the growth rate of average labour productivity (assumed to be at $1.75 \%$ in all countries in the baseline), they raise the IRR almost one to one and are therefore important for policymakers concerned with tertiary education incentives.

30. Tax changes in Figure 3.10 and thereafter are jointly applied to labour and replacement incomes.

31. The effect is small because the conditional probability of unemployment and, hence, the resulting reduction in life-time earnings are fairly small for upper-secondary degree holders in most countries, limiting employment-related increases in lifetime earnings for tertiary degree holders.

32. No side-effects of higher unemployment benefits on employment of secondary degree holders are taken into account.

33. Albeit occurring through the same channel (change in opportunity costs), the average IRR elasticity with respect to student work (at 0.10) is somewhat higher than that with respect to the average income tax rate (0.09) because a tax hike also lowers the net benefit from higher employability. No such offsetting force is at play with student work. 


\section{Can the structure by fields of education explain differences in returns across countries?}

37. Evidence available for a few OECD countries suggests that the returns to education can vary significantly across fields (Box 3). In this context, cross-country differences in average returns could partly reflect a composition effect. While no comprehensive data are available to compare returns to education by fields for all countries, a simple counterfactual simulation can be carried out. For each country, an IRR was calculated by multiplying the country-specific field mix by an estimate of the returns by field available for Canada (Stark, 2006). The resulting counterfactual IRRs were compared with an average OECD IRR computed in the same way. The differences to the average show the contribution of the field mix to the IRR obtained for each country. ${ }^{34}$ It turns out that their magnitude is relatively small, ranging from around -0.6 to 0.4 percentage points (Figure 3.11). It can be concluded that the observed differences in returns across countries can not be attributed to the effect of field structure.

\section{[Figure 3.11: Cross-country differences in IRRs implied by country-specific field composition]}

\section{Box 3. Returns to education by fields: evidence from national studies}

Given that the data sources used in this paper do not allow for computing returns by field of education or by level of diploma, this box briefly reviews evidence for Canada and Australia on these issues.

\section{Canada}

Based on 1995 earnings, Stark (2006) estimated private education returns for men at 9.9\%, 4.1\% and $1.3 \%$ respectively for Bachelor's, Master's level and $\mathrm{PhD}$ level. The corresponding returns for women are respectively $12.1 \%, 8.6 \%$ and $4.3 \%$. Taking into account the relative weights of each degree in the total number of graduates, these rates are comparable with an average return of around $9 \%$ (both men and women) for Canada computed in this paper (see Figure 3.9). Concerning fields, scientific fields tend to be more rewarding than non-scientific fields at the Bachelor's level, but there is a large dispersion (e.g. from $3.9 \%$ in Zoology and $4.4 \%$ in Fine Arts to $14.6 \%$ in Commerce and $23.3 \%$ in Actuarial science). By contrast, a Master's degree is generally more rewarding in non-science fields.

\section{Australia}

Borland (2002) founds an average IRR in Australia of $14.5 \%$. This contrasts with an $I R R$ of $9.6 \%$ in this study, but the gap may be due to the different method. Borland (2002) reports that when using Mincerian wage regressions, controlling for other individual characteristics, hours worked and cohort effects, the estimated IRR falls to around $10.5 \%$. By level of diploma, returns to tertiary education tend to decrease beyond the Bachelor's degree, much in line with the Canadian study. Concerning fields, business \& administration and engineering diplomas yield much higher returns (close to $20 \%$ ) than those of scientific, social and cultural fields (around $11 \%$ ).

\subsection{Financing the individual investment in tertiary education}

38. The relatively large individual returns to education observed in many countries in principle provide strong incentives for individual investment in tertiary education. However, the existence of market imperfections hinders the financing of this investment through market mechanisms such as individual student loans. On the supply side, the imperfections are mainly related to asymmetric information on students' abilities and motivation, the uncertainty about their future income and the lack of collateral. ${ }^{35} \mathrm{On}$ the demand side, students engaging in higher education are neither sure of completing the degree nor of the level of returns to be expected from it. Thus, students' risk aversion may further inhibit the development of

34. For comparison with the actual IRRs, the differences presented in Figure 3.11 were normalised by the ratio between the average actual and counterfactual IRRs.

35. For a survey of these issues see Barr (2001). 
loans. Because risk may be less bearable in low-income conditions, some government intervention in higher education may be justified on both efficiency and equity grounds (Chapman, 2005). ${ }^{36}$

\section{Financing systems in OECD countries}

39. In countries where fully private loans to students exist, they are often limited to students with collateral or creditworthy co-signatories, and to students in fields offering high future earnings (Johnstone, 2005). The information asymmetries behind this outcome are often seen to call either for a governmental guarantee on a private loans, or for the government itself to be a lender. Government-supported loans are generally either mortgage-type or income-contingent.

40. A good example of a mortgage-type system is the Dutch student loan system where fixed monthly repayment instalments are calculated in such a way that the debt is repaid over a relatively long period (typically 25 years). A well-known income contingent loan programme was developed in Australia in 1989. Under the Higher Education Contribution Scheme (HECS), students do not pay up-front for tuition fees, but after graduation they start reimbursing the costs of their higher education to the state, through the tax system. ${ }^{37}$ In New Zealand both tuition fees and an income contingent loan programme were introduced in 1992, but contrary to the Australian system, the fees are paid by students and their families directly to the university, and the choice of taking-up a loan is left open to the individual. The United Kingdom also recently introduced an income-contingent loan system while raising tuition fees.

41. A snapshot of the characteristics of existing loan systems in five OECD countries (Table 3.1) suggests that loan systems are designed not only to limit individual financial risks but also to provide a direct subsidy. Income thresholds for repayment range from $34 \%$ to $75 \%$ of average wages, the amortisation period is relatively long and all systems contain elements of interest rate subsidisation. In the five OECD countries under consideration, student work is also widespread providing a complementary form of financing and reducing the risk associated with loan-financed education. This may partly explain why, despite advantageous financial conditions, the take-up rates ${ }^{38}$ of student loans can be below $50 \%$ in some countries (Table 3.2) and why debt levels at graduation are often much below average income at that point (last row in Table 3.1).

\section{[Table 3.1: A comparison of loan systems for selected OECD countries]}

\section{[Table 3.2: A comparison of take-up rates for student loan systems]}

42. Student grants are another form of individual financing support. However, grants are generally targeted, often with cumbersome administrative requirements, and thus take-up rates can be low in some countries (Table 3.3). Only in Nordic countries, Luxembourg, the United States and the Netherlands grants have a large, sometimes universal, coverage. In the countries where grants play a limited role and where no loan systems have been developed the bulk of the individual financing has to rely on family networks and on student work.

36. In this context, equity can be defined as the equality of opportunities for two people with identical abilities and taste, irrespective of factors such as parental income.

37. Note that the system entails a budgetary burden for the initial payment of the fees before maturity is reached, in which fees for new students are broadly balanced by revenues from previous graduates (see below, Section 4). There could be additional problems related to changes in the demographic structure of the population.

38. Take-up rates correspond to the number of students taking loans over the total number of students. 
[Table 3.3: A comparison of take-up rates for student grants)]

\section{An evaluation of financing constraints}

43. A crude approximation of the degree of financial and/or liquidity constraints faced by prospective tertiary education students is provided by the ratio of the average annual expenses during study for a tertiary degree to the sum of the available sources of financial support. These include the amount of available individual loans and grants, but also family resources, for which calculations are less straightforward. As a very rough approximation, the latter can be set equal to the equivalised median household disposable income (i.e. adjusted for family size). In addition, estimates of expected earnings from part-time student work (adjusted for country-specific youth employment rates) are also included among possible financing sources for these computations.

44. This attempt to compare total investment costs with the available financing sources is displayed in Table 3.4. Typically, the average ratio of total costs to total funding is somewhat lower in universal funding systems than in family-based systems, despite tuition fees and living costs often being relatively high. A few countries stand out among family-based systems with costs to financing ratios are particularly high, including Mexico, Korea and Turkey.

\section{[Table 3.4: An estimation of total student cost and available financing per year (in US\$ PPP)]}

\subsection{Explaining aggregate investment in tertiary education}

45. The calculated private returns to education $(I R R)$, the information concerning student financing and the characteristics of tertiary education supply can be used to explain aggregate graduation patterns in OECD countries. The analysis is performed in an unbalanced panel using 19 countries $^{39}$ and gender as the cross-section dimension. The maximum time span covered is 1992-2002, but for several countries only the most recent years are available.

46. On the demand side, private returns are expected to influence graduation ratios positively. The ratio of education costs to the availability of individual financing, as proxy for the existence of liquidity constraints, is expected to display a negative sign. The responsiveness of supply of tertiary education, as measured by the STE indicator, is expected to be positively related to graduation ratios. For example, a university system that better matches students' preferences (e.g. because it offers a larger choice of programmes) is likely to attract more students. In addition, systems allowing for shorter study duration and intermediate diplomas are more attractive since they provide students with the option of deciding when to stop the investment (see Heckman et al., 2005). For similar reasons, those systems may induce lower dropout rates in case of high subjective discount rates.

47. Taking into account some of these determinants, a reduced form was estimated where tertiary graduation ratios are regressed on the IRR, the STE indicator, an indicator of financial constraints (derived from the last column of Table 3.4), a dummy for females and an output-gap indicator as a way of capturing possible cyclical components in the graduation ratios. ${ }^{40}$ Several specifications were tested (Table 3.5),

39. This includes all countries for which the IRRs were available except Luxembourg and Poland, where the STE indicator was not available.

40. As a caveat, it could be noted that tertiary graduation ratios can also depend on a number of other structural, cultural and socio-economic factors. For example, the demand for tertiary education may depend on the secular increase in the labour force participation of women; for this reason the specification does control for gender. The shocks affecting the long-term job prospects of tertiary graduates, such as skillbiased technological progress and globalisation are implicitly taken into account through the differences in 
including or not time fixed-effects and country-specific trends to capture other cross- and country-specific unobservable factors driving graduation ratios. In all specifications the explanatory variables have the expected sign and are significant. Higher IRRs, higher responsiveness of supply and lower liquidity constraints are associated with higher graduation ratios. As suggested by the effect of the female dummy, graduation ratios are generally higher for women than for men. The results are consistent across specifications, though the IRR and the supply indicator coefficients are fairly sensitive to whether fixed time effects and country-specific time trends are included. ${ }^{41}$

48. The next section discusses a number of potential policy reforms and in that context makes use of the above empirical results to present some stylised simulations that illustrate the effect of policy change on graduation ratios. For the sake of these simulations, the retained specification (shown in the third column of Table 3.5) is the one including fixed time effects and country-specific time trends since the omitted variable bias is likely to be smaller in this case. Since the size of coefficients varies to some extent across specifications, while their sign is systematically in line with priors, the simulations are best seen as illustrative of the qualitative impact of policy changes on graduation ratios rather than specific numerical quantifications.

\section{[Table 3.5: Reduced form regression results]}

\section{Policies to enhance tertiary education outcomes}

49. The analysis and empirical tools developed in previous sections provide a basis for assessing various policies that could address some of these problems. These include institutional reform of educational supply, introduction or greater reliance on fees and loan systems, reform of grant systems, easier access to student work, shortening study duration and tax reform. Policy change in each of these areas may reduce distortions to incentives but may also present trade-offs in respect to other policy objectives. The main challenges are to avoid negative repercussions on aggregate investment in tertiary education, equality of access and, more broadly, income distribution.

50. The policy simulations presented below are of various kinds. Some policies affect directly the investment in tertiary education (such as institutional reform or easing liquidity constraints) while others (such as easing taxation and student work) affect investment through their impact on the IRRs. It is difficult to find a common metric for assessing policy changes in different areas; as far as possible, the variables corresponding to particular policies were changed according to the dispersion observed in the sample (typically the shock corresponds to a move by all countries to the mean $-/+$ two standard deviations or alternatively to the minimum/maximum of the policy variable in question across the countries for which data are available).

\subsection{Reform of tertiary education institutions}

51. As documented by OECD (2006b), over the past decade many OECD countries have moved in the direction of increasing the autonomy and the accountability of tertiary education systems. Nonetheless, as highlighted in Section 3, OECD indicators on the institutional set-up of tertiary education suggest that in several countries considerable scope remains for moving towards more incentive-based and coherent

the IRRs. Other omitted variables are to some extent controlled for by introducing trends and time fixed effects in the equation.

41. Broader sensitivity analysis on the specification of the reduced form is carried out in Boarini, Nicoletti and Oliveira Martins (2007), including regressions where the assumption of a pre-determined IRR is relaxed. Both analyses show that the signs of coefficients shown in Table 3.5 are robust to the choice of regressors and to the assumptions of given IRR, while their absolute values may change to a larger extent. 
systems. Using the regression results to provide an indication of the potential gains, in terms of graduation ratios, that could be obtained from institutional reforms to enhance the flexibility and the accountability of tertiary institutions, reforms were simulated corresponding to an alignment of the STE indicator on the maximum observed in the sample of the regression (Australia) (Figure 4.1). The results show that all other OECD countries would benefit from such a reform, particularly so some continental European countries (Greece, Germany and France).

\section{[Figure 4.1: Impact of increasing the flexibility and accountability of tertiary education supply on} graduation ratios]

52. A related area in which most OECD countries have implemented reforms is the shortening of the study curricula offered by tertiary institutions. Within the EU, the Bologna process has had this effect. Again, empirical estimates obtained in the previous sections can be used to gauge the effects of such shortening through their effect on the $I R R$ and subsequently on graduation ratios. On average, a reduction of study duration from current levels to the cross-country mean less two standard deviations (i.e. to around three years) would increase graduation ratios by between 0.2 to 0.8 percentage points, with the largest effects obtained for Finland, France and Germany (Figure 4.2).

\section{[Figure 4.2: Impact of reducing study duration on graduation ratios]}

53. In practice, deep reforms of tertiary institutions are not easy because they imply changing entrenched beliefs and practices. Implementation therefore involves transitional costs and needs to overcome resistance from stakeholders. These costs are not accounted for in the simple experiments performed above. Also, these experiments are conducted under the assumption that the quality of graduates is not affected by reforms, while a trade-off could appear for instance between study duration and the quality of education. Similarly, shorter study duration might reduce the scope for student work.

\subsection{Introduction or greater reliance on tuition fees}

54. A number of countries have introduced (or re-introduced) tuition fees (Australia, Austria, the United Kingdom, and Poland) or considerably increasing them (e.g. Portugal, the Netherlands) (Table 4.1). However, in most countries the level of fees remains well below the overall spending per student (Figure 4.3). Raising tuition fees has often been accompanied by the introduction or reform of student loan systems that make available sufficient individual financing to cover fees, as well as living costs (see below).

\section{[Table 4.1: Introduction of tuition fees and loan systems in selected OECD countries]}

\section{[Figure 4.3: Ratio of tuition fees to spending per student, selected OECD countries]}

55. Increased reliance on tuition fees can help address some of the shortcomings of current tertiary education systems. For instance, tuition fees can encourage competition for quality amongst universities and make them more responsive to students' preferences, providing that the flexibility and accountability of the system is sufficient. The case for variable fees across institutions offering different curricula and programmes is also strong: different fields have different costs and returns (as outlined in Section 3). Variable fees may also meet differences in students' willingness to pay, allowing for example a local university to charge lower fees than an internationally renowned one.

56. Aside from orienting decisions about fields, fees are likely to affect positively student effort to successfully complete tertiary studies and to discipline the mere consumption of education services. For 
similar reasons, fees could also lead to a shortening of the average duration of studies, providing a fiscal dividend.

57. Another potentially positive effect of fees is to help reduce the risk of economic waste and the undesirable distributional effects implicit in systems that heavily subsidise all students. "Free" higher education benefits people who are likely to end up with high incomes and/or who originate disproportionately from high-income families, and is paid for by all citizens through (distorsive) taxes. This implies deadweight losses and involves income redistribution from low- to middle- and upper-income families.

58. Finally, fees can also contribute to increasing resources per student without creating budgetary pressures. A simple correlation for a cross-section of OECD countries (Figure 4.4) suggests a positive relation between graduation ratios and the spending per student. While the expansion and increase in quality of tertiary education may require more resources per student, public budgets are confronted with many other competing demands (notably in the social area). Indeed, when tertiary education systems are faced with such constraints, two basic alternatives are available: an increased use of private resources or rationing of enrolment or quality (where access to tertiary education is unrestricted). Rationing may not seem desirable and also raises equity problems since upper-income students may have more alternatives (such as studying abroad), and the students who will potentially be hurt the most by declining quality or numerus clausus are those that do not have these options.

[Figure 4.4: Graduation ratios vs. costs per student, 2001]

59. In introducing or raising fees, their positive effects should be weighed against their potentially negative influence on incentives to invest in tertiary education. Earlier IRR estimates and regression results can be used to illustrate this trade-off. Tuition fees (net of the associated grants) by country were set to the sample mean plus two standard deviations (around 4000 US\$ at PPPs). In most countries, this implies a substantial increase, notably where currently fees are very small or non existent (e.g. Nordic countries). The increase in fees negatively affects graduation ratios both through a fall in the IRR (as it increases direct costs) and via stronger liquidity constraints (assuming that all other factors remain equal). The cumulated negative effect can be large in absolute terms (above 2.7 percentage points for Finland, Denmark and Ireland). This result suggests that increases in tuition fees need to be accompanied by well-designed financing systems to ensure good study access to all students, regardless of their family background. Given that the main effect relates to increased liquidity constraints (the indirect impact through the IRRs being relatively minor) among possible compensating policies, a natural candidate is the development of individual financing. Indeed, countries introducing or raising tuition fees have taken simultaneous action in this field.

[Figure 4.5: Impact of an increase in tuition fees on graduation ratios] 


\subsection{Introduction or greater reliance on student loans}

60. Loan systems can reduce liquidity constraints and thereby enhance equality of access. Moreover, as compared with other financing channels, such as grants, loans may raise incentives for swift and successful study completion. In turn, loans could have a positive effect on graduation ratios. As a generic feature, universal (as opposed to means-tested) government-supported loan systems may be seen as desirable to prevent students from depending on their families' willingness to pay for tertiary education. In this context, it also seems desirable for the loan system to include a loan entitlement large enough to cover both tuition fees (where applicable) and living costs.

61. In order to address risk aversion, which may be particularly pronounced among students from a low-income background, loan repayments are often made income-contingent. ${ }^{42}$ However, incomecontingent loans may sometimes present some complications related to the verification of graduates' income. This verification is best done through the tax system, in the presence of an effective tax collection. Hence, a country with a leaky tax system may have problems implementing income-contingent loans.

62. The implementation of a loan system may also entail a liquidity burden for the public sector, in that the flow of repayments from graduates may approach the flow of new loans only after some time (Barr, 2001).

63. Moreover, any student loan system is faced with the prospect that able graduates may migrate. In general, it could be complicated to enforce repayment in these conditions and, more specifically, loans with income-contingent repayment would pose a particular challenge. To create financial incentives for graduates to remain in the country, New Zealand recently introduced interest write-offs for borrowers living in the country for at least six consecutive months.

64. To assess the effect of easing liquidity constraints on investment, the regression results were used to simulate the impact of aligning the ratio of costs to financing resources (Table 3.4 above) to the minimum in the sample. The impact ranges from above 1.5 percentage points in Portugal and Spain to virtually zero in Denmark and Finland (Figure 4.6). The simulation is necessarily illustrative, as in countries with universal funding systems covering most investment costs, the need to further ease liquidity constraints could be questioned. The simulation results are clearly more relevant in the case of familybased systems, where the liquidity constraints are likely to be more binding. However, insofar as reforms of universal funding systems involve use of tuition fees, easing liquidity constraints will have a positive impact in those systems too.

[Figure 4.6: Impact of easing liquidity constraints on graduation ratios]

\subsection{Reform of grant systems}

65. The main argument used for the introduction of grants is that, despite the appealing features of the loan systems, information problems may still prevent loan systems from completely addressing asymmetric information and risk aversion that may have a special bearing for low-income households. But this is not the only rationale for having grants, which could also be seen as a way of offsetting the negative incentives created by progressive taxes (e.g. Nordic countries).

42. Mortgage-type loans and a "graduate tax" system have been also proposed, but they seem less appealing (see Barr, 2001). 
66. Some studies have found that low-income students and their families usually overestimate the costs and under-estimate the returns of tertiary education. ${ }^{43}$ In these cases, a possible solution would be the existence of means-tested grants only for the first years of higher education, after which students would be better informed and willing to take loans to continue studying.

67. Where grants are maintained to preserve returns and equality of access, they could be reformed. At least two options that are not mutually exclusive could be contemplated. Both involve support being given initially as loans, but then, under certain conditions, being converted to grants. One condition would be the finalisation of studies within a given time frame. This would create incentives to reduce study duration and student performance. Another condition would be to have sufficient tax liabilities to allow the loan repayment to be offset by the grant. This option would reduce migration of high-skilled workers - a particularly relevant issue in countries where tertiary education is heavily subsidised - but could also be seen as unduly restricting migration flows.

\subsection{Access to student work}

68. Another way to relax liquidity constraints and encourage private incentives to invest in higher education is to make access to part-time student work easier, for instance by implementing recommendations contained in the OECD Job Strategy. Greater scope for student work may also help address excessive risk aversion. ${ }^{44}$ The potential trade-off between raising fees and increasing graduation ratios could be eased if the labour market is flexible enough to accommodate additional part-time labour supply by students.

69. To illustrate the impact of additional income from student work, a simulation was carried out assuming that students spend one-third of their time working in paid employment at the gross wage rate of upper-secondary degree holders; their earnings are taxed at $10 \%$ on average. These additional revenues reduce the opportunity cost of studying and, hence, increase the $I R R$, which in turn increase graduation ratios. This increase reaches around one percentage point in Denmark and Finland (Figure 4.7). These results should be taken with caution, however, because they do not factor in the potential repercussions of student work for the quality and the duration of studies.

\section{[Figure 4.7: Impact of introducing or increasing part-time student work on graduation ratios]}

\subsection{Changes in the tax systems}

70. Tax reforms are rarely motivated with reference to their effects on incentives for investment in higher education but, nonetheless, may have such effects. In particular, lower marginal tax rates on labour earnings have a positive effect on returns to education. At the same time, however, such changes could have a distributional effect that may be seen as undesirable, but that might be offset by other changes in tax systems, such as e.g. higher property taxes. Lower marginal tax rates will also increase the dispersion of returns, with the increased risk possibly providing an offset to the increase in tertiary education investment led by higher average returns.

71. The dispersion of marginal tax rates is particularly wide across OECD countries in the sample (ranging from nearly $70 \%$ in Hungary to $28 \%$ in Greece); this makes it difficult to use the metric used in

43. See Usher (2006). Hence, a flanking policy would be to inform students about the average returns of their education, the risks associated with such investments (e.g. employment probabilities) and the conditions for repayment of student loans.

44. Note that the base calculation of IRR assumes that students do not earn income from paid employment (reliable data on student employment, hourly wages and tax rates is rarely available). 
the previous simulations. Therefore, the marginal rates were arbitrarily reduced by 5 percentage points in all countries. This increases the $I R R \mathrm{~s}$, which in turn leads to higher graduation ratios (Figure 4.8). On average, reducing marginal tax rates by 5 percentage points increases graduation ratios by 0.3 percentage points, with the largest effects in Hungary, Germany and Finland.

\section{[Figure 4.8: Impact of a decrease of marginal tax rates on graduation ratios]}

\section{Summary of main findings and policy implications}

72. The analysis and indicators provided in this paper highlight a number of stylised facts and some avenues for reform of higher education systems in the OECD:

- There are significant cross-country differences in tertiary graduation ratios, defined as the yearly number of new graduates over the population 20-29 years old, with the highest observed in New Zealand, Korea and Ireland, and the lowest in Turkey, Mexico and Greece. However, these ratios have been growing steadily everywhere, much faster for females than for males, such that gender convergence has been almost achieved in many countries. Stocks of tertiary human capital still differ widely across countries, ranging from around 10\% of the population 25-64 years old in Southern Europe to above 35\% in North America. The distribution of graduates by field is skewed, with Social Sciences and Law generally accounting for the largest share; male and female graduates tend to be concentrated in different fields.

- The institutional set-up of university systems, summarised by an indicator of the supply of tertiary education, varies considerably across OECD countries, with some of them (e.g. Greece, Germany) having institutions with little room for autonomy, flexibility and accountability relative to others (e.g. Australia, Canada, the United Kingdom). Funding mechanisms also differ markedly across countries, but private participation has generally been extended over recent years, by increasing the share of private institutions, the share of costs covered by student fees or both.

- The development of financing systems for students has been uneven across OECD countries. Some countries have created universal loan systems (e.g. most English-speaking countries), and others provide generous grants (e.g. Nordic countries), but the majority of countries still rely mainly on family transfers. In many countries, the amount of annual investment in tertiary education (e.g. for living expenses and other costs of education) represents a significant share of resources for a median household, even where tuition fees are heavily subsidised.

- Investment in tertiary education generates private benefits, summarised by the internal rates of return to tertiary education. These are large relative to investments in alternative assets, but to a different extent across countries, ranging from around 4\%-6\% per year of education in Spain, Italy, Germany, Greece and Sweden to above 10\% in Ireland, Portugal, the United Kingdom, Poland (women) and Switzerland. Their main determinants are gross wage premia (ranging across countries from about $25 \%$ to $90 \%$ above the salary of an upper-secondary educated worker) and a number of policy-related factors that affect the costs and benefits of investing in higher education.

- Policy-driven differences in private returns to education and institutional features of the tertiary education systems are important determinants of the investment in tertiary human capital. Higher private returns to tertiary education, more incentive-based university systems and lower financial constraints are found to lead to higher investment, as measured by graduation ratios. 
73. While the mix and focus of tertiary education reform will depend on each country's specific conditions, this paper has identified several possibilities for reforms of tertiary education systems, each of them requiring arbitration among different public policy objectives:

- Empirical results suggest that changing tertiary education systems in the direction of higher supply flexibility and accountability is likely to improve graduation ratios. Directions for reform would involve more autonomy for universities in student selection and staff policy, more reliance on independent and public evaluation and funding based on outputs rather than inputs. The possibility for offering more diversified studies, notably shorter duration grades, could help meeting individual demands for education more effectively.

- Acknowledging the large private returns from higher education, a number of countries have been raising (or introducing) tuition fees to ease financing constraints of universities, while at the same time enhancing the efficiency of tertiary education systems and the effectiveness of public support. Raising fees can be helpful for improving students' incentives and reducing study duration. However, they also have a negative impact on returns and may strengthen liquidity constraints. Therefore, generally they have been accompanied by appropriate individual financing policies.

- With or without fees, a student loan system to finance the direct and living costs of tertiary education would help maintain equality of access and exploit at best the pool of talents in the population. Either public loans or public guarantees for private loans can soften liquidity constraints and ease the access to tertiary education for low-income students. However, these systems may not fully address the problem of an excessive risk aversion by potential students, especially when coupled with insufficient information about the returns to education. Some countries have addressed this problem by tying loan repayments to future incomes after graduation.

- Policies aimed at improving the dynamism of labour markets, such as those recommended in the OECD Jobs Strategy, can have a positive effect on incentives to engage in tertiary education by making part-time work more easily accessible to students, thereby reducing the opportunity cost of studying and helping them finance their living costs while enrolled in university. This could also contribute to reduce risk aversion, but may have costs in terms of increasing study duration.

- Student grants may seem debatable in conditions of high private returns and in view of the prospective incomes of recipients after graduation. Even when grants are justified as a way of maintaining returns in the face of progressive taxation or ensuring equality of access, reforms in grant systems may be desirable to strengthen individual incentives. For example, loans could be (partly or fully) converted to grants upon finalisation within a set time in order to encourage shorter study duration. As well, loans could be offset against future tax liabilities, increasing the incentives to seek jobs in the country of graduation. However, trade-offs would still arise as the first solution may curb enrolment of risk-averse students and the second solution may be seen as unduly restricting migration of high-skilled workers.

- While investment in tertiary education has typically not been a primary motivation for tax reforms, changes in taxation can have implications for incentives to invest in tertiary education. In particular, a less progressive tax system will increase average returns to tertiary education, although it may raise general distributional concerns. In addition, a less progressive tax system implies a higher dispersion of returns, thereby potentially raising the risk of investing in education. 
ECO/WKP(2007)36

\section{LIST OF TABLES AND FIGURES}

\section{Tables}

3.1. A comparison of loan systems for selected OECD countries

3.2 A comparison of take-up rates for student loan systems

3.3 A comparison of take-up rates for student grants

3.4 An estimation of total student cost and available financing per year (In US\$ PPP)

3.5 Reduced form regression results

4.1 Introduction of tuition fees and loan systems in selected OECD countries

\section{Figures}

2.1 Trends in tertiary human capital

New tertiary graduates as a share of the 20-29 population by gender for selected years

Flows of new tertiary graduates by field of education, 2004

Gross wage premia from tertiary education

Stocks of tertiary human capital: the effect of adjusting for wage premia, 2001

The structure of the supply of tertiary education indicator

Tertiary education supply indicator by category, 2005-2006

Composite supply indicator of tertiary education (STE), 2005-2006

Supply indicator and coherence of tertiary education systems

Individual returns to tertiary education illustrated

Marginal effect of higher education on the employment probability

Net direct costs of tertiary education

Opportunity costs of tertiary education

3.10 Sensitivity analysis on the IRRs: effects of changes in the main drivers

3.11 Cross-country differences in the IRRs implied by country-specific field composition

4.1 Impact of increasing the flexibility and accountability of tertiary education supply on graduation ratios

4.2 Impact of reducing study duration on graduation ratios

4.3 Ratio of tuition fees to spending per student, selected OECD countries

4.4 Graduation ratios vs. costs per student, 2001

4.5 Impact of an increase in tuition fees on graduation ratios

4.6 Impact of easing liquidity constraints on graduation ratios

4.7 Impact of introducing or increasing part-time student work on graduation ratios

4.8 Impact of a decrease of marginal tax rates on graduation ratios 
Table 3.1. A comparison of loan systems for selected OECD countries

\begin{tabular}{|c|c|c|c|c|c|}
\hline & Australia & Netherlands & Sweden & $\begin{array}{l}\text { United } \\
\text { Kingdom }\end{array}$ & United States \\
\hline $\begin{array}{l}\text { Income } \\
\text { threshold for } \\
\text { repayment }\end{array}$ & $\begin{array}{c}A \$ 38149 \\
(74.5 \% \text { of } A W) \\
\text { or US } \$ 27622\end{array}$ & $\begin{array}{c}€ 15000 \\
(40 \% \text { of } A W) \\
\text { or US } \$ 16687^{1}\end{array}$ & None & $\begin{array}{c}£ 15000 \\
(52.5 \% \text { of } A W) \\
\text { or US } \$ 23946\end{array}$ & $\begin{array}{l}\text { US } \$ 10712 \\
(34 \% \text { of } A W)\end{array}$ \\
\hline $\begin{array}{l}\text { Standard } \\
\text { repayment } \\
\text { rates }\end{array}$ & $\begin{array}{l}\text { From } 4 \% \text { to } 8 \% \\
\text { of all income }\end{array}$ & Mortgage-style & $\begin{array}{l}\text { Mortgage-style } \\
\text { with an upward- } \\
\text { adjustment index } \\
\text { of } 2 \% \text { per year }\end{array}$ & $\begin{array}{l}9 \% \text { of income above } \\
\text { the threshold }\end{array}$ & $\begin{array}{l}\text { Mortgage-style } \\
\text { or Income- } \\
\text { Contingent }\end{array}$ \\
\hline $\begin{array}{l}\text { Amortization } \\
\text { period }\end{array}$ & .. & 25 years & 25 years & .. & $10-25$ years \\
\hline $\begin{array}{l}\text { Loan } \\
\text { forgiveness }\end{array}$ & $\begin{array}{l}\text { At death/ } \\
\text { disability } \\
\text { With a limit of } \\
\text { US } \$ 57554 \text { for } \\
\text { most full-free } \\
\text { courses and } \\
\text { US } \$ 71942 \text { for } \\
\text { Dentistry, } \\
\text { Medicine and } \\
\text { Veterinary } \\
\text { Science } \\
\end{array}$ & $\begin{array}{l}\text { After } 25 \text { years of } \\
\text { repayments }\end{array}$ & At age $70 /$ death & $\begin{array}{l}\text { At death/disability/ } \\
\text { after } 25 \text { years of } \\
\text { entering repayments }\end{array}$ & $\begin{array}{l}\text { At death/ } \\
\text { disability/ } \\
\text { after } 25 \text { years of } \\
\text { repayments }\end{array}$ \\
\hline $\begin{array}{l}\text { Subsidies } \\
\text { during studies }\end{array}$ & $\begin{array}{l}\text { Real interest } \\
\text { subsidy } \\
\text { (interest= } \\
\text { inflation): } 2.8 \%\end{array}$ & $\begin{array}{l}\text { Interest }= \\
\text { government's rate } \\
\text { of borrowing: } 3.05 \%\end{array}$ & $\begin{array}{l}\text { Subsidy of } 30 \% \text { of } \\
\text { the cost of } \\
\text { borrowing: } 2.8 \%\end{array}$ & $\begin{array}{l}\text { Real interest subsidy } \\
\text { (interest=inflation): } \\
2.4 \%\end{array}$ & $\begin{array}{l}\text { No interest rate } \\
\text { for subsidized } \\
\text { loans. Market } \\
\text { rate for the other } \\
\text { loans. }\end{array}$ \\
\hline $\begin{array}{l}\text { Subsidies after } \\
\text { studies }\end{array}$ & $\begin{array}{l}\text { Real interest } \\
\text { subsidy } \\
\text { (interest= } \\
\text { inflation): } 2.8 \%\end{array}$ & $\begin{array}{l}\text { Interest }= \\
\text { government's rate } \\
\text { of borrowing: } 3.05 \%\end{array}$ & $\begin{array}{l}\text { Subsidy of } 30 \% \text { of } \\
\text { the cost of } \\
\text { borrowing: } 2.8 \%\end{array}$ & $\begin{array}{l}\text { Real interest subsidy } \\
\text { (interest=inflation): } \\
2.4 \%\end{array}$ & $\begin{array}{l}\text { No subsidy, } \\
\text { market rates }\end{array}$ \\
\hline $\begin{array}{l}\text { Percentage of } \\
\text { students } \\
\text { working during } \\
\text { term }\end{array}$ & $70 \%$ & $91.1 \%$ & .. & $56 \%$ & $80 \%$ \\
\hline $\begin{array}{l}\text { Average debt } \\
\text { at graduation }\end{array}$ & $\begin{array}{c}\text { A } \$ 14697 \\
(29 \% \text { of } A W) \\
\text { or US\$10 } 642^{1} \\
\end{array}$ & $\begin{array}{c}€ 8700 \\
(23 \% \text { of } A W) \\
\text { or US\$9 } 678^{1} \\
\end{array}$ & $\begin{array}{l}\text { SEK230 } 000 \\
(74 \% \text { of } A W) \\
\text { or US } \$ 25308^{1} \\
\end{array}$ & $\begin{array}{c}£ 8800 \\
(31 \% \text { of } A W) \\
\text { or US\$14 } 048^{1} \\
\end{array}$ & $\begin{array}{l}\text { US } \$ 19300 \\
(61 \% \text { of } A W)\end{array}$ \\
\hline $\begin{array}{l}\text { Average } \\
\text { income at } \\
\text { graduation }\end{array}$ & $\begin{array}{c}\text { A } \$ 38000 \\
(74 \% \text { of } A W) \\
\text { or US } \$ 27514^{1}\end{array}$ & $\begin{array}{c}€ 28000 \\
(74 \% \text { of } A W) \\
\text { or US } \$ 31148^{1}\end{array}$ & $\begin{array}{l}\text { SEK290 } 400 \\
(94 \% \text { of } A W) \\
\text { or US } \$ 31954^{1}\end{array}$ & $\begin{array}{c}£ 22000 \\
(77 \% \text { of } A W) \\
\text { or US } \$ 35121^{1}\end{array}$ & $\begin{array}{l}\text { US } \$ 34100 \\
(107 \% \text { of } A W)\end{array}$ \\
\hline
\end{tabular}

..$=$ not applicable.

AW = Average worker's annual wage. For a definition, see Taxing wages (2006).

1. Converted with the 2006 PPPs.

Sources: Usher, A. (2005). Global Debt Patterns: An International Comparison of Student Loans Burdens and Repayment Conditions., EuroStudent Report 2005, NCES (US), Student Income and Expenditure Survey for 2004/2005 (UK), www.csn.se (Sweden), www.goingtouni.gov.au (Australia) 
Table 3.2. A comparison of take-up rates ${ }^{1}$ for student loan systems, 2003-2004 ${ }^{2}$

(Per cent)

\begin{tabular}{lc}
\hline Sweden & 85 \\
United Kingdom & 81 \\
Australia & 77 \\
Luxembourg & 72 \\
New Zealand & $60^{3}$ \\
Canada & 50 \\
Denmark & 50 \\
United States - Total loans & 50 \\
$\quad$ of which: Federal loans & 48 \\
Finland & 40 \\
Hungary & 30 \\
Japan & 24 \\
Germany & 25 \\
The Netherlands & 20 \\
Poland & 11 \\
Slovak Republic & 3
\end{tabular}

Table 3.3. A comparison of take-up rates ${ }^{1}$ for student grants, 2003-2004 ${ }^{2}$ (Per cent, non-repayable financing)

\begin{tabular}{ll}
\hline Sweden & 85 \\
Denmark & 80 \\
Finland & 80 \\
Norway & 78 \\
Luxembourg & 72 \\
United States - Total grants & 63 \\
$\quad$ of which: Federal grants & 34 \\
The Netherlands & 62 \\
Korea & 40 \\
Ireland & 31 \\
France & 30 \\
Belgium (Flemish) & 29 \\
Australia & 27 \\
Portugal & 25 \\
Poland & 25 \\
Germany & 25 \\
Spain & 23 \\
Slovak Republic & 13 \\
Mexico & 10 \\
Italy & 9
\end{tabular}

1. Take-up rates represent the number of aid recipients over the total number of students entitled to receive aid.

2. When available, or the most recent year.

3. Average of part-time and full-time students. Among full-time students, the take-up rate is about $76 \%$ Note: Countries with the same take-up rates for grants and loans are those with student aid packages that include a combination of both funding forms.

Source: Usher, A. (2005), Global Debt Patterns: An International Comparison of Student Loans Burdens and Repayment Conditions, US National Center for Education Statistics, HIS, Eurostudent Report 2005 and national sources. 


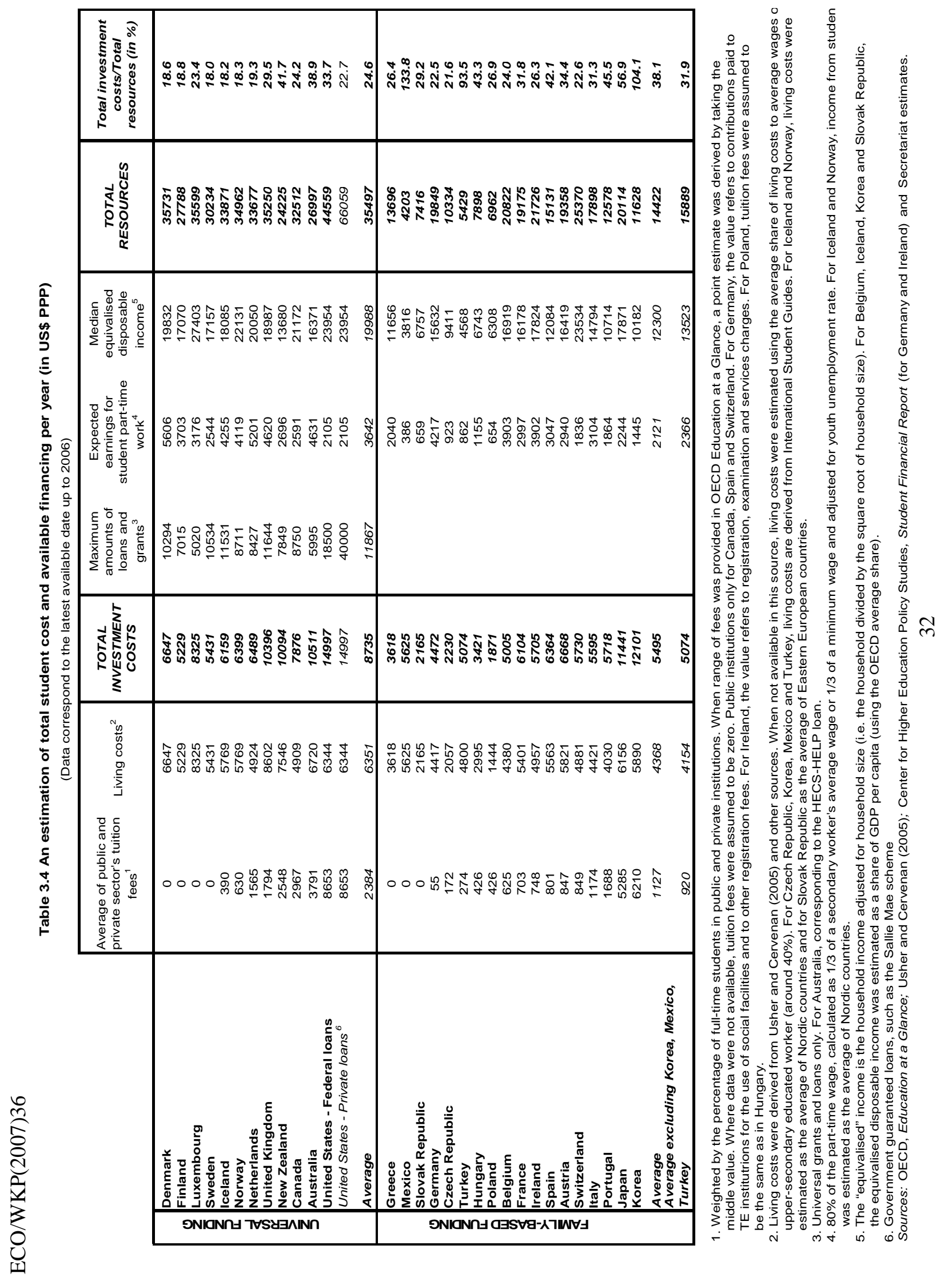


ECO/WKP(2007)36

Table 3.5. Reduced form regression results

\begin{tabular}{|c|c|c|c|}
\hline & $\begin{array}{l}\text { Pooled model } \\
\text { (1) } \\
\end{array}$ & $\begin{array}{l}\text { Pooled model with } \\
\text { country-specific time } \\
\text { trend } \\
\text { (2) }\end{array}$ & $\begin{array}{l}\text { Pooled model with country- } \\
\text { specific time trend and year } \\
\text { fixed effects }{ }^{1} \\
\text { (3) }\end{array}$ \\
\hline \multicolumn{4}{|l|}{$\begin{array}{l}\text { Dependent Variable: } \\
\text { Log of graduation ratio }\end{array}$} \\
\hline IRR & $\begin{array}{l}5.84^{\star * *} \\
{[0.77]}\end{array}$ & $\begin{array}{l}3.27^{* * *} \\
{[0.82]}\end{array}$ & $\begin{array}{c}3.19^{* * *} \\
{[0.85]}\end{array}$ \\
\hline Supply indicator & $\begin{array}{c}0.17^{\star * *} \\
{[0.02]}\end{array}$ & $\begin{array}{c}0.20^{* * *} \\
{[0.03]}\end{array}$ & $\begin{array}{c}0.21^{\star * *} \\
{[0.03]}\end{array}$ \\
\hline Financial constraints & $\begin{array}{l}-0.02^{* * *} \\
{[0.00]}\end{array}$ & $\begin{array}{c}-0.03^{* * *} \\
{[0.00]}\end{array}$ & $\begin{array}{c}-0.03^{\star * *} \\
{[0.00]}\end{array}$ \\
\hline Output gap & $\begin{array}{c}0 \\
{[0.01]}\end{array}$ & $\begin{array}{c}-0.03^{* * *} \\
{[0.01]}\end{array}$ & $\begin{array}{c}-0.03^{* * *} \\
{[0.01]}\end{array}$ \\
\hline Female dummy & $\begin{array}{l}0.22^{\star * *} \\
{[0.04]}\end{array}$ & $\begin{array}{l}0.21^{* * *} \\
{[0.02]}\end{array}$ & $\begin{array}{l}0.21^{\star * *} \\
{[0.02]}\end{array}$ \\
\hline Constant & $\begin{array}{c}0.09 \\
{[0.12]}\end{array}$ & $\begin{array}{c}0 \\
{[0.17]} \\
\end{array}$ & $\begin{array}{l}-0.21 \\
{[0.22]} \\
\end{array}$ \\
\hline Observations & 266 & 266 & 266 \\
\hline R-squared & 0.54 & 0.84 & 0.85 \\
\hline
\end{tabular}

Standard errors in brackets

${ }^{*}$ significant at $10 \%$; ${ }^{* *}$ significant at $5 \%$; ${ }^{* * *}$ significant at $1 \%$

1. This is the specification used in the simulations presented in section 4 .

Source: Authors' calculations. 


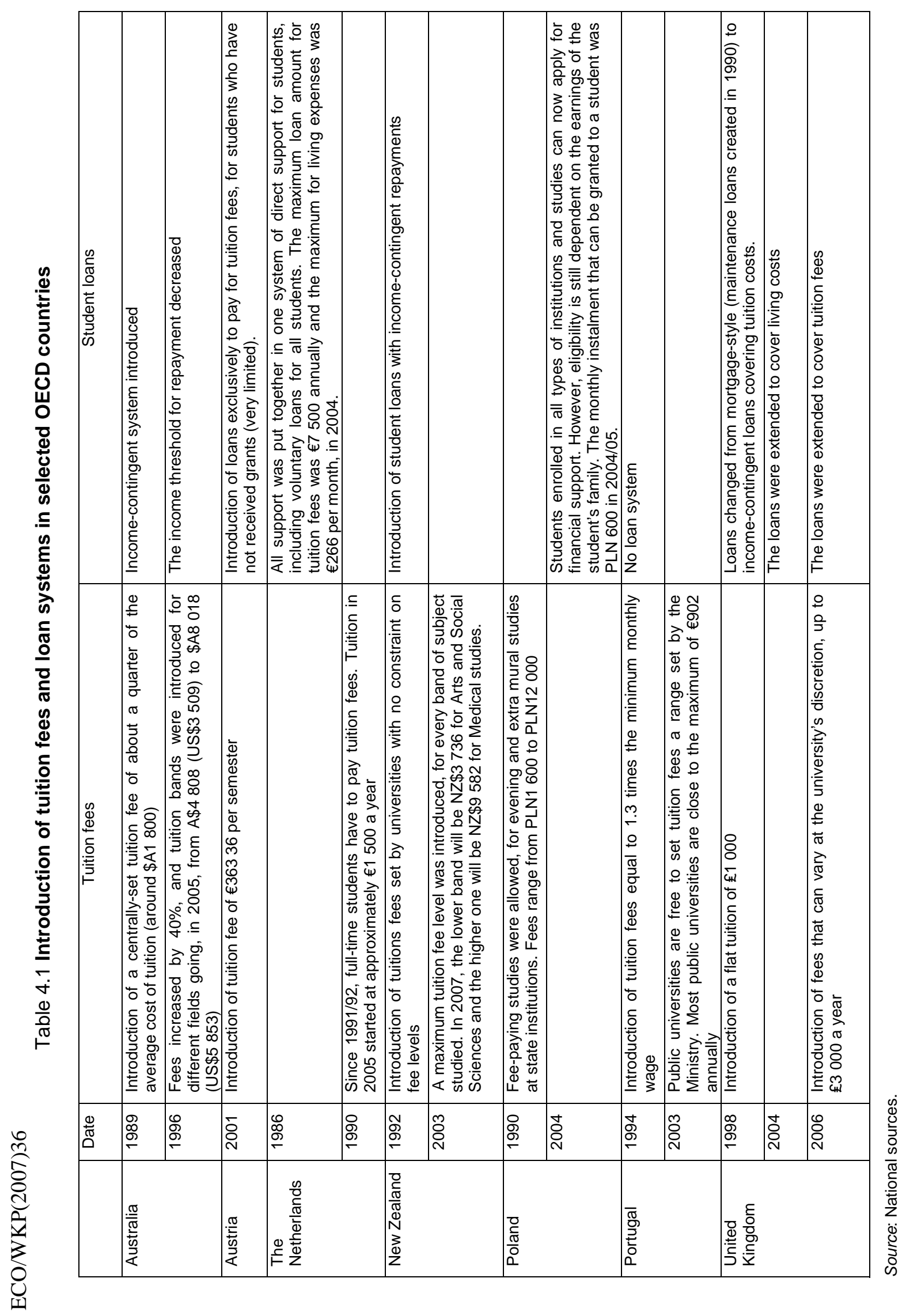




\section{Figure 2.1 Trends in tertiary human capital ${ }^{1}$}

OECD average

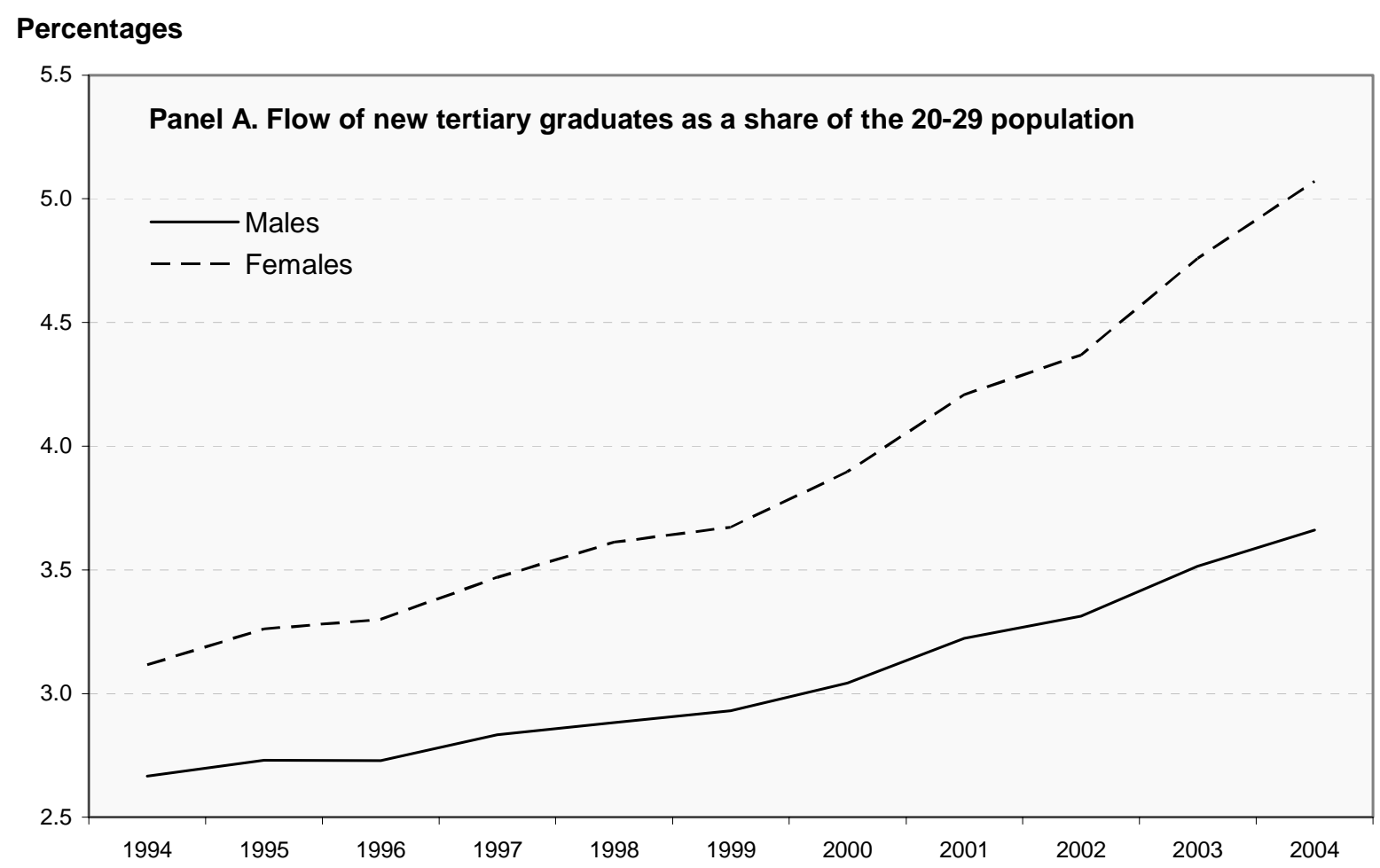

\section{Percentages}

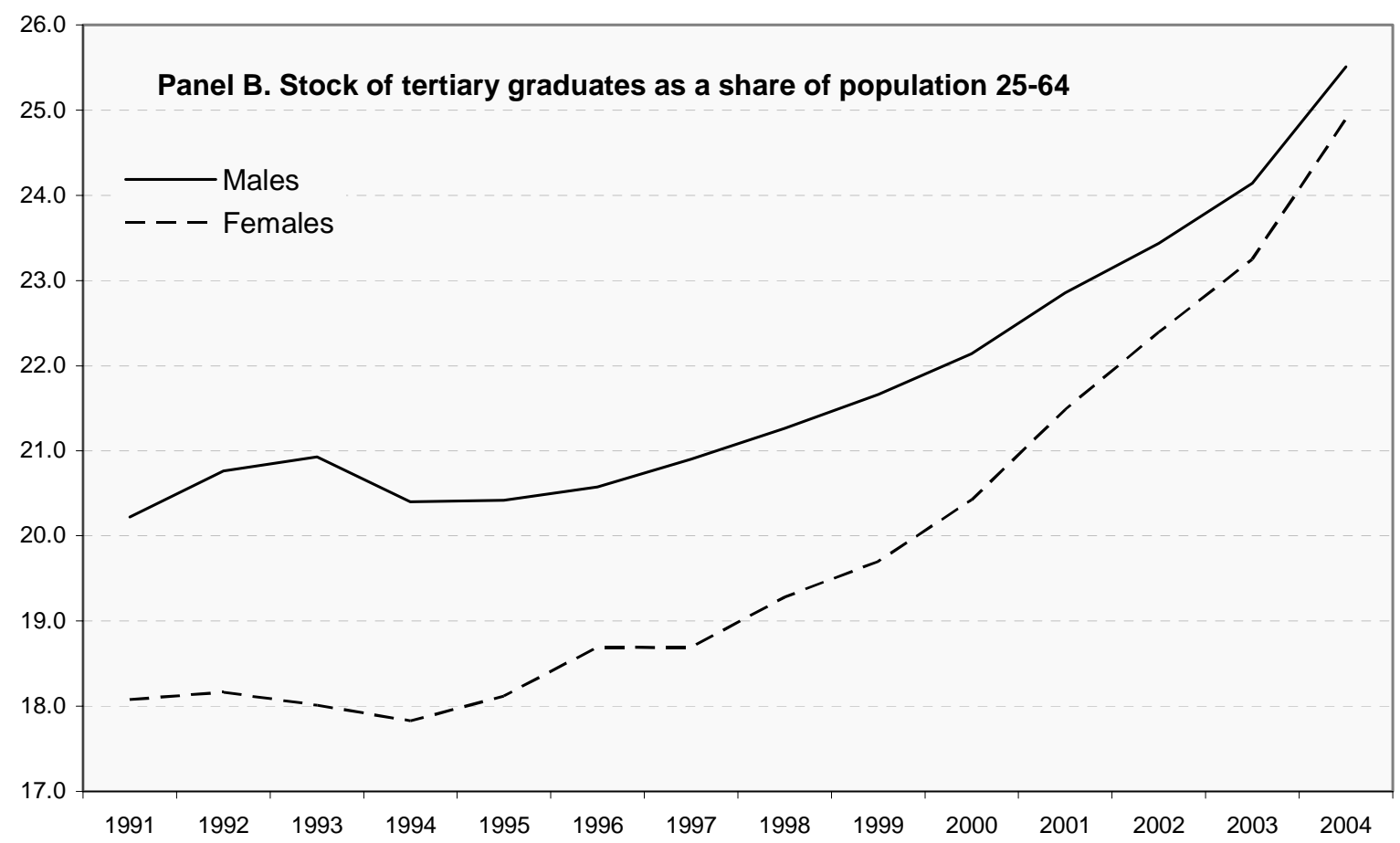

1. Tertiary graduates cover all individuals, including individuals over 29.

Source: OECD, EAG (2006), UNESCO education database, Eurostat and Authors' calculations. 
Figure 2.2 New tertiary graduates as a share of the 20-29 population by gender for selected years ${ }^{1}$

Males
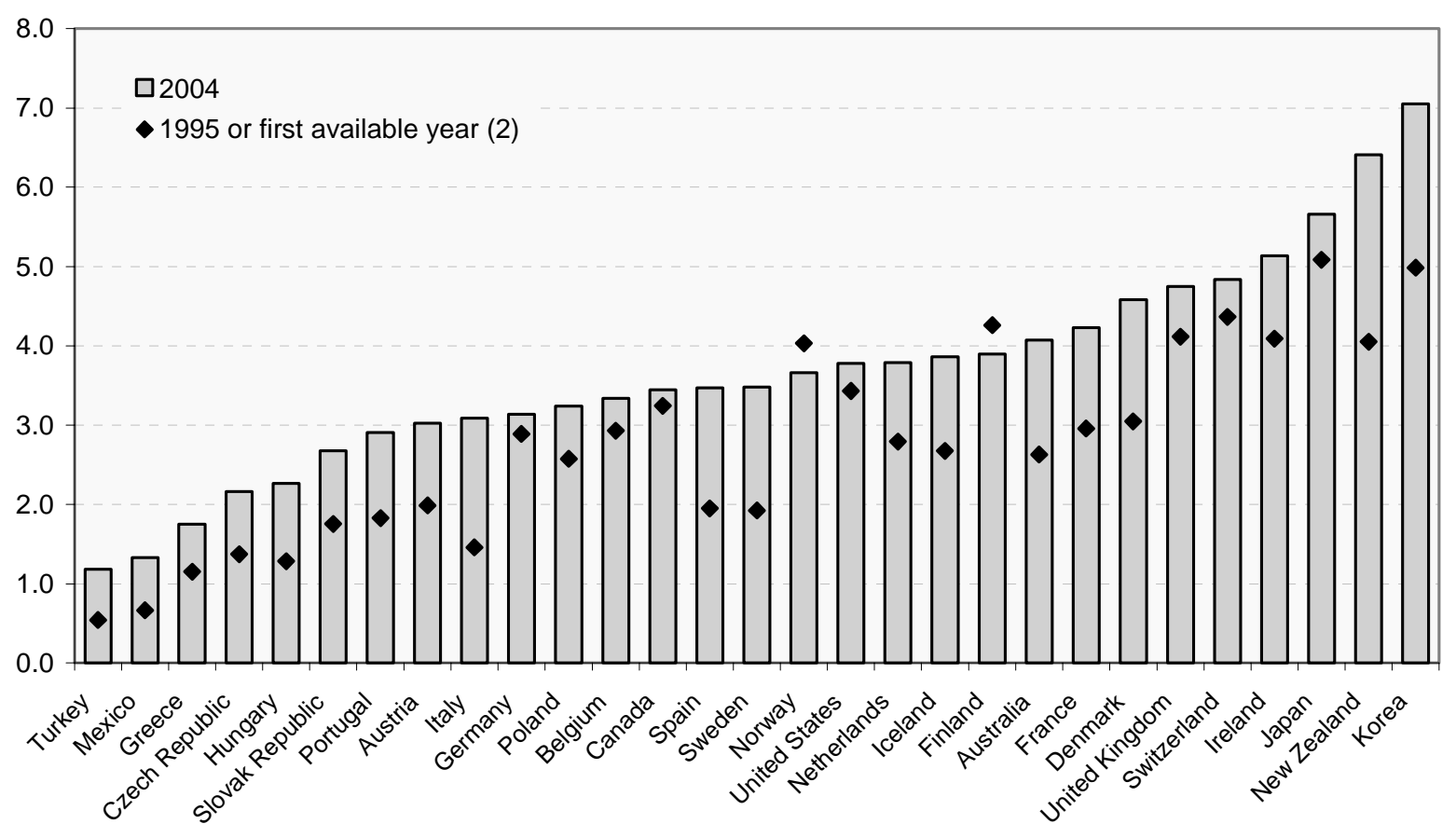

Females

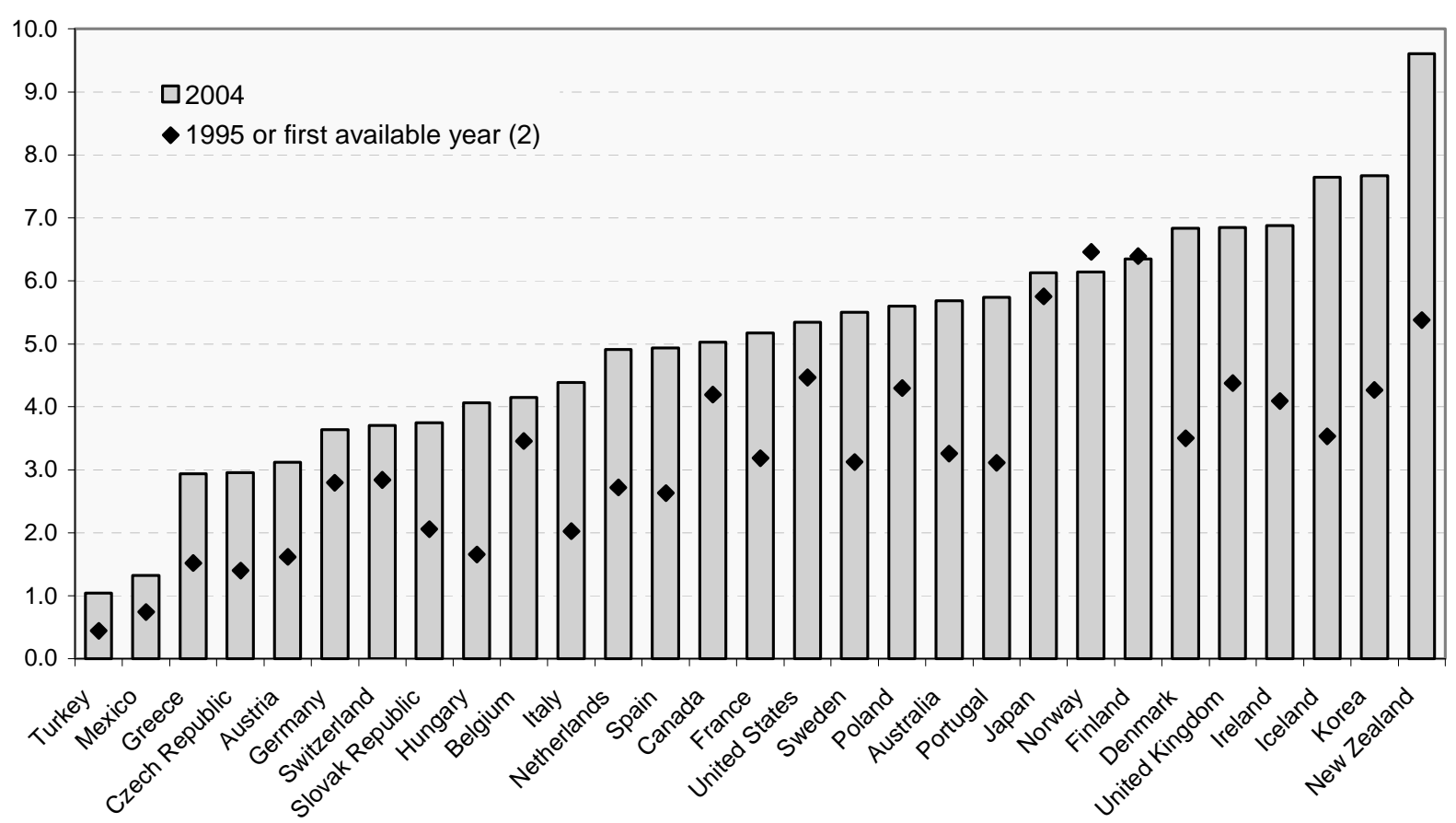

1. Tertiary graduates cover all individuals, including individuals over 29.

2. 1996 for Mexico and New Zealand, 1998 for Iceland, 1999 for Switzerland and 2000 for Belgium and Poland. Source: OECD, EAG (2006), UNESCO education database, Eurostat and Authors' calculations. 
Figure 2.3. Flows of new tertiary graduates by field of education, 2004

(OECD average, shares in total graduates)

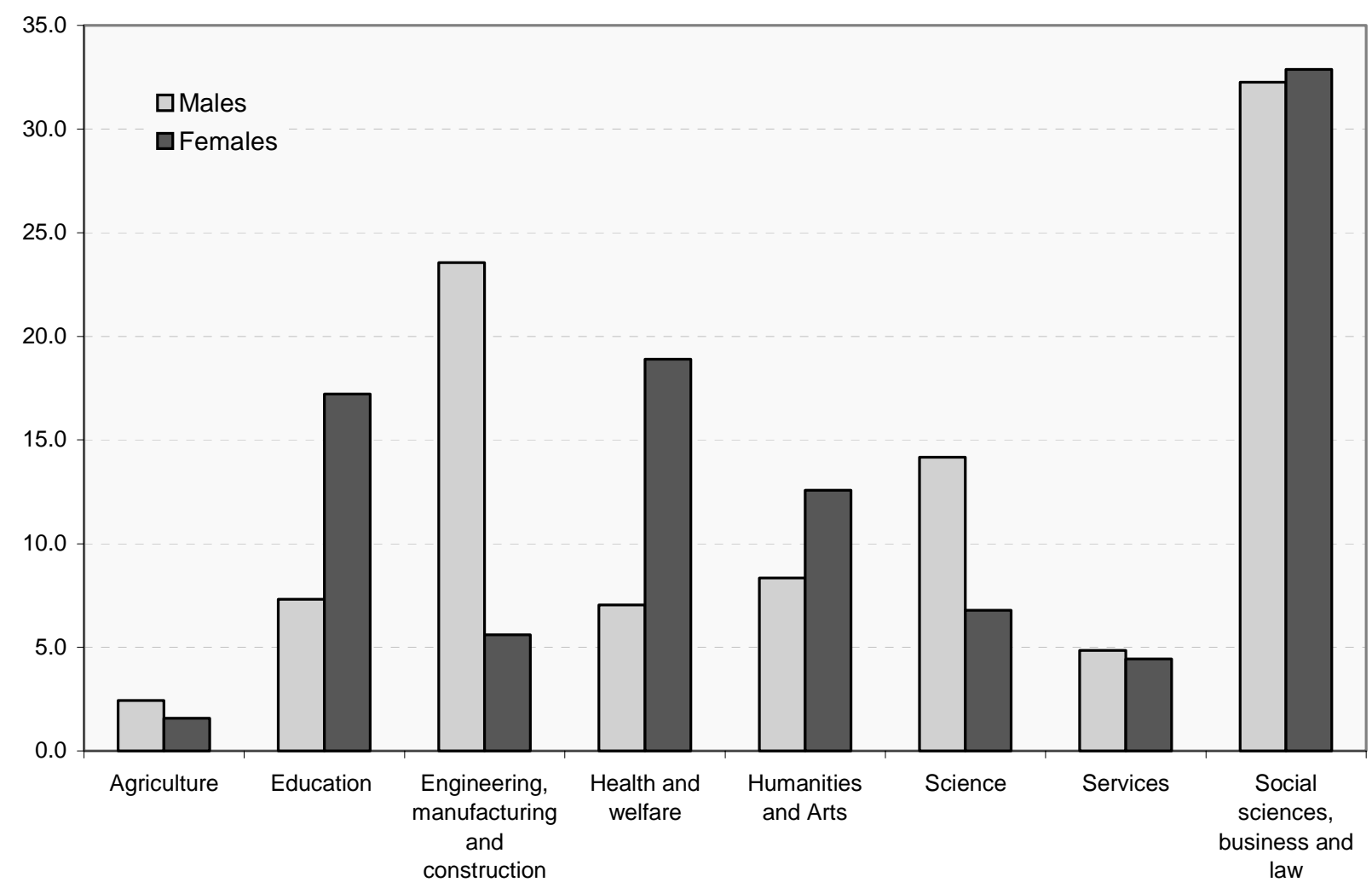

Source: OECD, EAG (2006). 
Figure 2.4 Gross wage premia from tertiary education ${ }^{1}$

$2001^{2}$
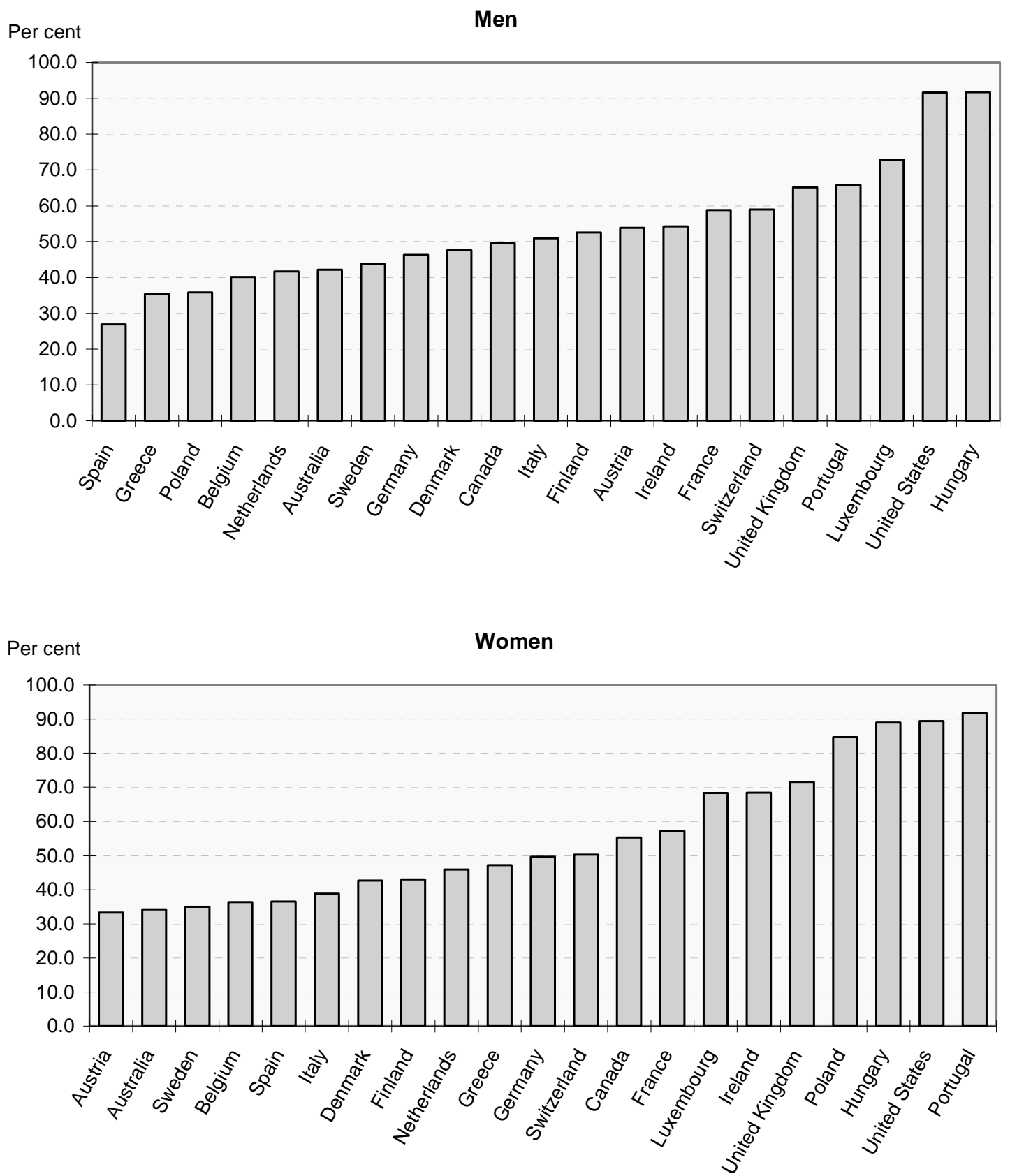

1. Estimates of the increase in gross hourly earnings relative to a worker with a secondary education degree, controlling for individual characteristics other than education attainment.

2. Except Hungary 1997 and Poland and Switzerland 2000.

Source: the European Community Household Panel (ECHP), the Consortium of Household Panels for European Socio-Economic Research (CHER), the Cross-National Equivalent File (CNEF), and the Household, Income and Labour Dynamics in Australia Survey (HILDA) and Authors' calculations. For details see Strauss and de la Maisonneuve (2007). 
Figure 2.5 Stocks of tertiary human capital : the effect of adjusting for wage premia, 2001

Males

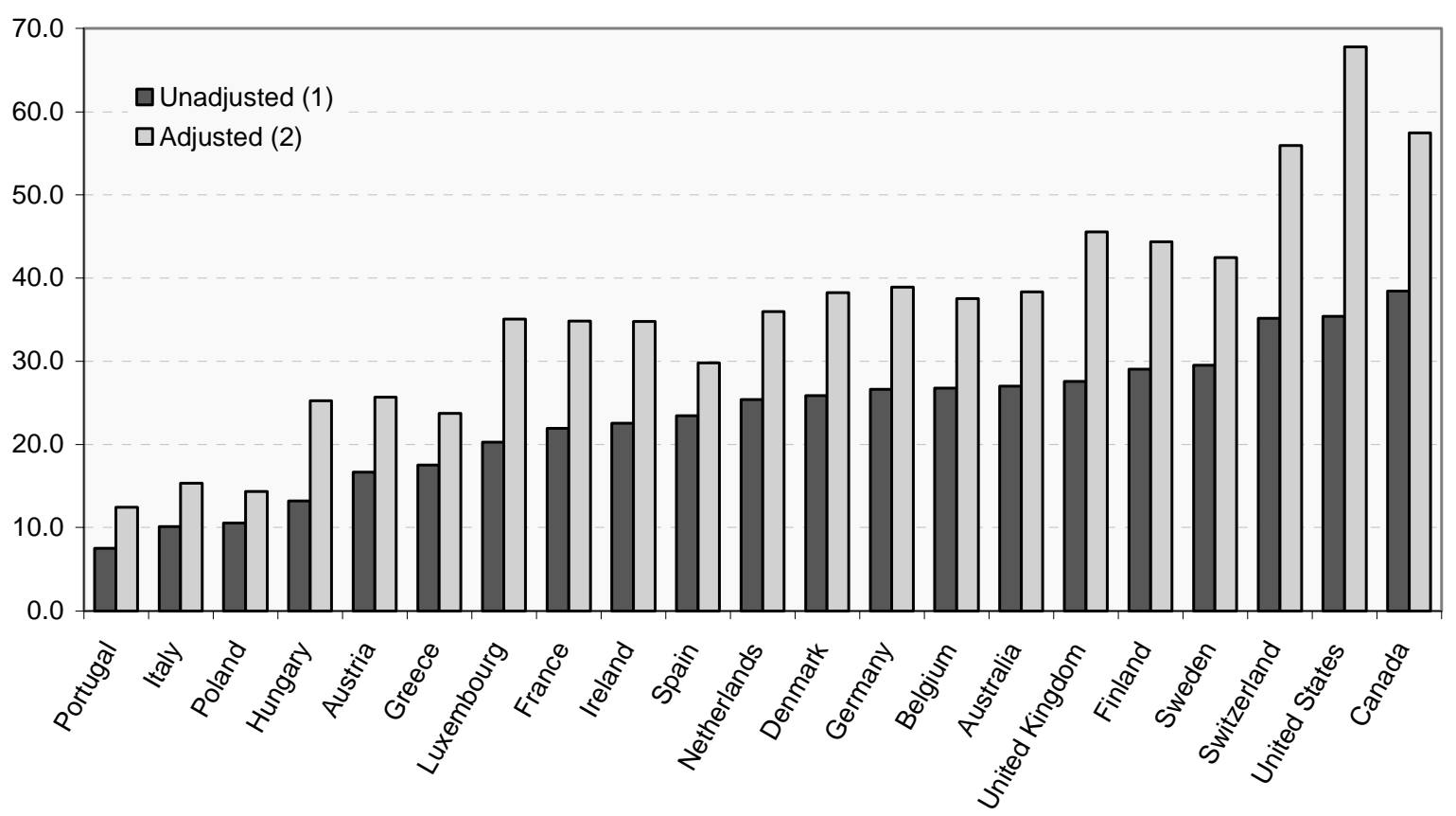

Females

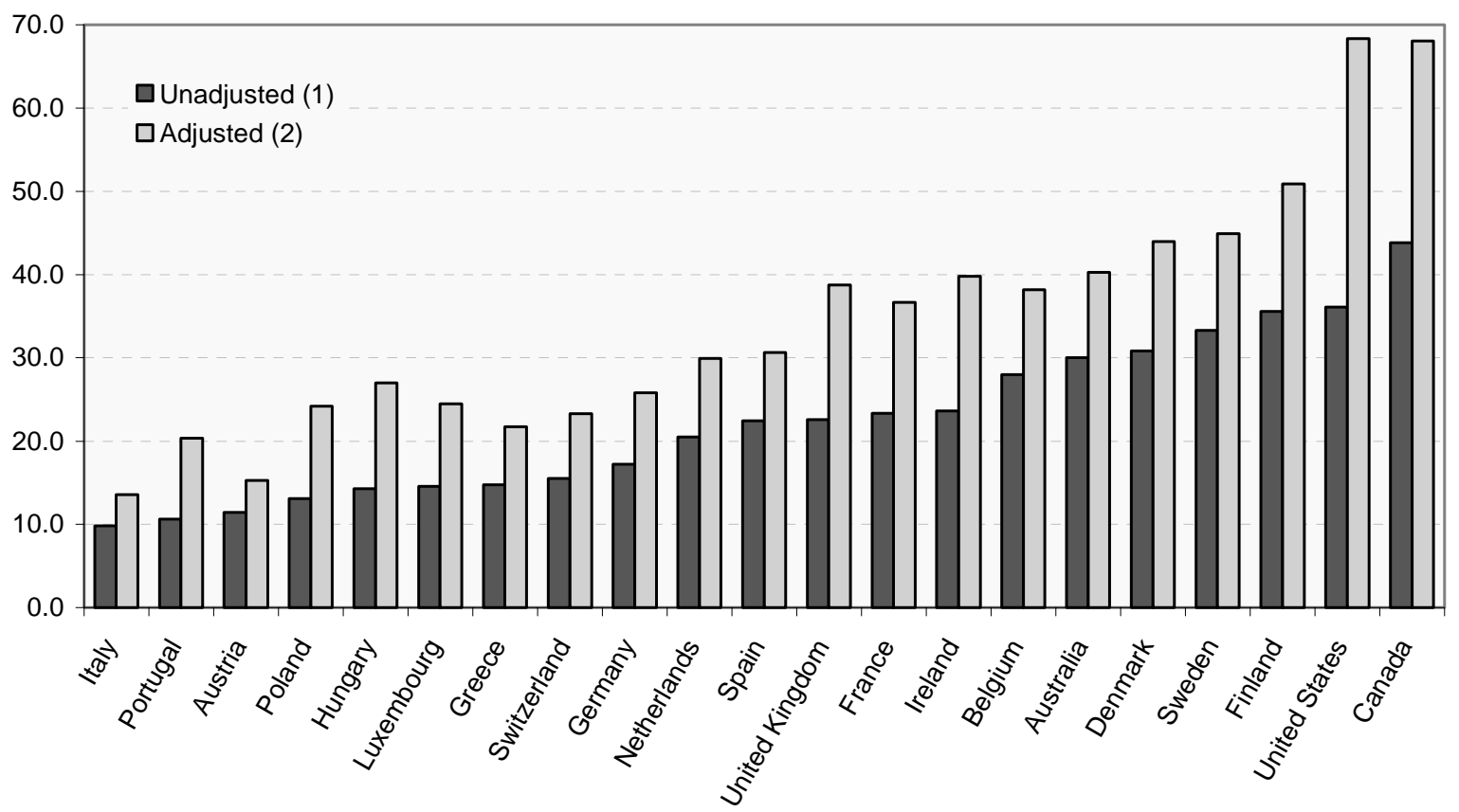

1. Population that has attained tertiary education, as a $\%$ of population aged $25-64$

2. Unadjusted stock of tertiary human capital multiplied by (1+wage premia) derived from figure 2.4

Source: OECD, EAG (2006) and Authors' calculations. 


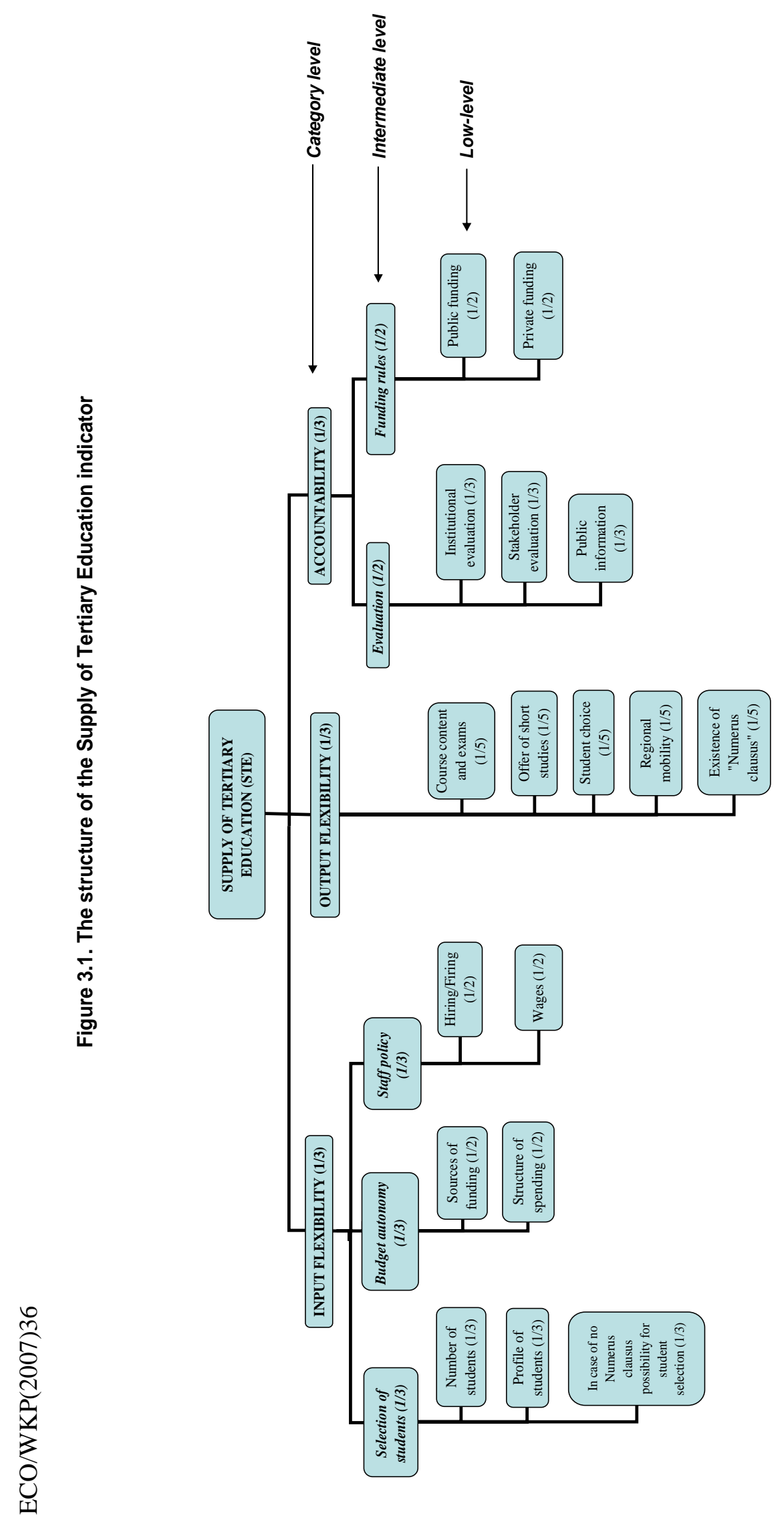

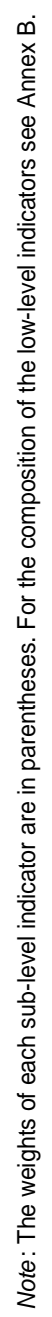


Figure 3.2. Tertiary education supply indicator by category, 2005-2006

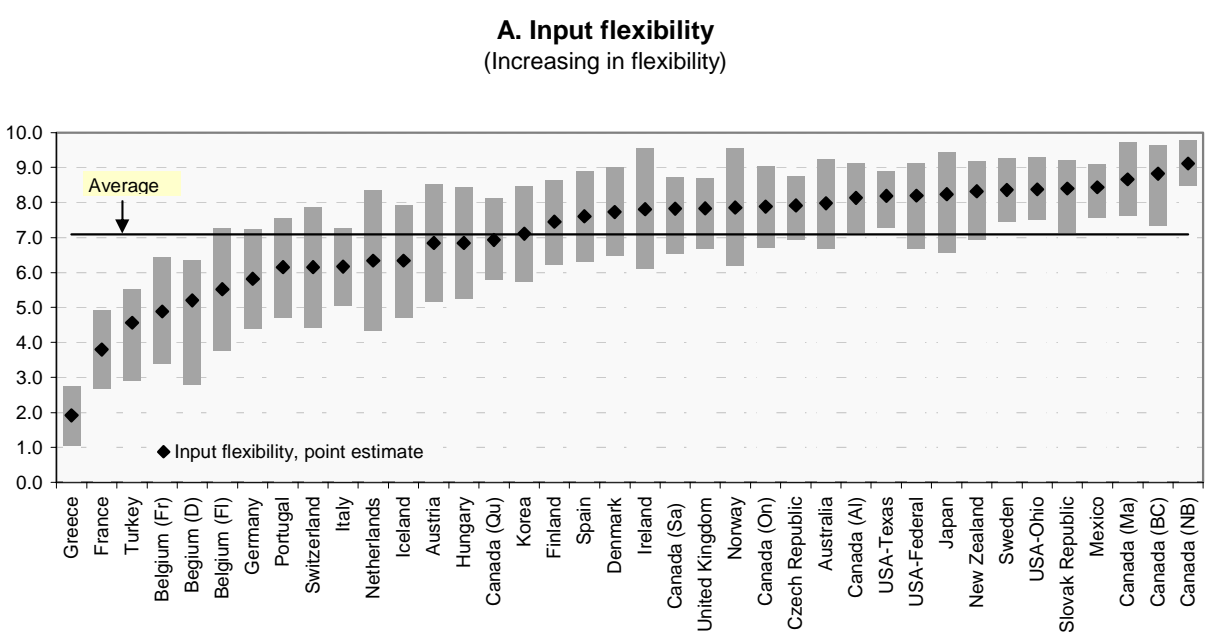

B. Supply flexibility

(Increasing in flexibility)

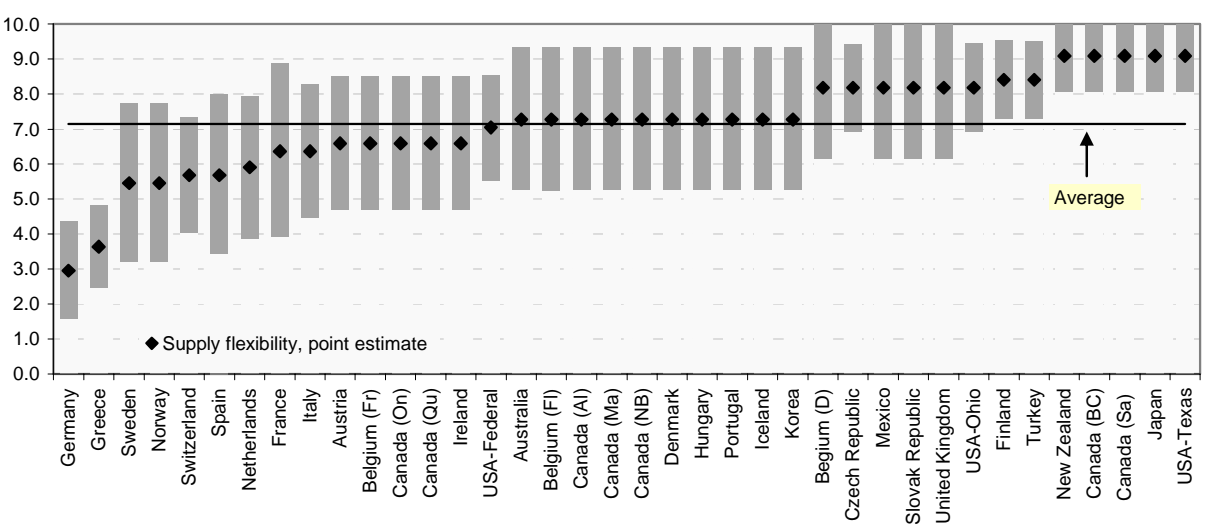

C. Accountability

(Increasing in accountability)

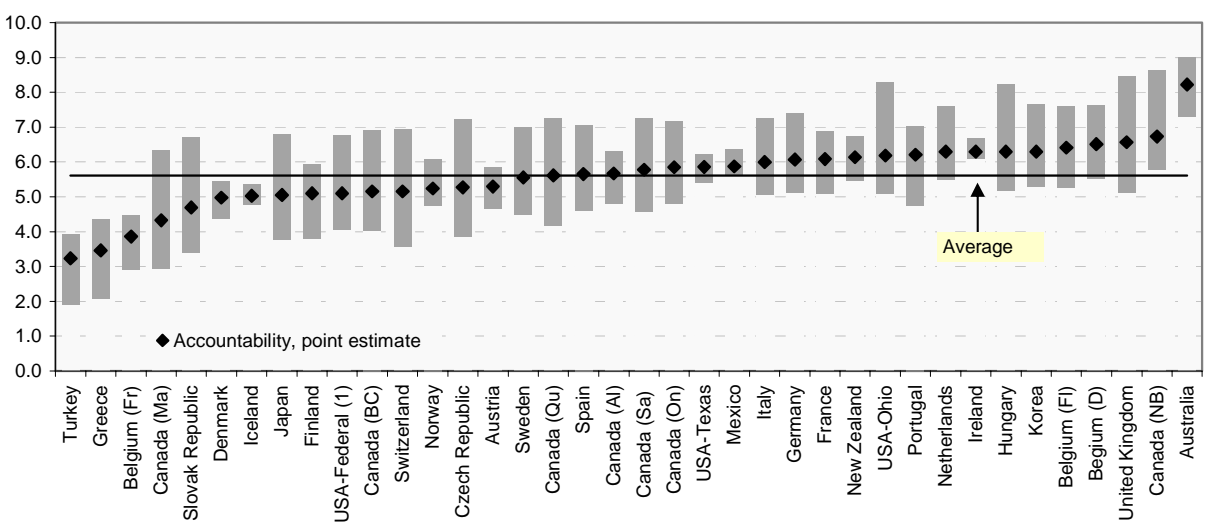

Note: Canadian provinces are : Al: Alberta, BC: British Columbia, Ma: Manitoba, NB: New Brunswick,

On: Ontario, Qu: Québec and Sa: Saskatchewan. Belgian regions are : Fr: French Community, Fl: Flemish Community and D: German-speaking Community.

The bars correspond to the $95 \%$ confidence intervals obtained through the random weight technique.

1. This value for USA-Federal is indicative as federal funds only account for a small share of total funding of tertiary education institutions.

Source: Authors' calculations based on questionnaire answers received from OECD Member countries. 
Figure 3.3. Composite supply indicator of tertiary education (STE), 2005-2006 (Increasing in input and supply flexibility and accountability)

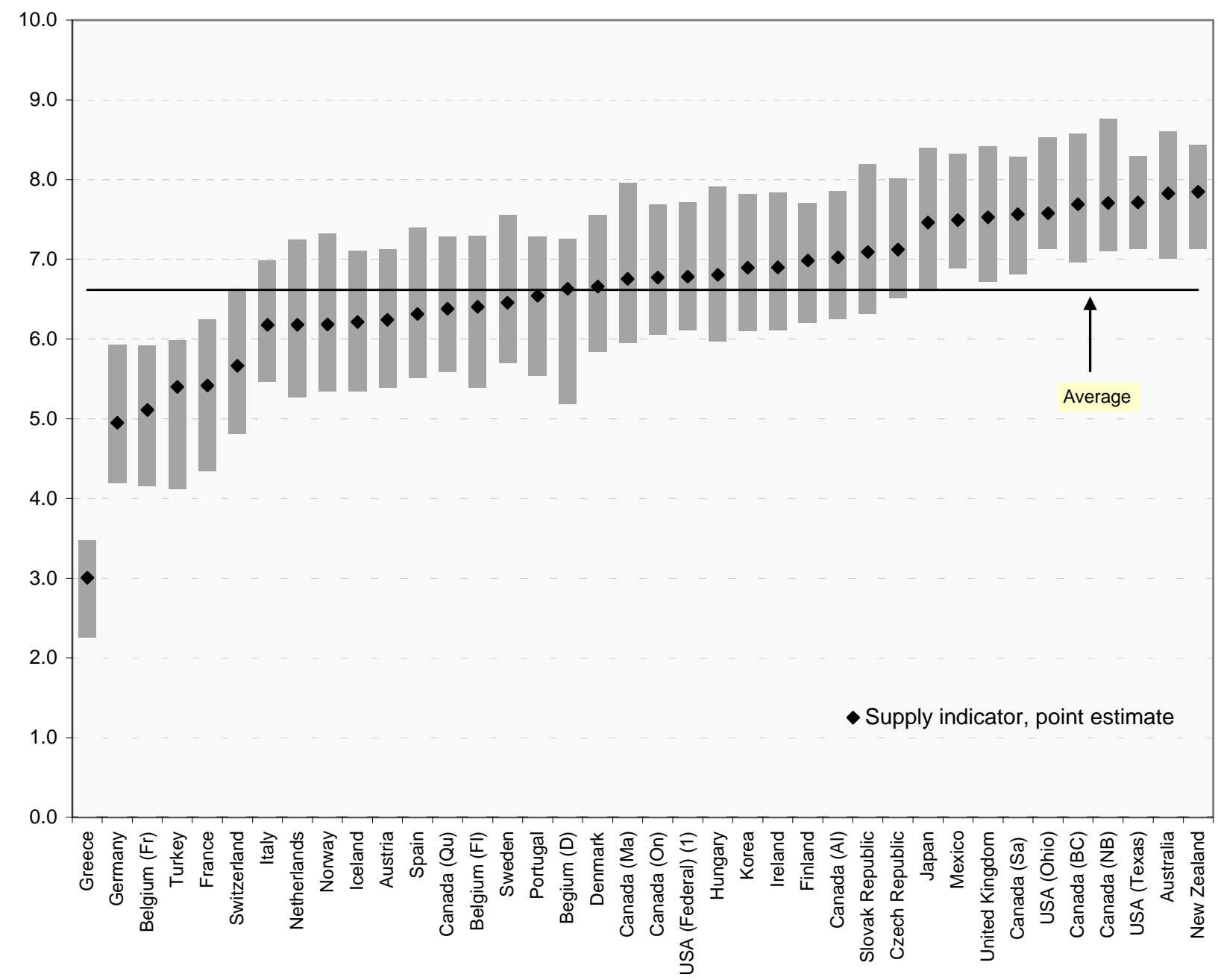

Note: Canadian provinces are : Al: Alberta, BC: British Columbia, Ma: Manitoba, NB: New Brunswick,

On: Ontario, Qu: Québec and Sa: Saskatchewan. Belgian regions are : Fr: French Community, Fl: Flemish Community and D: German-speaking Community.

The bars correspond to the $95 \%$ confidence intervals obtained through the random weight technique.

1. In interpreting this value for Federal provisions concerning supply flexibility and accountability it should be taken into account that federal funds only account for a small share of total funding of US tertiary education institutions.

Source : Authors' calculations based on questionnaire answers received from OECD Member countries. 
Figure 3.4. Supply indicator and coherence of tertiary education systems

\section{Supply indicator}

(Increasing in flexibility and accountability)

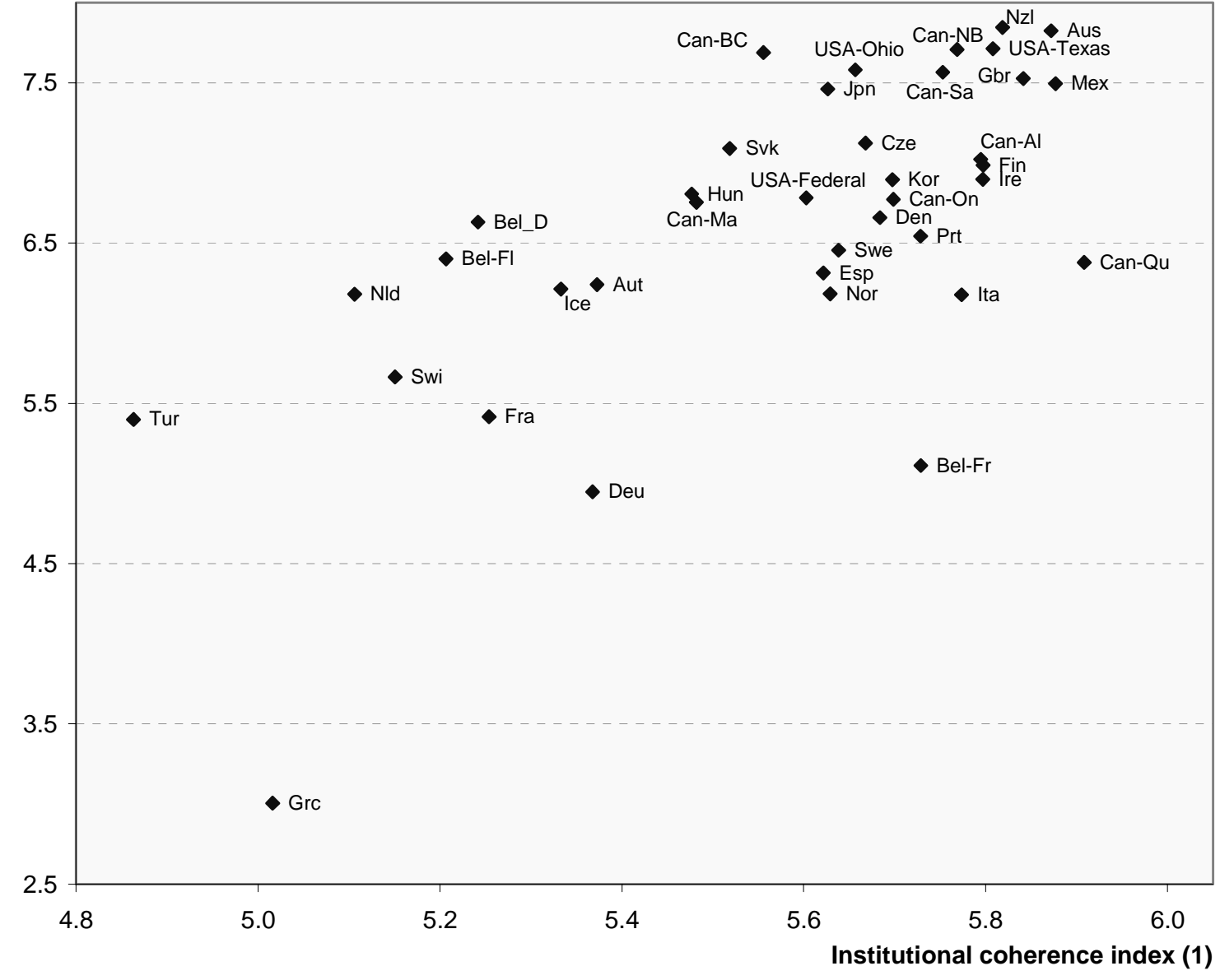

(Increasing in coherence)

Note: Canadian provinces are : Al: Alberta, BC: British Columbia, Ma: Manitoba, NB: New Brunswick, On: Ontario, Qu: Québec and Sa: Saskatchewan. Belgian regions are : Fr: French Community, Fl: Flemish Community and D: German-speaking Community.

1. The institutional coherence index is based on five intermediate level indicators (Selection of students, Budget autonomy, Staff policy, Evaluation and Funding rules) completed by the output flexibility.

Source: Authors' calculations based on questionnaire answers received from OECD Member countries. 
ECO/WKP(2007)36

Figure 3.5. Individual returns to tertiary education illustrated

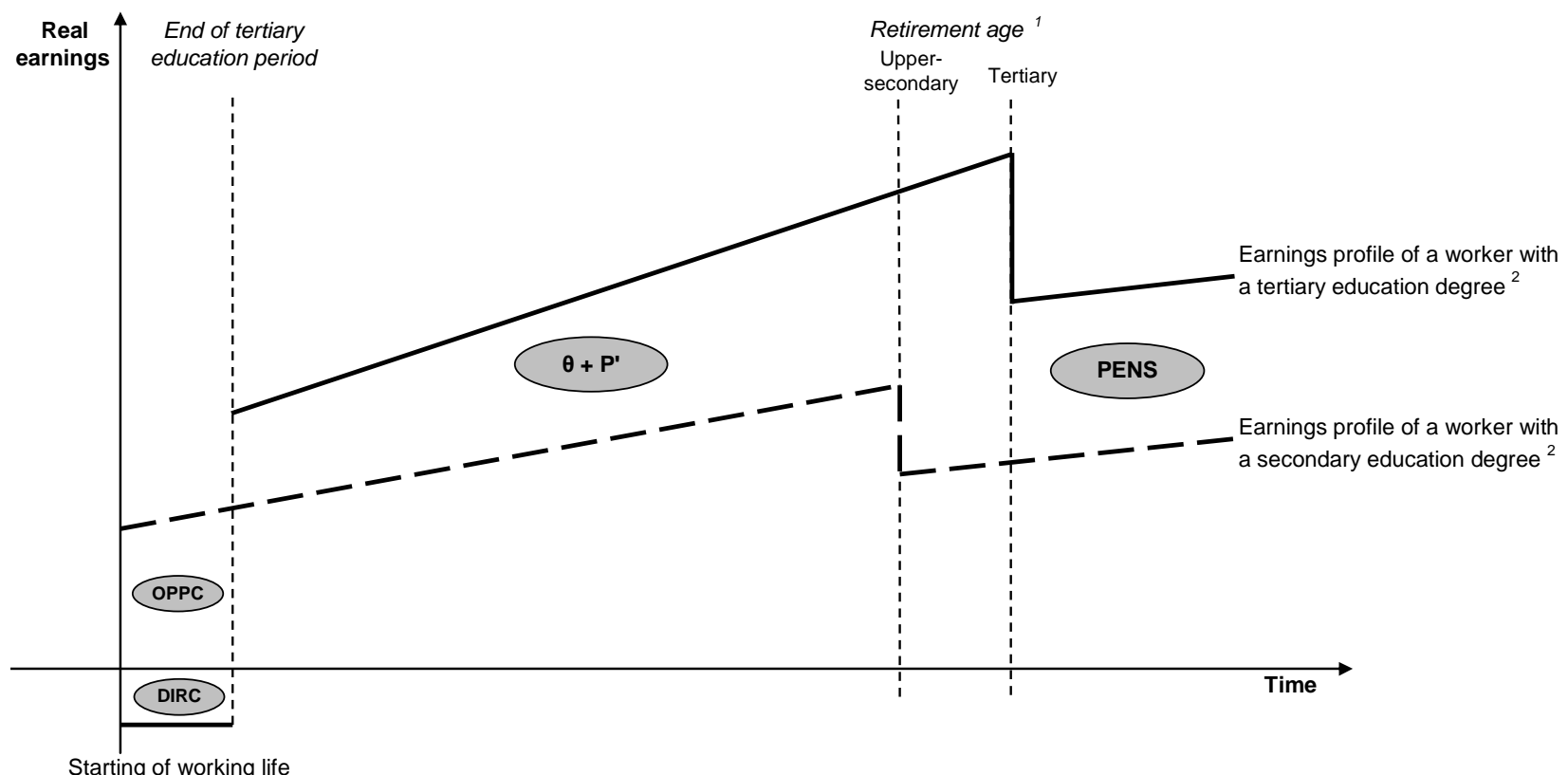

DIRC : Direct costs of tertiary education

OPPC : Opportunity costs of not starting to work after secondary education

$\boldsymbol{\theta}+\mathbf{P}^{\prime}$ : Wage \& employability premia associated with tertiary education (net of taxes and benefits)

PENS : Retirement premia for tertiary education workers (net of taxes)

1. Assuming the same length of working life.

2. Assuming partial indexation of pension benefits. 
Figure 3.6. Marginal effect of higher education on the employment probability ${ }^{1}$ $2001^{2}$
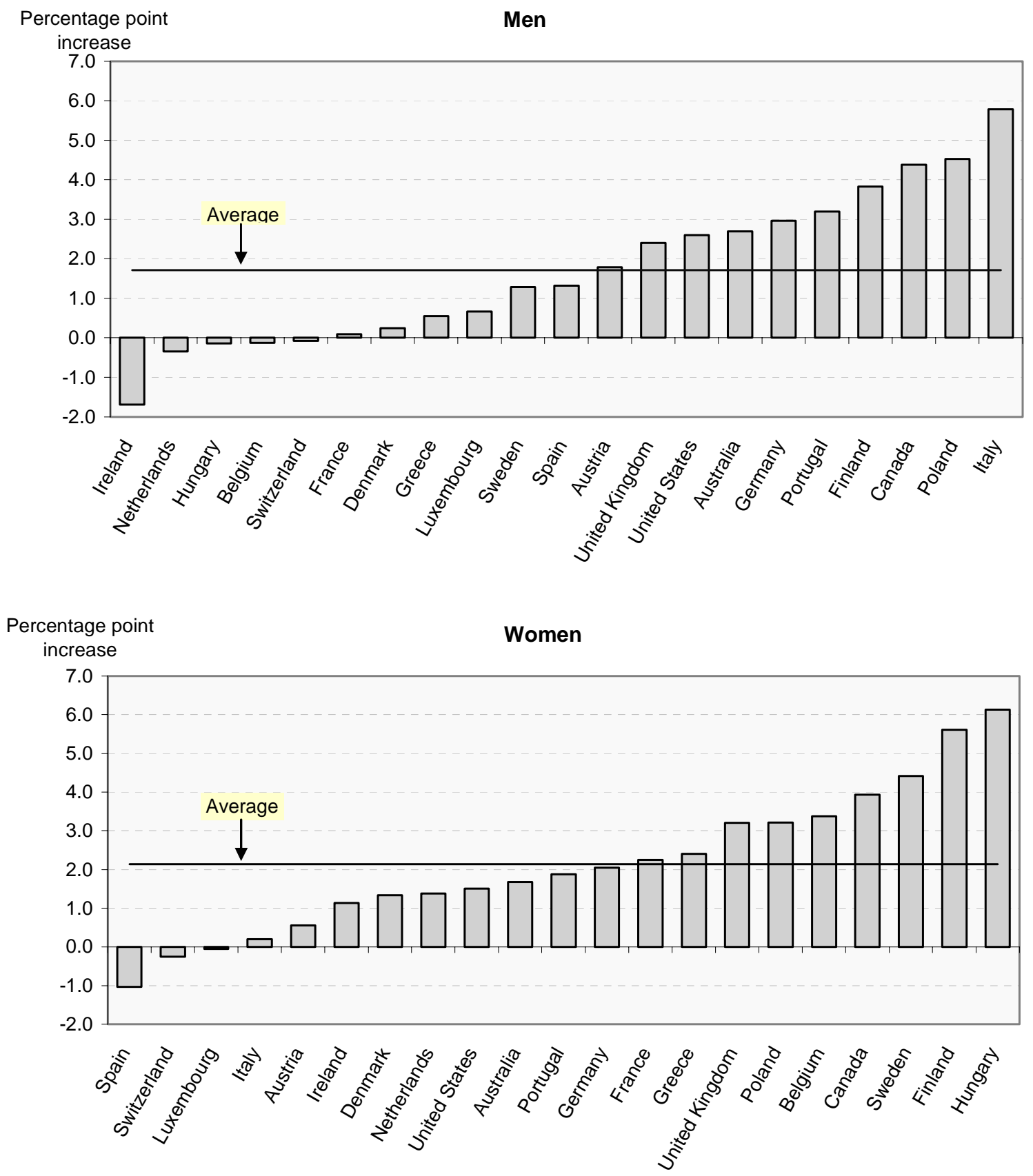

1. Increase in probability of employment: Tertiary degree holders relative to holders of upper secondary degree.

2. Except Hungary 1997 and Poland and Switzerland 2000.

Source: the European Community Household Panel (ECHP), the Consortium of Household Panels for

European Socio-Economic Research (CHER), the Cross-National Equivalent File (CNEF), and the

Household, Income and Labour Dynamics in Australia Survey (HILDA) and OECD calculations.

For details see Boarini and Strauss (2007). 
Figure 3.7. Net direct costs of tertiary education ${ }^{1}$
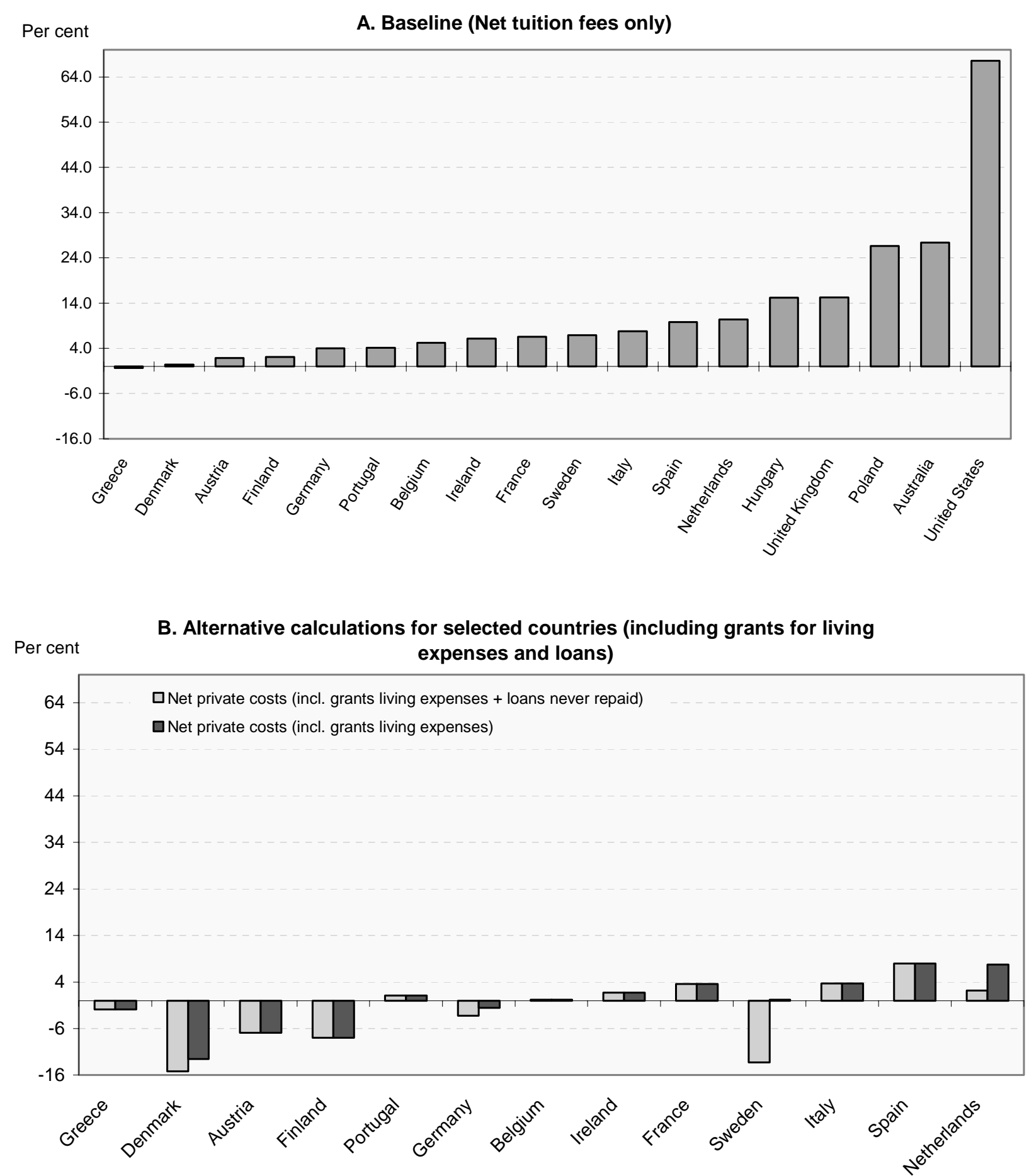

1. In $\%$ of gross annual wages of an upper-secondary degree holder.

Source: Authors' calculations based on EAG (2005), indicators B1.1 and B3.2b. 
Figure 3.8 Opportunity costs of tertiary education

(Foregone income while studying) ${ }^{1}$

Per cent

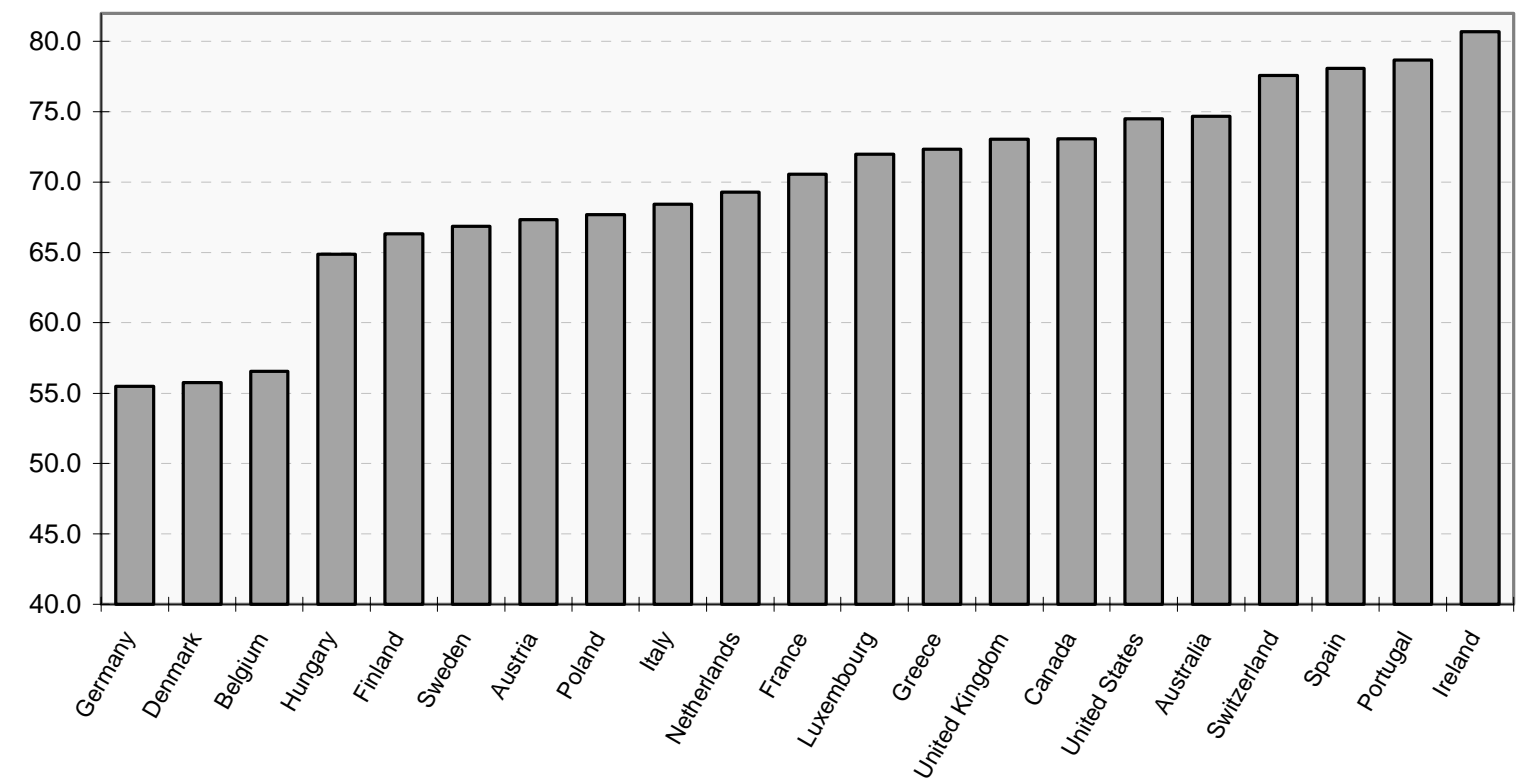

1. Adjusted for average tax rate, average tax on unemployment benefits and unemployment replacement rate.

Average for men and women. The data in the figure are expressed in $\%$ of the gross annual wages of an upper-secondary degree holder.

Source: Boarini and Strauss (2007). 
Figure 3.9 Estimates of the Internal Rates of Return to Tertiary Education ${ }^{1}$ $2001^{2}$
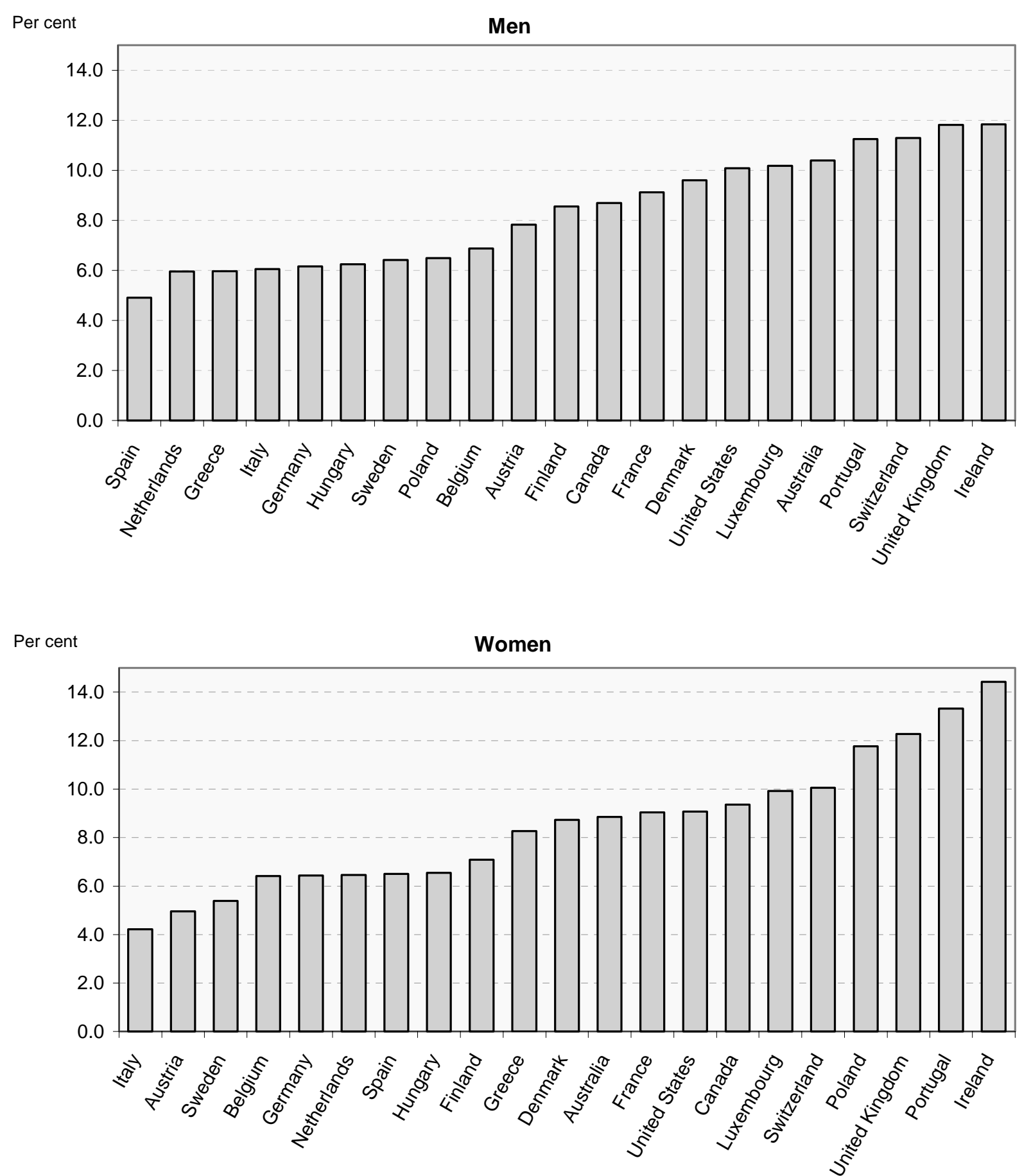

1. Uniform labour productivity growth across countries assumed to be $1.75 \%$ per year.

2. Except Poland and Switzerland: 2000 and Hungary: 1997.

Source: Boarini and Strauss (2007). 
Figure 3.10. Sensitivity analysis on the IRRs: effects of changes in the main drivers ${ }^{1}$ Male-female average, 2001

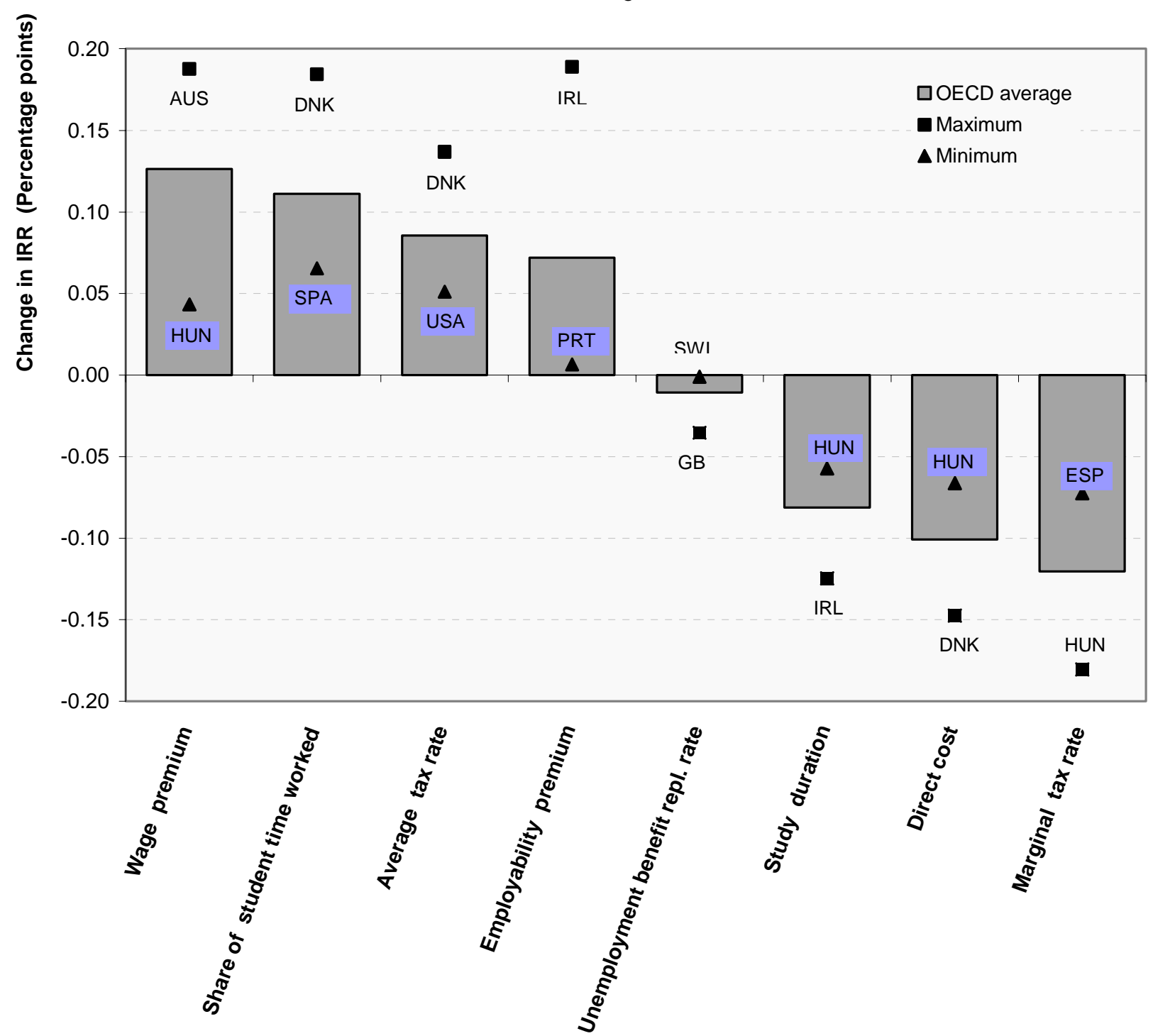

1. All drivers are changed by 1 percentage point except study duration that is changed by $1 \%$. Source: Authors' calculations. 
Figure 3.11. Cross-country differences in the IRRs implied by country-specific field composition ${ }^{1}$

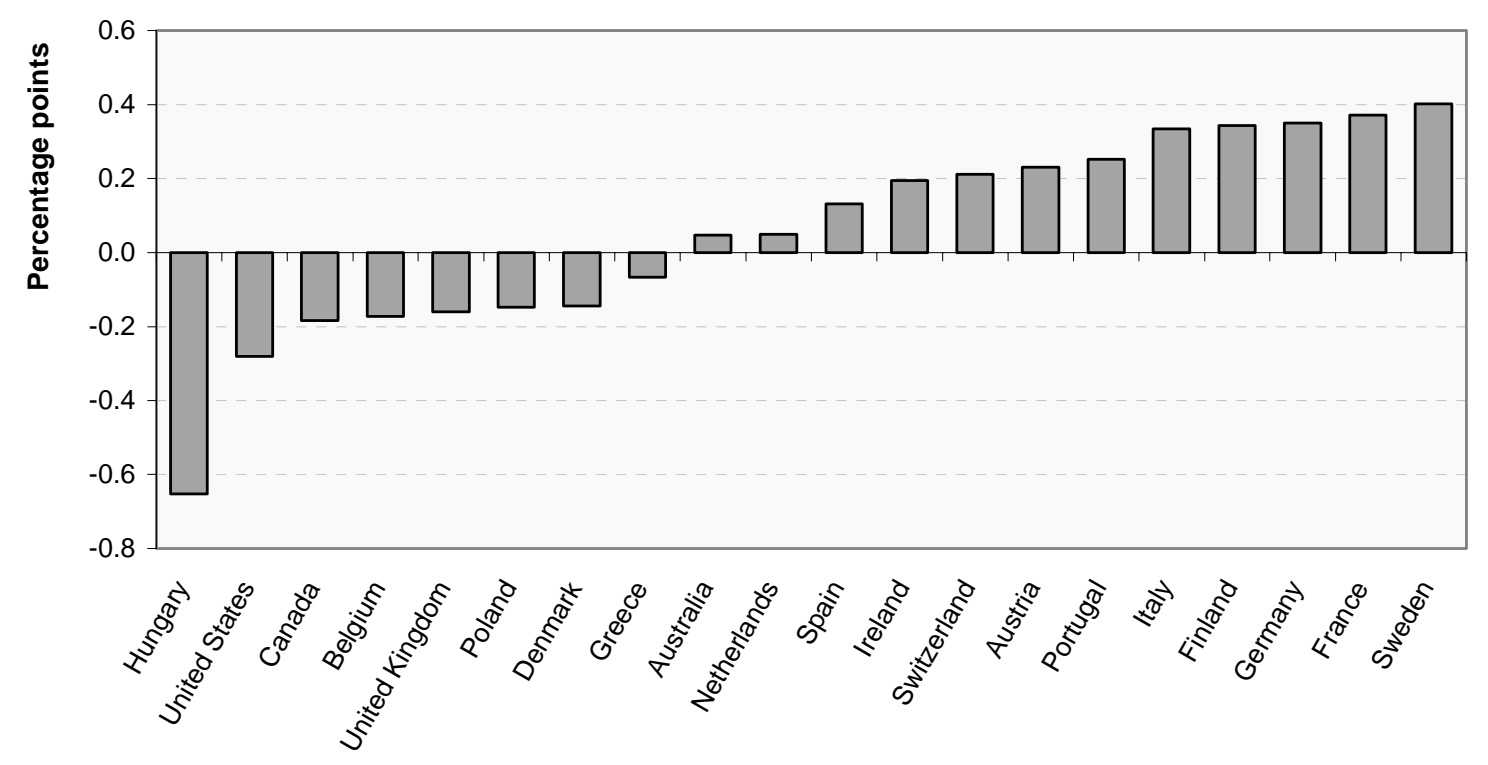

1. Assuming that returns by field are the same as estimated by Stark (2006) for Canada.

\section{IRR by field}

$\begin{array}{lr}\text { Agriculture } & 4.9 \\ \text { Education } & 5.4 \\ \text { Engineering, manufacturing and construction } & 13 \\ \text { Health and welfare } & 12.75 \\ \text { Humanities and Arts } & 4 \\ \text { Science } & 11.9 \\ \text { Services } & 9.1 \\ \text { Social sciences, business and law } & 11.65 \\ \text { Average } & 9.1\end{array}$

Note: The figure displays the differences between the counterfactual IRRs by country and their OECD average. For comparison with the IRRs computed in the text, the differences were normalised by the ratio between the actual and the counterfactual average IRR. Source: OECD, EAG(2006) and Stark (2006). 
Figure 4.1. Impact of increasing the flexibility and accountability of tertiary education supply on graduation ratios ${ }^{1}$

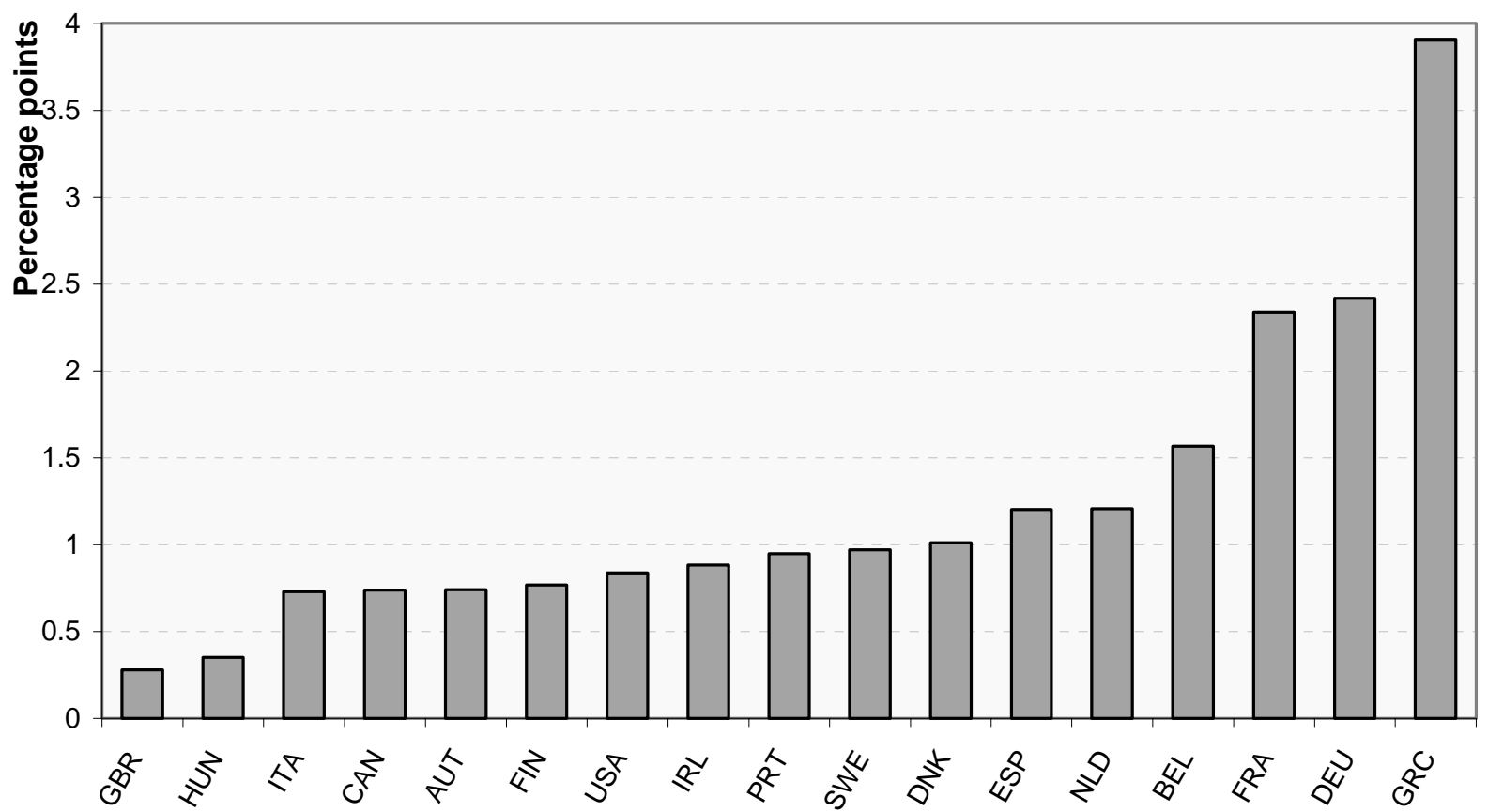

1. Effect of aligning the STE indicator on the maximum in the sample of the regression presented in table 3.5 (Australia). Source: Authors' calculations. 
Figure 4.2. Impact of reducing study duration on graduation ratios ${ }^{1}$

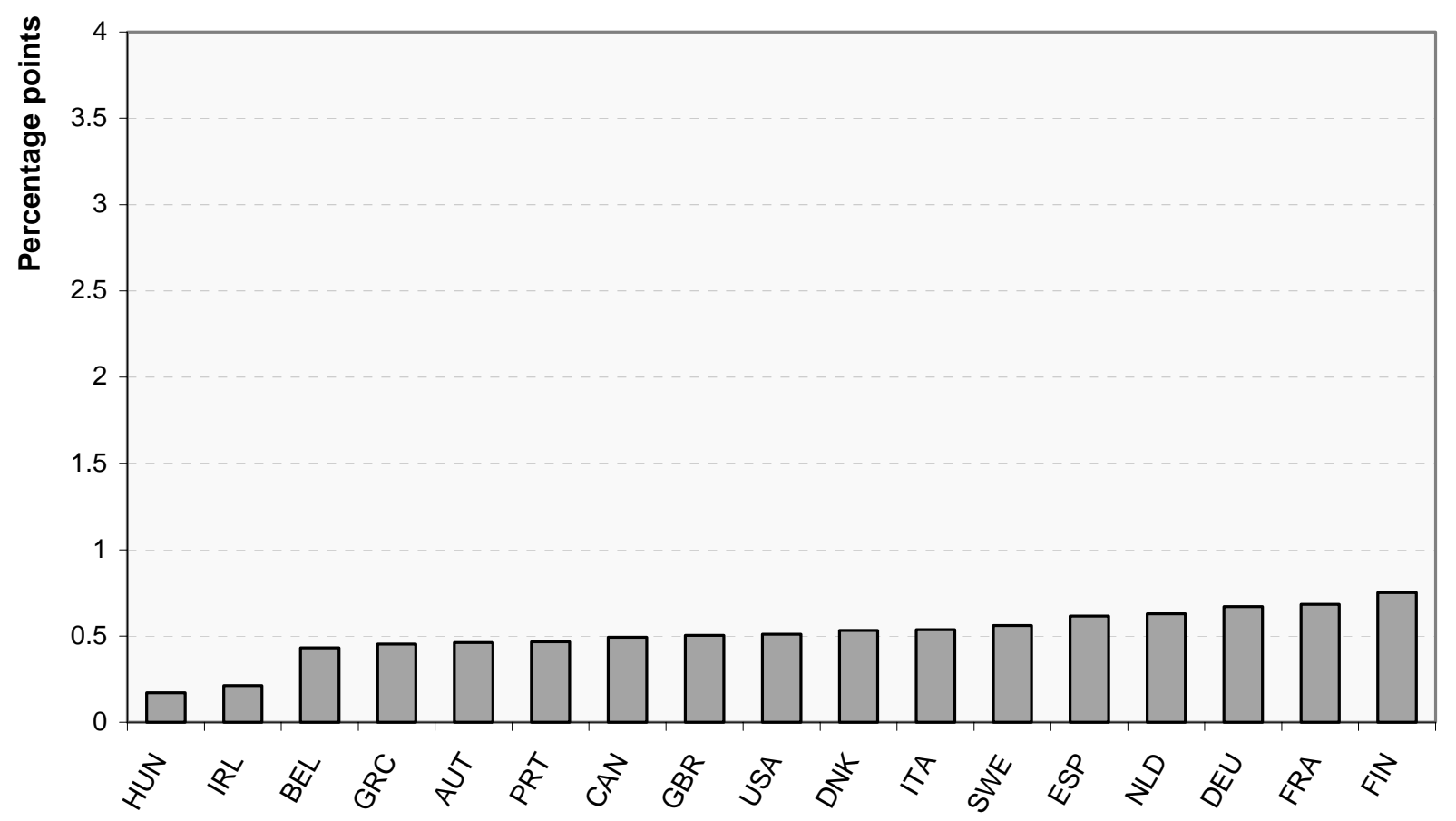

1. Effect on graduation ratios of setting study duration at the sample mean level minus two standard deviations. (Australia is not included because the study duration is already below the sample mean minus two standard deviations). Source: Authors' calculations. 
Figure 4.3 Ratio of tuition fees to costs per student, selected OECD countries
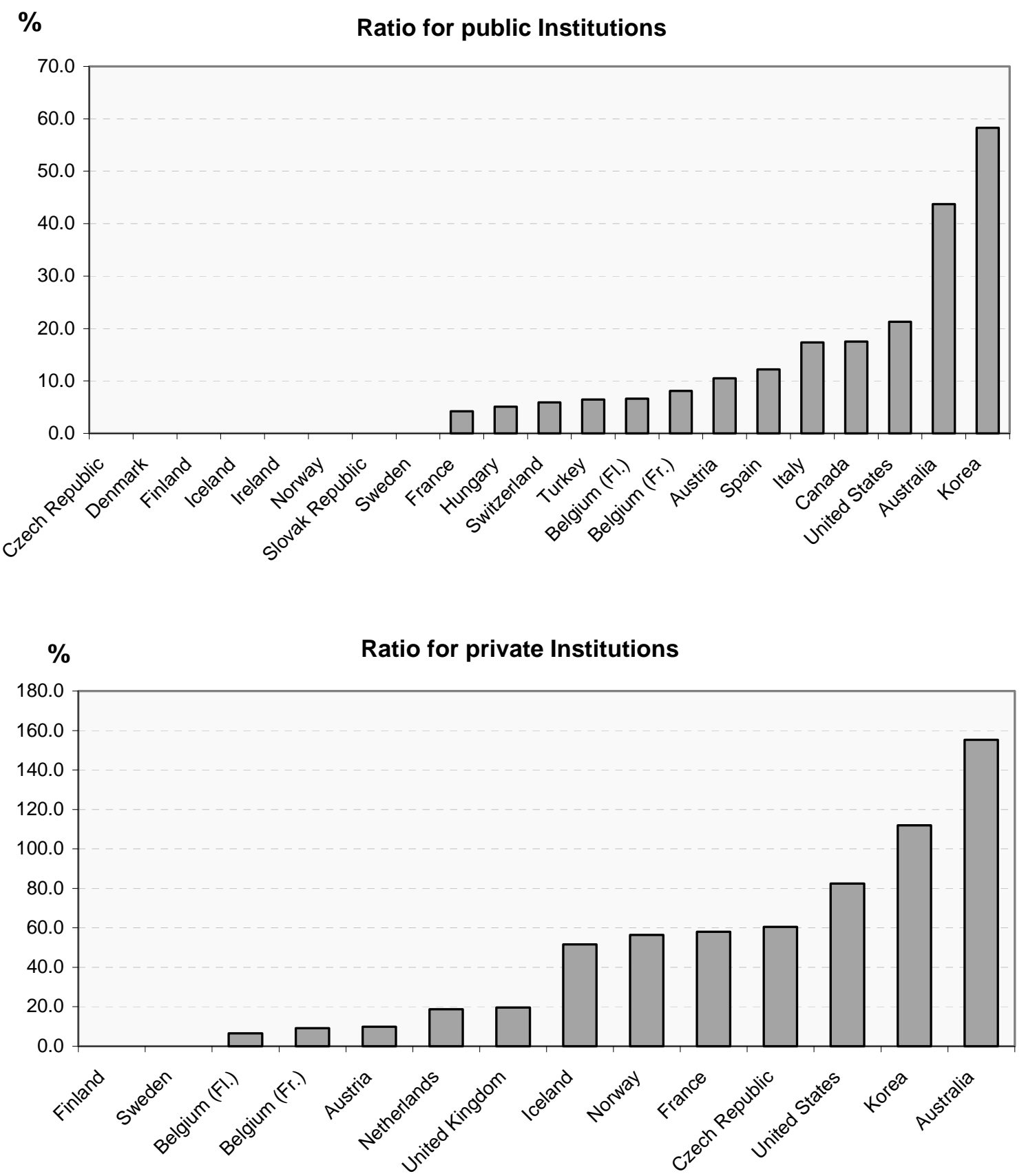

Source: OECD Education at a glance (2006). 
Figure 4.4. Graduation ratios vs. costs per student, 2001

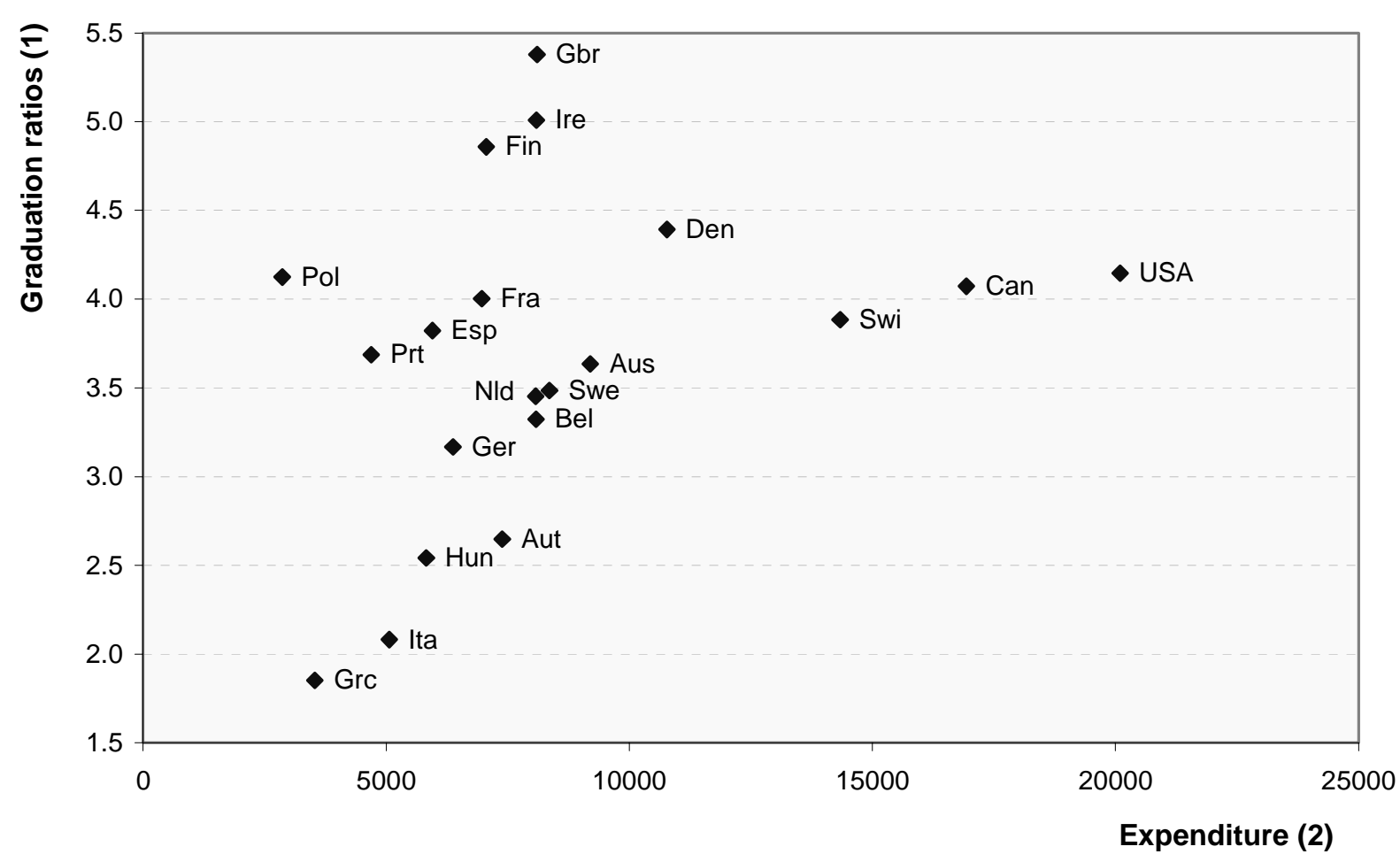

1. Tertiary graduates as a share of the 20-29 population.

2. Annual expenditure on educational institutions per student for all services.

In equivalent US dollars converted using PPPs for GDP, based on full-time equivalents.

All tertiary education excluding R\&D activities.

Source: OECD, EAG (2006) and Authors' calculations. 
Figure 4.5. Impact of an increase in tuition fees on graduation ratios ${ }^{1}$

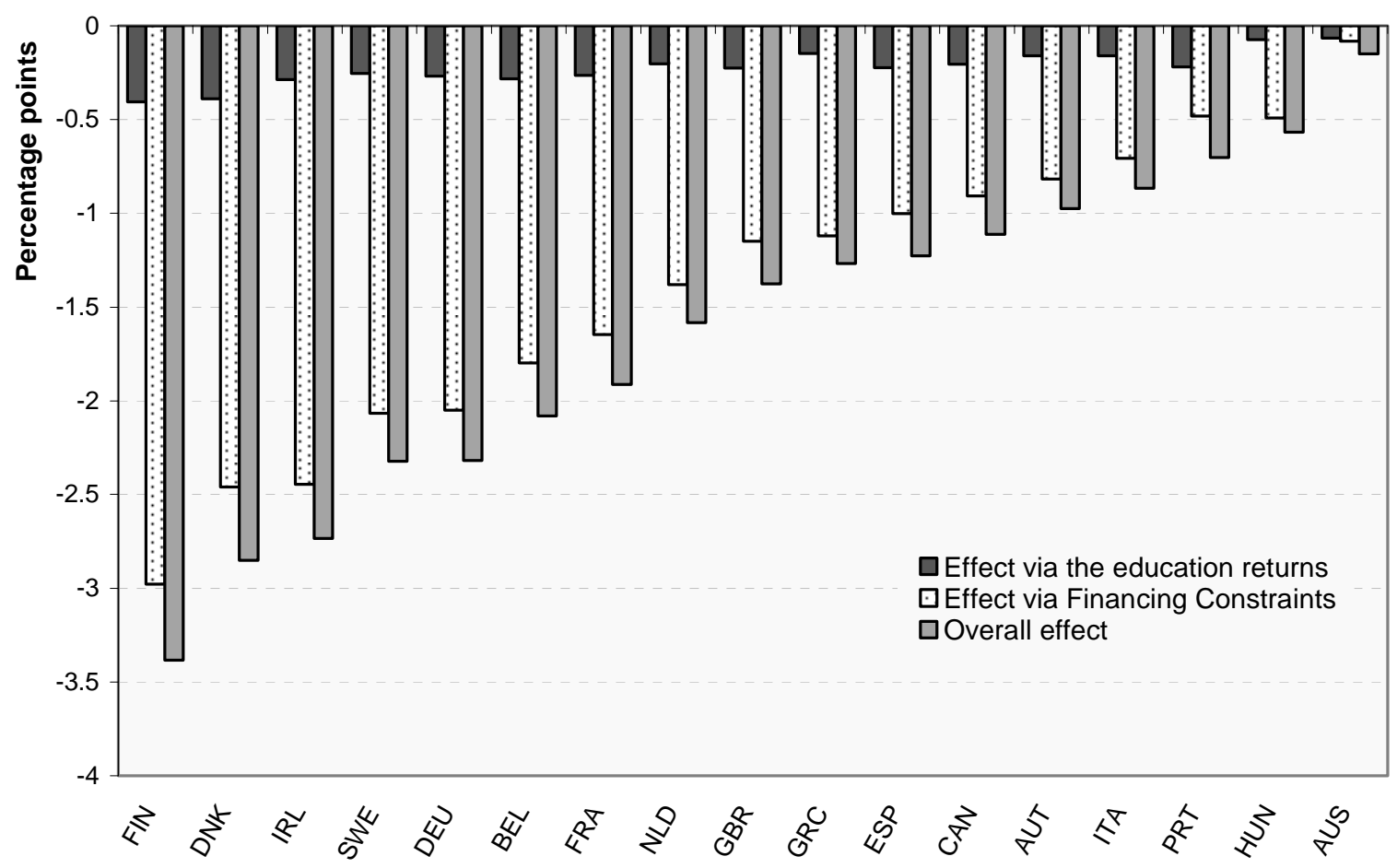

NB: This simulation assumes that no complementary policies to address financing constraints are implemented.

1. Effect on graduation ratios of increasing tuition fees up to the sample mean plus two standard deviations.

(The United States are not included because the level of net tuition fees are already above the sample mean plus two standard deviations).

Source: Authors' calculations. 
Figure 4.6. Impact of easing liquidity constraints on graduation ratios ${ }^{1}$

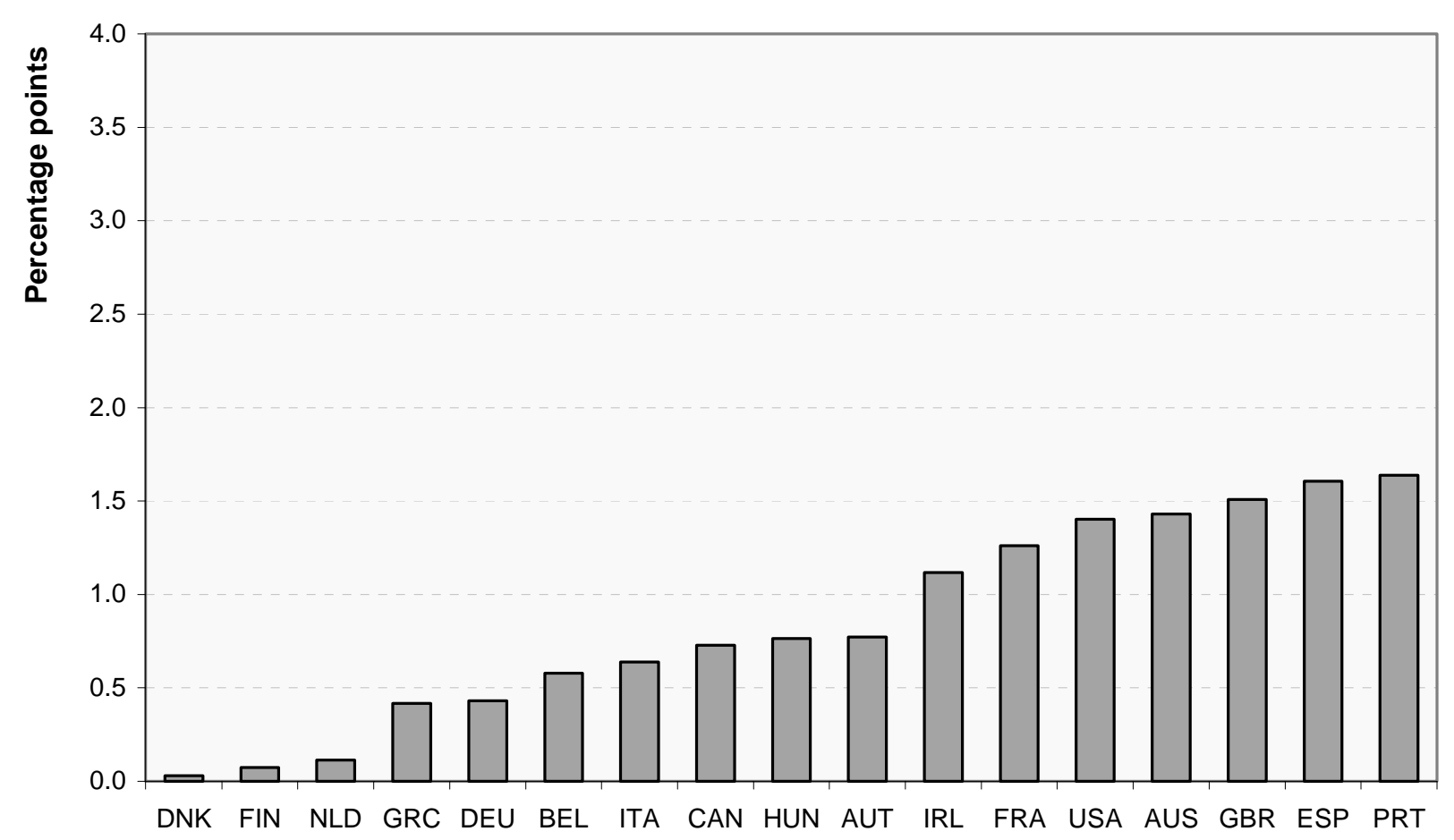

1. Effect of an alignment of the ratio of investment costs to financing resources (see table 3.4 ) on the minimum in the sample. (This benchmark was preferred as the sample mean minus two standard deviations is below the minimum). Source: Authors' calculations. 
Figure 4.7. Impact of introducing or increasing part-time student work on graduation ratios

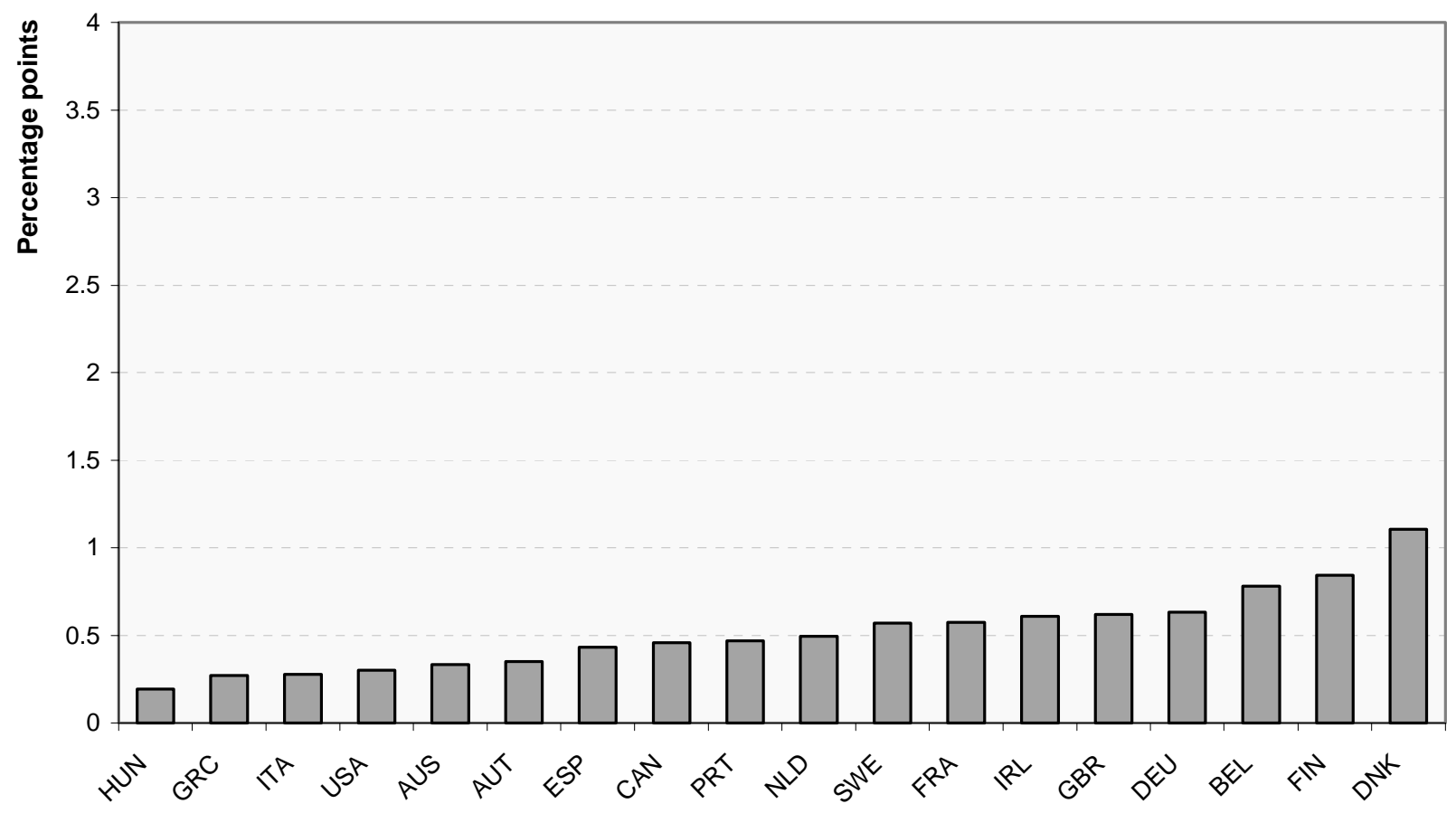

1. Effect on graduation ratios of introducing or increasing part-time work for students (corresponding to $33 \%$ of their time, taxed at $10 \%$ ). (Due to the lack of available data, it was not possible to compute a sample mean and standard deviation of student part-time work).

Source: Authors' calculations. 
Figure 4.8. Impact of a decrease of marginal tax rates on graduation ratios ${ }^{1}$

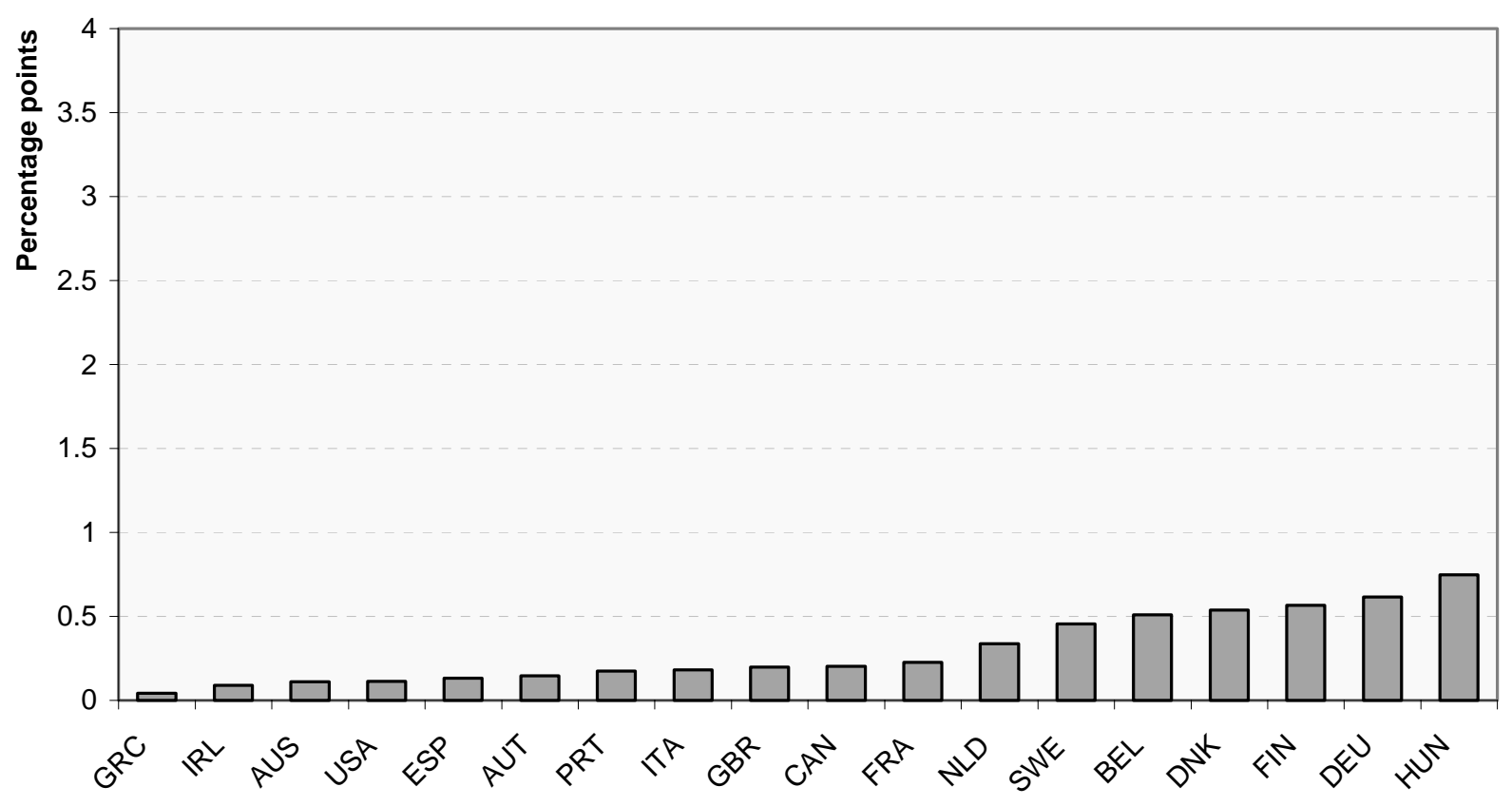

1. Effect on graduation ratios of decreasing marginal tax rates by 5 percentage points. Source: Authors' calculations. 
ECO/WKP(2007)36

\section{ANNEX: SUPPORTING MATERIAL ON DATA SOURCES AND STRUCTURAL INDICATORS}

\section{A. DATA SOURCES AND DERIVATION OF INDIVIDUAL VARIABLES}

\section{Derivation of the graduation ratios}

74. Graduation statistics can cover either the number of graduates or the number of graduations for a given year. The number of graduates refers to head-counts - the individual is only counted once for the highest diploma achieved in a reference year, even if he or she obtained several diplomas in different qualifications and/or fields. The number of graduations refers to the number of diplomas delivered by tertiary education institutions during the reference period. ${ }^{45}$

75. The number of graduations can be ill-suited for cross-country comparisons. Indeed, the same graduate can be counted several times for each qualification obtained in a given year in different fields, and over time if intermediate diplomas are delivered during study duration. These characteristics can depend on the country-specific institutional set-up of tertiary education. For this reason, the OECD Directorate for Education has estimated harmonised graduate statistics (OECD Education at a Glance, 2004c, 2006a; hereafter $\mathrm{EaG})$.

\section{Harmonised graduate statistics: the unduplicated count method}

76. The harmonisation of graduate statistics consists in distinguishing graduates by the cumulative duration of study ignoring the national degree structure. To illustrate this adjustment, assume that in country A the tertiary education system offers a short first degree with 3-year duration and a second degree with additional 2-year duration; while in country B the system offers only a long degree programme with 5-year duration. Moreover, also assume that in country A there are 33\% of an age cohort enrolled in tertiary education that obtains a first degree and only $11 \%$ that continues to study until the completion of a second degree. In system B, 25\% of an age cohort enrolled in tertiary education graduate from the long programme after 5 years. The structure of study duration in each country is as follows:

\begin{tabular}{|l|l|l|r|r|r|r|c|c|}
\hline & Enrolment & year1 & year2 & year3 & Year4 & year5 & \multicolumn{2}{|c|}{ Harmonised graduates } \\
\hline & & & & $1^{\text {st }}$ degree & $2^{\text {nd }}$ degree & $1^{\text {st }}$ degree & $2^{\text {nd }}$ degree \\
\hline System A & 100 & & & 33 & & 11 & 22 & 11 \\
\hline System B & 100 & & & & & 25 & & 25 \\
\hline
\end{tabular}

77. If one reports the total number of graduates in systems $\mathrm{A}$ and $\mathrm{B}$ without adjusting for the different national degree structure, country A would have a total cumulated number of 44 graduates while country B would have 25 graduates. In order to eliminate the double counting over time, system A should only report 22 graduates for the 3-year programme, and 11 for the 5-year programme (or a total cumulated number of 33 graduates). System B would still report 25 graduates for the 5-year programme.

45. More details can be found in the UN/OECD/EuroStat "Manual on Data collection on Education Systems" Vol. 1. 
78. However, the harmonised number of graduates (estimated on an unduplicated-count basis) is only available for the most recent years (mainly 2004). Therefore, for the purposes of this project, the crosssection information on number of graduates was combined with the time trend of graduations. More precisely, for year 2004, the number of graduates corresponds to the statistics compiled by the Directorate for Education. These numbers were than retropolated using a time index derived from the graduation statistics.

79. The number of graduations (or diplomas) was derived from the UNESCO database for the years 1991 to 1997. From 1998 to 2004, the number of graduations (or diplomas) was derived from the OECD EaG database for all OECD countries, except Portugal and Greece where they are derived from the Eurostat New Cronos database. The differences in level between the two sources were adjusted using a splicing method.

80. Finally, the number of graduates estimated in this way was normalised by the population aged 20-29 in order to derive the so-called graduation ratios used in the main text. It has to be noted that these graduation ratios differ from the graduation rates published in that the latter are expressed relative to the population at the typical age of graduation. However, the computation of the typical age of graduation for a long time period (1991-2004) is not straightforward, thus a simpler normalisation was preferred here. Moreover, using a larger segment of the population can also make the graduation ratios less sensitive to the demographic trends prevailing in each country.

\section{Stock of tertiary graduates}

81. The stocks of tertiary graduates correspond to the population having attained a tertiary education degree normalised by the total population aged 25-64. The stocks were derived from the OECD EaG database for the years 1997 (or 1998) to 2004. For the earlier years (until 1991), these data were retropolated using the graduation ratios described above to proxy the inflows of tertiary graduates and the ratio of population aged 60 to the population aged 25-59 to proxy the outflows (to retirement) of tertiary graduates.

\section{Stock of secondary graduates}

82. Population having attained secondary education was derived from the OECD EaG database for the years 1997 (or 1998) to 2004. These data were retropolated until 1991 assuming that trend growth over the first three years available would have prevailed in the past. The stock of secondary graduates was normalised by the population aged 25-64.

\section{Total expenditure per student}

83. Data for the financial year 2001 was derived from the OECD EaG database. Expenditure on education per student at a particular level of education is calculated by dividing the total expenditure on educational institutions at that level by the corresponding full-time equivalent enrolment. Only those educational institutions and programmes for which both enrolment and expenditure data are available are taken into account. Expenditure in national currency is converted into equivalent US dollars by dividing the national currency figure by the purchasing power parities (PPP). 


\section{B. AN INDICATOR OF THE INSTITUTIONAL SET-UP OF TERTIARY EDUCATION}

84. This Annex presents results concerning an indicator on the supply of core tertiary education services (hereafter, STE) computed using the replies of Member countries to a questionnaire. The tertiary education questionnaire contained forty-nine questions concerning both private and public institutions and covering their autonomy and accountability, the structure of academic activities, rules for allocating funds and their public/private mix, and the diversification of the curricula they offer. ${ }^{46}$ Twenty-eight Member countries have provided answers to the Secretariat. ${ }^{47}$ In order to ensure full cross-country comparability, these replies were cross-checked by OECD education experts, who verified the accuracy of some of the entries partly based on information contained in a series of country reviews of tertiary education (OECD, 2006b).

85. The first step in constructing the STE indicator was to subdivide this information into three main categories as described in the main text: Input flexibility, Output flexibility and Accountability.Within each of these three categories individual replies received a score between 0 and $10 .{ }^{48}$ For items falling in the first category, the scores increase as the replies denote more flexibility in the use of inputs. For instance, the higher the autonomy to select the number of students and their profile, or to hire and set staff salaries, the higher the score. For items covered by the second category, the scores increase as the replies denote more flexibility in the supply of core tertiary education services. For instance, the higher the autonomy to set course content, to offer more diversified studies or when there is no constraint associated with a numerus clausus, the higher the score. Finally, for items falling into the third category, the scores increase with the degree of accountability of tertiary education institutions. It was assumed that the presence of an independent evaluator, the involvement of stakeholders in the evaluation process and the availability to the public of evaluation reports ensure stronger accountability. It was also assumed that funding based on output-based rules and with a large share of business finance would ensure a stronger accountability than other funding systems. The detailed scoring for each of the individual questions is provided in Tables A.B.1-3.

\section{[Table A.B.1: Coding of the Input Flexibility category]}

\section{[Table A.B.2: Coding of the Output Flexibility category]}

\section{[Table A.B.3: Coding of the Accountability category]}

86. The next two steps were first to aggregate the scores for the individual questions belonging to each category into 17 lower-level indicator and, subsequently, to aggregate the lower-level indicators for input flexibility and accountability were aggregated into five intermediate-level indicators according to the nesting structure depicted in Figure 3.1 of the main text. The low-level indicators underlying the output flexibility category could not be clustered into intermediate indicators. At each step, the aggregation was made by computing simple arithmetic averages of the scores. To give an example, within the input flexibility category, the intermediate indicator for budget autonomy is the simple average of two low-level indicators for the sources of funding and the structure of spending. The former is the simple average of the scores for two individual questions concerning the autonomy to set tuition fees and raise funds. For each of

46. For a discussion of the supply characteristics of core education systems, see among others, Winston (1999); Santiago (1999) and Teixeira et al. (2004).

47. For Belgium and Canada and the United States, answers were also provided for some sub-national levels of government.

48. This range is arbitrary, but does not affect qualitatively the results. 
these questions there were three possibilities (Yes, No and Some) that were coded $(10,0,2.5)$, respectively. Thus, the low-level indicator sources of funding reaches the value of 10 when institutions have full autonomy to set tuition fees and to raise funds. The same was done for the three individual questions included in the low-level indicator for the structure of spending.

87. This aggregation procedure was applied to construct each of the five intermediate indicators (selection of students, budget autonomy, staff policy, evaluation and funding rules). The category indicators were then obtained as the simple averages of the constituent intermediate (or, in case of the output flexibility, low-level) indicators. It should be stressed that the resulting hierarchical structure for each of the three categories reflects the type and extent of information collected in the different areas of the questionnaire, which are not necessarily uniform.

88. Finally, the composite STE indicator was computed as the simple average of the three category indicators. To test the sensitivity of results to alternative weighting schemes for the low-level indicators, a random weight technique was applied. This technique applies weights drawn from a uniform probability distribution (in the range $[0,1]$ ) to derive confidence intervals around the mean estimates (see Conway, Janod and Nicoletti, 2005). The confidence intervals for the category indicators and the composite indicator are displayed in Figures 3.2 and 3.3 in the main text.

89. By construction, the composite indicator can vary from an extreme situation where the supply of tertiary education has no input flexibility, high supply restrictions and low accountability to an equally extreme system with full input flexibility, no supply restrictions and strong accountability. The results for the composite indicator, the three main categories and intermediate-level indicators are provided in Table A.B.4.

[Table A.B.4 Breakdown of the composite indicator into its main components] 


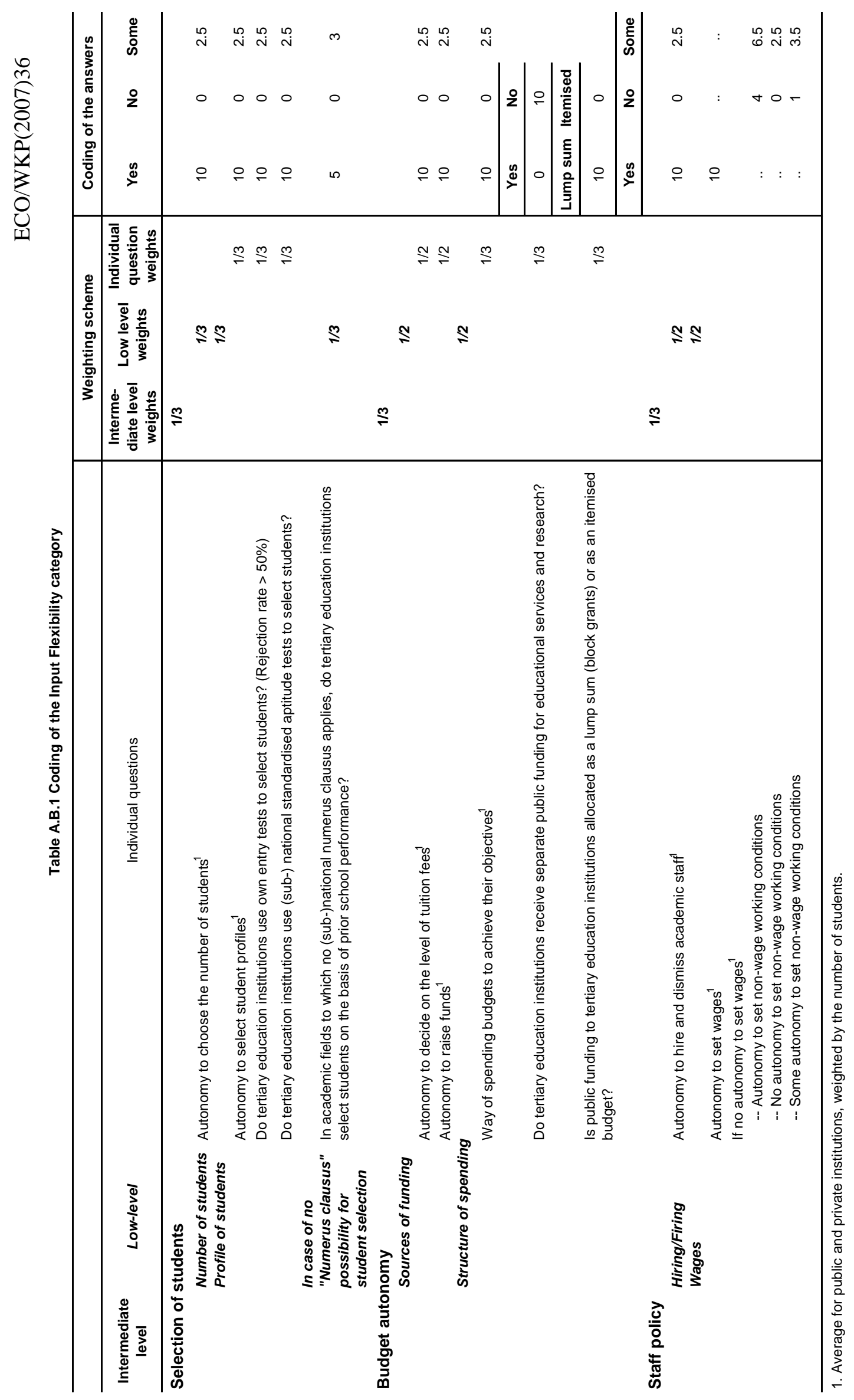




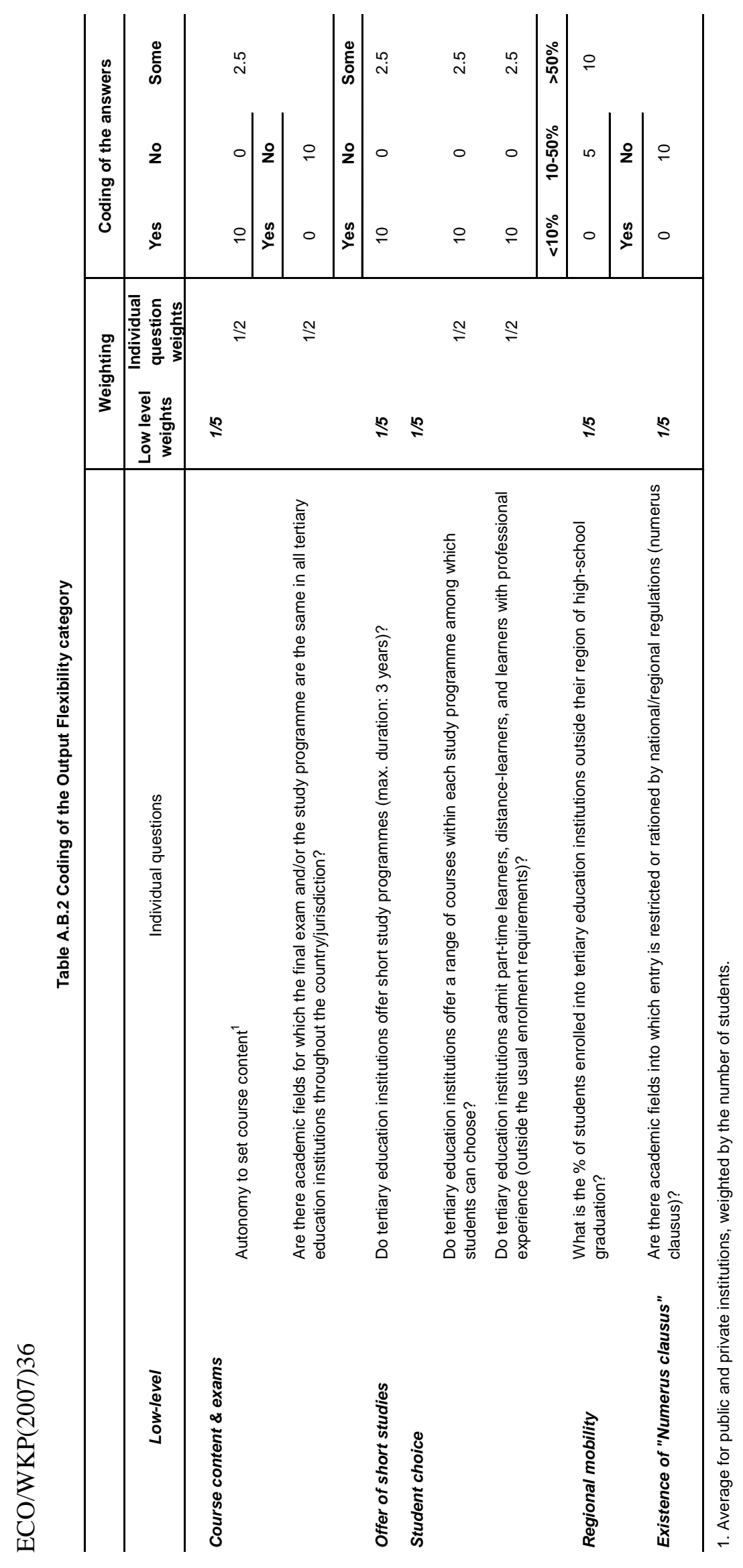




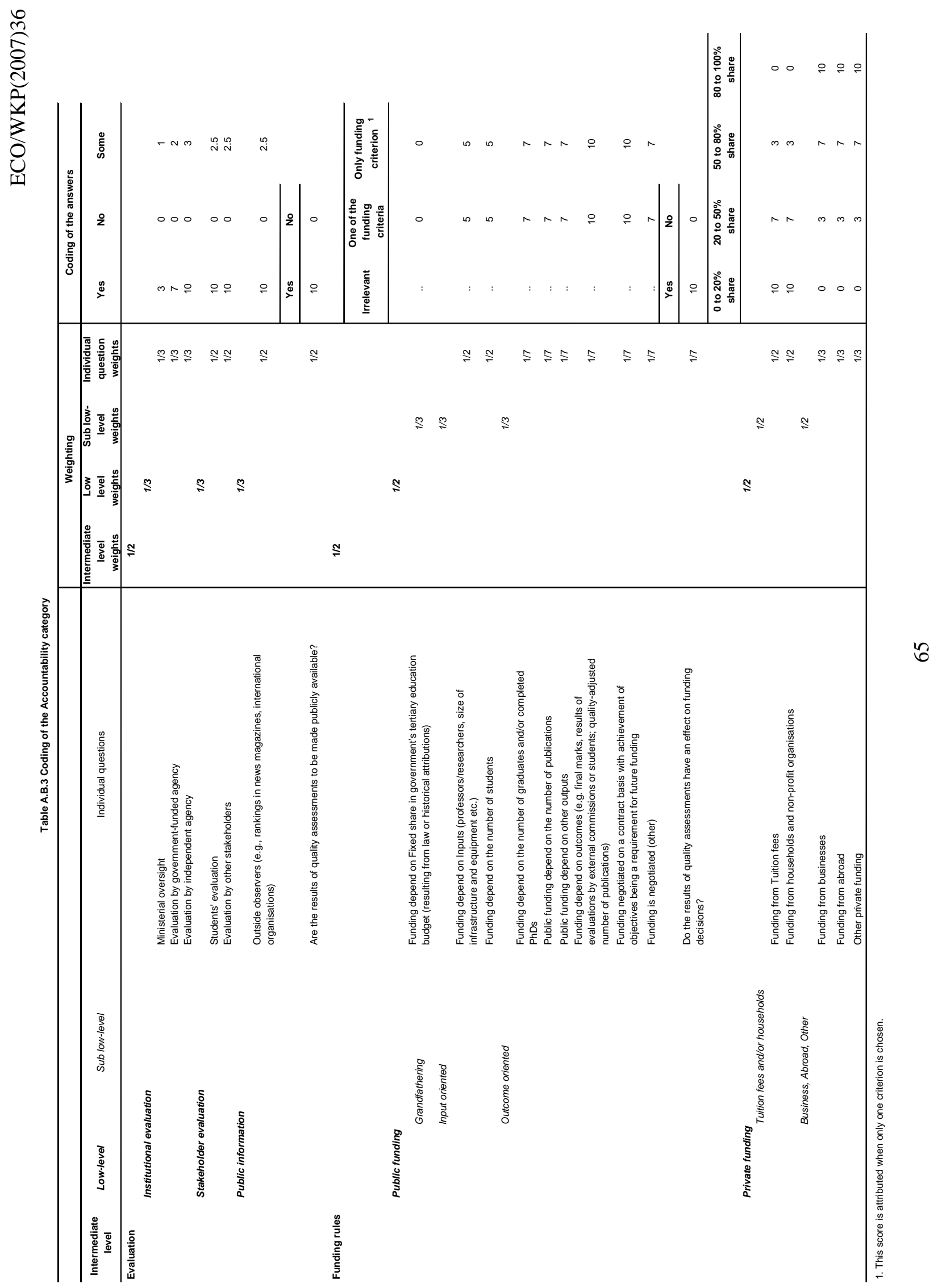




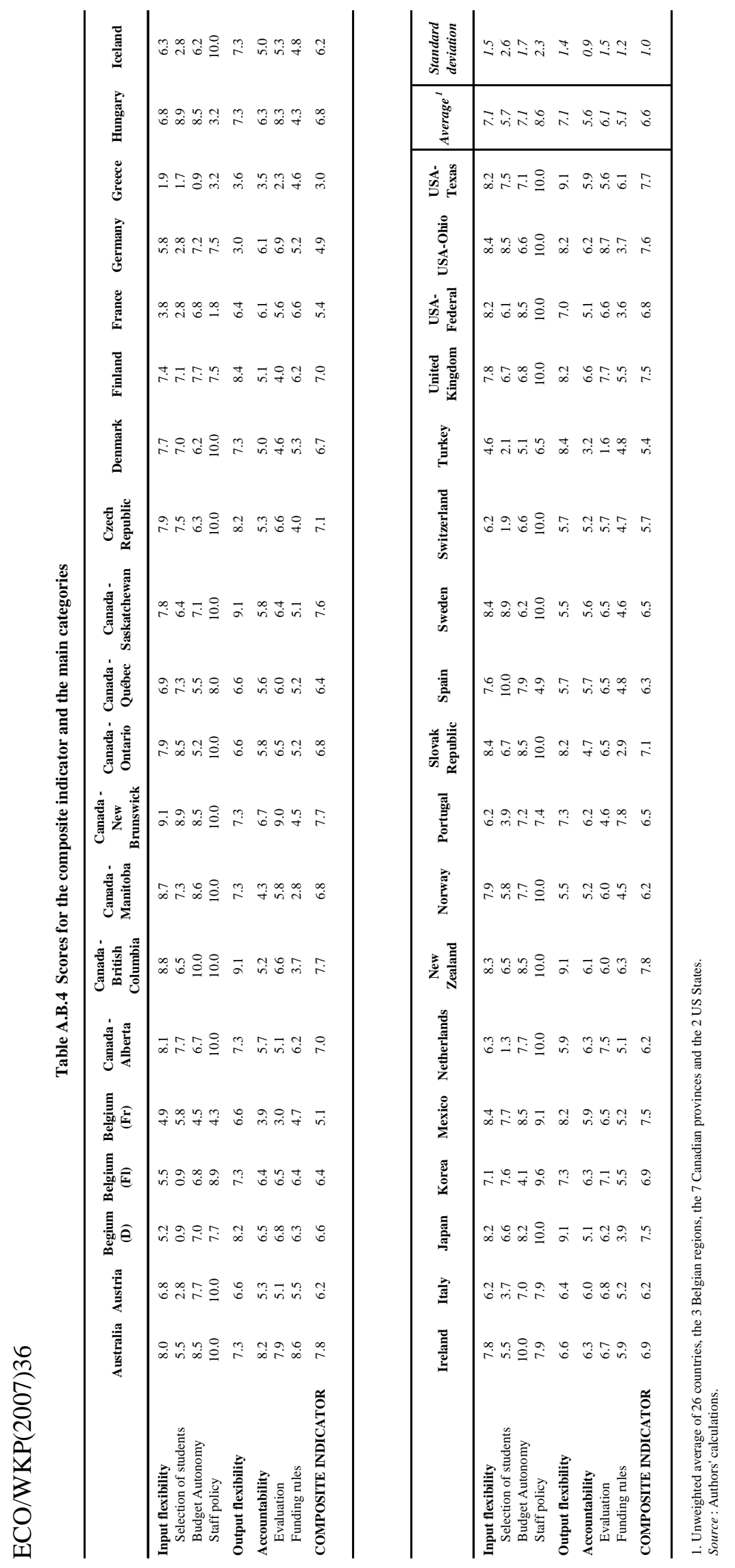




\section{SYSTEMS OF INDIVIDUAL FINANCING OF TERTIARY EDUCATION: AN INDICATOR OF LIQUIDITY CONSTRAINTS}

90. This Annex describes the taxonomy and the construction of an indicator of liquidity constraints that is used to characterise the different types of individual financing systems for tertiary education. The information was gathered for each OECD country from various sources (government websites, student information websites, OECD Education at a Glance, EC/Eurydice database, research projects, academic journals and working papers on the subject). For each OECD country, the following items are covered:

- Funding available

- Are there grants available?

- Are there loans available?

- What are the take-up rates for grants and loans?

- What is the percentage of full-time students working during term?

- What is the situation for part-time students/mature students?

- Loan characteristics

- Is there an income threshold for repayment?

- What are the standard repayment rates?

- What is the amortization period?

- Are there cases of loan forgiveness?

- How are repayments collected?

- What is the origin of the loan resources?

- Loan Subsidies

- Are there interest subsidies during studies?

- Are there interest subsidies during repayment?

- Are there subsidies specifically linked to low-income?

- Are there tax-related repayment subsidies?

- Tax Incentives

- Are there tax incentives for higher education?

\section{A taxonomy of individual funding systems}

91. The taxonomy was constructed taking into account, on the one hand, the students' status vis-à-vis their families, and, on the other hand, the type of funding available. Two main groups have emerged: individual and family-based systems. Individual-based systems are those that consider higher education students as financially independent from their parents. In these cases, family income is typically not taken 
into account for determining the level and the type of funding. In family-based systems, higher education students are considered as being members of their families, both for the purposes of financing and taxation.

92. In individual-based systems, funding is available to all students either through universal grants or loans, irrespective of their family income. The loan take-up rates were also taken into account when classifying countries in this group. For example, the Netherlands and Hungary were not classified as "universal loan systems" because their actual take-up rates of loans is very low $(20 \%$ and $30 \%$, respectively). In contrast, "family-based systems" impose restrictions on students" eligibility for financial aid. Typically, the funding is means-tested and/or allocated on the basis of merit scholarships. The countries classified in each of these groups are as follows:

\begin{tabular}{|c|c|c|c|}
\hline & Universal Grants & Universal Loans & Limited Financing \\
\hline Individual-based system & $\begin{array}{l}\text { Finland, Netherlands }{ }^{1}, \\
\text { Sweden, Denmark, } \\
\text { Norway }^{3}\end{array}$ & $\begin{array}{l}\text { Australia, Canada }^{2} \text {, } \\
\text { lceland, New Zealand, } \\
\text { United Kingdom, United } \\
\text { States }\end{array}$ & \\
\hline Family-based system & & Luxembourg & $\begin{array}{l}\text { Austria, Belgium, Czech } \\
\text { Republic, France, } \\
\text { Germany }{ }^{4} \text {, Greece, } \\
\text { Ireland, Italy, Japan, } \\
\text { Korea, Hungary, Mexico, } \\
\text { Poland, Portugal, Slovak } \\
\text { Republic, Spain, Turkey, } \\
\text { Switzerland }\end{array}$ \\
\hline
\end{tabular}

1. There is a universal loan system, but take-up rates are only of $20 \%$ of students.

2. The federal loans are means-tested, but the income ceiling for the loan is rather high and is not binding for most students.

3. Student aid in Norway actually takes the form of both a grant and a loan, but the grant part is higher for students living away from home.

4. A universal student loan system, the KfW (Kreditanstalt für Wiederaufbau) loan, was only introduced in 2006.

5. A universal loan system was introduced in 2001 but the take-up rates are still low (30\% of students).

\section{Construction of an indicator of the availability of individual financing}

93. In addition to the taxonomy developed above, the ratio between higher education costs and resources available to finance them was approximated. This indicator, with its components, is provided in Table 3.4 in the main text. The education costs correspond to tuition fees and living costs. The resources are those available through each country's financing systems (grants and loans) when available, and also through families' financing capacity, as well as possible revenue from student part-time work. The different sources used in this calculation are as follows:

- $\quad$ Tuition fees: The tuition fees presented are an average of public and private sector. They are weighted by the percentage of full-time students in each type of institution. The main source is OECD Education at a Glance 2006, Table B5.1. For Canada, Spain and Switzerland, tuition fees only cover public institutions. For Germany and Ireland, the amount imputed to tuition fees corresponds to entry costs, service charges and registration fees. For Poland, tuition fees were assumed to be the same as in Hungary. For Greece, Luxembourg and Mexico, where no data on tuition fees were available, fees were assumed to be zero.

- Living costs: For Australia, Austria, Belgium, Canada, Finland, France, Germany, Ireland, Italy, Japan, the Netherlands, New Zealand, Sweden, the United Kingdom and the United States, the living costs were derived from Usher and Cervenan (2005). This estimate of living costs includes housing rents and food for an academic year. For Luxembourg, Greece, Hungary, Poland, Portugal, Spain and Switzerland, living costs were estimated using an average ratio of around 
$40 \%$ of opportunity costs (drawing from Boarini and Strauss, 2007). This ratio was derived for the countries where both living and opportunity costs were available. For the Czech Republic, Korea, Mexico and Turkey, the living costs were taken from websites of national guides for international students (see below). For Iceland and Norway, living costs were estimated as the average of other Nordic countries (Denmark, Finland and Sweden) and for the Slovak Republic, as the average of other Eastern European countries (the Czech Republic, Hungary and Poland).

Living cost information derived from national websites:

Czech Republic: http://www.slu.cz/zahranicni-styky/socrates/erasmus/dokumenty/brozura_opf.doc;

Korea: http://web.pknu.ac.kr/ oir/english/upfile/board6.pdf;

Mexico: http://intercambio.itam.mx/extranjeros/extranjeros_visas_eng.html;

Turkey: http://www.studyturkey.metu.edu.tr/universitylife/expenses.htm

- Grants and loans: The maximum annual amount of aid available was used. This usually means the maximum amount available for the average student not living with parents, and does not consider additional aid such as those for disability, single parents, etc. As for the United States there are two different loan programmes (public and private) with different maximum amounts, the estimations were done separately, although Table 3.4 in the main text only reports data for the well-known Sallie Mae loan system. Luxembourg, Norway and Sweden have financial aid packages that are composed of both grants and loans. The information on loan ceilings was derived from national websites or on-line available documents, as follows:

Australia:http://www.goingtouni.gov.au/Main/Quickfind/PayingForYourStudiesHELPLoans/Default.htm

Canada: http://www.hrsdc.gc.ca/en/hip/cslp/Publications/InvestingYourFuture_e.pdf

Denmark: http://www.su.dk/

Finland: http://www.kela.fi/in/internet/english.nsf/NET/081001141316IL?openDocument

Iceland: http://www.lin.is/um lin/English.html

Luxembourg:http://www.cedies.public.lu/publications/autres_publications/01_financement/statistiques_aid efi/AideFi_en_chiffres.pdf

Netherlands: http://www.oecd.org/dataoecd/39/18/37411491.pdf

New Zealand: http://www.studylink.govt.nz/financial-assistance/student-loan/whats-in-a-student-loan.html

Norway: http://www.minocw.nl/documenten/bhw-107-bgo107.pdf

Sweden:http://www.csn.se/English/Students/ThisIsHowMuchStudentAidYouCanReceive/TheTotalAmoun tIsTheSumOfTheGrantAndLoan.asp?MenyIdnr=1016

United Kingdom:

http://www.direct.gov.uk/en/EducationAndLearning/UniversityAndHigherEducation/StudentFinance/Stud entFinanceFactsheets/DG_10034881

United States Federal Loans:

http://www.salliemae.com/get_student_loan/find_student_loan/undergrad_student_loan/federal_student_lo ans/stafford_loans/

United States Private Loans:

http://www.salliemae.com/get_student_loan/find_student_loan/parent_loans/private_student_loans/tuition _answer/

- $\quad$ Expected earnings of student part-time work: Expected earnings from one-third of a full-time job paid at $80 \%$ of the reference wage. The latter corresponds to a secondary worker's average wage at an early-career stage (derived from Individual Household data). For the Czech Republic, Japan, Korea, Mexico, New Zealand, the Slovak Republic and Turkey, the reference wage is the minimum wage (derived from the OECD Database on Earnings - Directorate for Employment, 
Labour and Social Affairs). These estimates were adjusted for youth employment rates (derived from the OECD Labour Force Statistics Database). For Iceland and Norway, income from student work was estimated as the average of the other Nordic countries (Denmark, Finland and Sweden).

- Median equivalised disposable income: is derived from the 'mean equivalised disposable income' multiplied by the ratio of median to mean income (both provided by Member countries to the OECD Directorate for Employment, Labour and Social Affairs). The 'mean equivalised disposable income' is the household income adjusted by household size (i.e. the household income divided by the square root of household size). For Belgium, Iceland, Korea and the Slovak Republic, the mean equivalent disposable income was estimated as a share of GDP per capita (using the OECD average share). 


\section{BIBLIOGRAPHY}

Aghion, P. and E. Cohen (2004), Éducation et croissance, Rapport Conseil Analyse Économique, La Documentation française, Paris.

Barr, N. (2001), The Welfare State as Piggy Bank: Information Risk, Uncertainty and the Role of the State, Oxford University Press, Oxford.

Barro, R. and J. Lee (1993), "International Comparisons of Educational Attainment", Journal of Monetary Economics, 32(3), pp.363-394.

Becker, G.S. (1967) "Human Capital and the Personal Distribution of Income: An Analytical Approach", Ann Arbor, Michigan: University of Michigan Press.

Blöndal, S., S. Field and N. Girouard (2002), "Investment in Human Capital through Upper-Secondary and Tertiary Education”, OECD Economics Studies, 34 (1), pp.41-90.

Boarini, R. and H. Strauss (2007), "The Private Internal Rates of Return to Tertiary Education: New estimates for 21 OECD countries", OECD Economics Department Working Papers, forthcoming.

Boarini, R, G. Nicoletti and J. Oliveira Martins (2007), "Investment in Tertiary Education: Does Labour Market Matter?, OECD Economics Department Working Papers, forthcoming.

Borland, J. (2002), "New Estimates of the Private Return to University Education in Australia", Melbourne Institute Working Paper No. 14/02

Braga de Macedo, J. and J. Oliveira Martins (2006), "Growth, Reform indicators and Policy complementarities", NBER Working Paper No. 12544, forthcoming in Economics of Transition.

Chapman, B. (2005). "Income Contingent Loans for Higher Education: International Reform", Centre for Economic Policy Research, The Australian National University Discussion Paper No. 491.

Conway, P., V. Janod and G. Nicoletti (2005), "Product Market Regulation in OECD Countries: 1998 to 2003", OECD Economic Department Working Papers No. 419; available at http://www.oecd.org/eco

De La Fuente, A. and R. Doménech (2000), "Human Capital In Growth Regressions: How Much Difference does Data Quality Make?", OECD Economics Department Working Papers No. 262.

De la Fuente, A., and J.F. Jimeno (2005), "The Private and Fiscal returns to Schooling and the Effect of Public Policies on Private Incentives to Invest in Education: A General Framework and Some Results for the EU", CESifo Working Paper No. 1392.

Epple, D., R. Romano and H. Sieg (2006), "Admission, Tuition, and Financial Aid Policies in the Market for Higher Education", Econometrica, 74 (4).

Freeman, R. (1986), "Demand for Education," in Handbook of Labor Economics: Vol.I, Edited by O. Ashenfelter and R. Layard (Netherlands: Elsevier Pubs, 1986).

Heckman, J.J., L.J. Lochner and P.E. Todd (2005), "Earnings Functions, Rates of Return, and Treatment Effects: The Mincer Equation and Beyond", NBER Working Paper No. 11544.

HIS-Higher Education Information System (2005), Eurostudent Report. 
Jacobs, B. and F. Van der Ploeg (2006), "A Guide to Reform of Higher Education", Economic Policy, 21 (47).

Johnstone, B. (2005), "Higher Education Accessibility and Financial Viability: The Role of Student Loans". World Report on Higher Education: The Financing of Universities, Barcelona.

Le, T., J. Gibson and L. Oxley (2005), "Measures of Human Capital: A Review of the Literature", New Zealand Treasury Working Paper No. 05/10.

OECD (2004a), Taxing Wages, Paris.

OECD (2004b), OECD Handbook for Internationally Comparative Education Statistics: Concepts, Standards, Definitions and Classifications, Paris.

OECD (2004c), Education at a Glance: OECD, Paris.

OECD (2005), Pensions at a Glance, Paris.

OECD (2006a), Education at a Glance, Paris

OECD (2006b), OECD Thematic Review of Tertiary Education: Country Background Reports (several issues); available at http://www.oecd.org/edu

OECD (2006c), Taxing Wages, Paris.

OECD (2007), Economic Policy Reform: Going for Growth, Paris.

Psacharopoulos, G. (1981), "Returns to education: an updated international comparison", Comparative Education no. 17, pp. 321-341.

Psacharopoulos, G. (1995), "The Profitability of Investment in Education: Concepts and Methods", The World Bank Human Capital Development and Operations Policy Working Paper No. 63.

Rotschild, M. and White L.J. (1995) "The Analytics of Pricing in Higher Education and Other Services in Which Customers are Inputs." Journal of Political Economy, June, 103, pp.573-86.

Santiago, P. (1999)," Conduct in the Higher Education Industry", unpublished manuscript, Department of Economics, Northwestern University, Illinois.

Sianesi, B. and J. Van Reenen (2003), "The Returns to Education: Macroeconomics", Journal of Economic Surveys, vol. 17(2).

Stark, A. (2006), "Which Fields Pay, Which Fields Don't? An Examination of the Returns to University Education in Canada by Detailed Field of Study", Economic Analysis and Policy Division, Department of Finance, Canada, mimeo.

Strauss, H. and C. de la Maisonneuve (2007), "The Wage Premium on Tertiary Education : New Estimates for 21 OECD Countries", OECD Economics Department Working Papers (forthcoming).

Teixeira, P. B. Jongbloed, D. Hill and A. Amaral (2004), "Markets in Higher Education: Rhetoric or Reality?” Kluwer Academic Publishers, Dordrecht. 
Usher, A. (2006), "Grants for Students: What They Do, Why They Work", ON: Educational Policy Institute, Toronto.

Usher, A. (2005), "Global Debt Patterns: An International Comparison of Student Loans Burdens and Repayment Conditions", ON: Educational Policy Institute, Toronto.

Usher, A. and A. Cervenan (2005), "Global Higher Education Rankings 2005”, ON: Educational Policy Institute, Toronto.

Winston, G.C (1999), "The Awkward Economics of Higher Education", The Journal of Economic Perspectives, Vol. 13 (1), pp.3-12. 


\section{WORKING PAPERS}

The full series of Economics Department Working Papers can be consulted at www.oecd.org/eco/Working_Papers/

575. Product market competition in the OECD countries: taking stock and moving forward (September 2007) Jens Hoj and Guiseppe Nicoletti

574. Too little destruction too little creation: A Schumpeterian diagnosis of barriers to sustained growth in Ukraine (September 2007) Christian Gianella and William Tompson

573. How do the OECD Growth Projections for the G7 Economies Perform? A post-mortem. (September 2007) Lukas Vogel

572. Austria's deepening economic integration with Central and Eastern Europe (August 2007) Rina Bhattacharya

571. Meeting the challenges of decentralization in France (July 2007) Stéphanie Jamet Faire face aux défis de la décentralisation en France (juillet 2007) Stéphanie Jamet

570. Enhancing incentives to improve performance in the education system in France (July 2007) Paul O’Brien

Renforcer les incitations à une meilleure performance du système éducatif en France (juillet 2007) Paul O'Brien

569. Combating poverty and social exclusion in France (July 2007) Stéphanie Jamet

Lutter contre la pauvreté et l'exclusion social en France (juillet 2007) Stéphanie Jamet

568 The competition law and policy indicator (July 2007) Jens Hoj

567. Structural policies and economic resilience to shocks (July 2007) Romain Duval, Jørgen Elmeskov and Lukas Vogel

566. Family policy in Hungary: how to improve the reconciliation between work and family? (July 2007) Philip Hemmings

565. Encouraging sub-national government efficiency in Hungary (July 2007) Alessandro Goglio

564. Integration of immigrants in OECD countries: do policies matter? (July 2007) Orsetta Causa and Sébastien Jean

563. The unemployment impact of immigration in OECD countries (July 2007) Sébastien Jean and Miguel Jiménez

562. Migration in OECD countries: labour market impact and integration issues (July 2007) Sébastien Jean, Orsetta Causa, Miguel Jiminez and Isabelle Wanner

561. The internationalisation of production, international outsourcing and employment in the OECD (June 2007) Margit Molnar, Nigel Pain and Daria Taglioni 
560. Why has Swedish inflation been persistently low?

(June 2007) Felix Hüefner

559. The Swedish housing market - better allocation via less regulation (June 2007) Felix Hüefner and Jens Lundsgaard

558 Linkages between performance and institutions in the primary and secondary education sector (June 2007) Douglas Sutherland and Robert Price

557. Toward a more efficient taxation system in New Zealand (June 2007) Annabelle Mourougane

556. Income inequality, poverty and social spending in Japan (June 2007) Randall Jones

555. Improving the efficiency of health care spending: selected evidence on hospital performance (May 2007) Espen Erlandsen

554. Cross-country analysis of efficiency in OECD health care sectors: options for research (May 2007) Unto Häkkinen and Isabelle Joumard

553. What promotes fiscal consolidation: OECD country experience (May 2007) Stéphanie Guichard, Mike Kennedy, Echkard Wurzel and Christophe André

552. Globalisation and the macroeconomic policy environment (April 2007) Karine Hervé, Isabell Koske, Nigel Pain, Franck Sédillot

551. Why has core inflation remained so muted in the face of the oil shock? (April 2007) Paul van den Noord and Christophe André

550. Housing markets and adjustments in monetary union (April 2007) Peter Hoeller and David Rae

549. Financial markets in Iceland (March 2007) Peter Tulip

548. The political economy of delaying fiscal consolidation (March 2007) Boris Cournède

547. The impact on growth of higher efficiency of public spending on schools (March 2007) Frédéric Gonand

546. Performance indicators for public spending efficiency in primary and secondary education (February 2007) Douglas Sutherland, Robert Price, Isabelle Joumard and Chantal Nicq

545. Monetary policy and macroeconomic stability in Latin America: the cases of Brazil, Chile, Colombia and Mexico

(February 2007) Luiz de Mello and Diego Moccero

544. The Brazilian "tax war": the case of value-added tax competition among the states (February 2007) Luiz de Mello

543. Public spending efficiency: institutional indicators in primary and secondary education (January 2007) Frédéric Gonand, Isabelle Joumard and Robert Price 